\title{
MODEL PREDICTIVE CONTROL OF A DOUBLY FED INDUCTION GENERATOR
}

\author{
By \\ Kumeshan Reddy
}

Submitted in fulfilment of the academic requirements for the degree of Master of Science in Electrical Engineering College of Agriculture, Science and Engineering University of KwaZulu-Natal

NOVEMBER 2020

Academic Supervisor: Dr. A.K. Saha

Examiner's Copy 


\title{
MODEL PREDICTIVE CONTROL OF A DOUBLY FED INDUCTION GENERATOR
}

\author{
SUBMITTED BY
}

Kumeshan Reddy

\section{IN FULFILMENT OF THE DEGREE OF}

Master of Science in Electrical Engineering from the University of KwaZulu-Natal,

Durban, South Africa

\author{
DATE OF SUBMISSION
}

NOVEMBER 2020

SUPERVISED BY

Dr. Akshay Kumar Saha

As the candidate's supervisor, I agree to the submission of this thesis

Signed:

Name: Dr. A.K. Saha

Date: $27 / 11 / 2020$ 


\section{COLLEGE OF AGRICULTURE, ENGINEERING AND SCIENCE}

\section{Declaration 1 - Plagiarism}

I, Kumeshan Reddy, declare that

1. The research reported in this thesis, except where otherwise indicated, is my original research.

2. This thesis has not been submitted for any degree or examination at any other university.

3. This thesis does not contain other persons' data, pictures, graphs or other information, unless specifically acknowledged as being sourced from other persons.

4. This thesis does not contain other persons' writing, unless specifically acknowledged as being sourced from other researchers. Where other written sources have been quoted, then:

a. Their words have been re-written, but the general information attributed to them has been referenced

b. Where their exact words have been used, then their writing has been placed in italics and inside quotation marks and referenced.

5. This thesis does not contain text, graphics or tables copied and pasted from the Internet, unless specifically acknowledged, and the source being detailed in the thesis and in the References sections. 
COLLEGE OF AGRICULTURE, ENGINEERING AND SCIENCE

\section{Declaration 2 - Publications}

DETAILS OF CONTRIBUTION TO PUBLICATIONS that form part and/or include research presented in this thesis (include publications in preparation, submitted, in press and published and give details of the contributions of each author to the experimental work and writing of each publication) are listed below.

Publication 1:

K. Reddy and A.K. Saha, "Model predictive control applied to a doubly fed induction generator," submitted to the 29th Southern African Universities Power Engineering Conference, 2021.

Publication 2:

K. Reddy and A.K. Saha, "A comparative study on direct torque control algorithms applied to a doubly fed induction generator," submitted to the 29th Southern African Universities Power Engineering Conference, 2021 


\section{Acknowledgments}

My deepest gratitude goes out to my supervisor, Dr. Akshay Kumar Saha, for his ongoing guidance and motivation throughout my research.

I would like to thank my family for their continuous support throughout my research.

I would lastly like to thank God, who made this research possible. 


\begin{abstract}
The world is currently is energy despair. For years, the world has relied on fossil fuels as the main energy source to produce electricity. At the start, this worked well as there was an abundance. However, due to the increase in population, urbanisation and the birth of many industries, this fuel source has been put under strain. Furthermore, the harmful emissions from the use of fossil fuels has been a great contributor to the destruction of our precious ozone layer. This in turn has gradually increased the harmful effects of global warming on Earth. The need for clean, reliable sources of energy has increased over time, and in a few years, it is expected to be the only source of energy utilized in the production of electrical energy. The research undertaken in this project involves the control of the doubly fed induction generator, which is used in wind energy conversion systems. Commonly termed DFIG, this generator has gained worldwide popularity and is used in majority of wind energy conversion systems. It provides direct grid connection and uses only a partially rated converter. However, the conventional control methods used in the control of the DFIG are either difficult to implement or inefficient. Some require complex tuning of proportional-integral controllers while some produce distorted results. The aim of this research was to investigate and evaluate the application of model predictive control to the control of the DFIG. There exist various different control strategies for the control of the DFIG. This research involved implementing all of the different control strategies via conventional methods and then via the use of model predictive control. Despite there being various methods to implement model predictive control, due to its simplicity and strong suitability, finite control set model predictive control was used in this research. Each of the control strategies implemented both conventionally and via model predictive control were thoroughly analysed in terms of the steady state response, dynamic response and quality of stator current. A comparison between the corresponding control methods is also presented.
\end{abstract}




\section{Table of Contents}

Declaration 1 - Plagiarism ....................................................................................... ii

Declaration 2 - Publications ................................................................................... iv

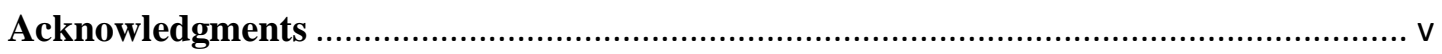

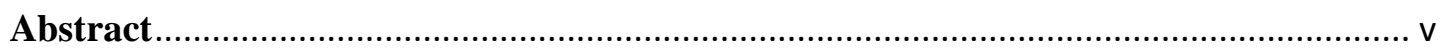

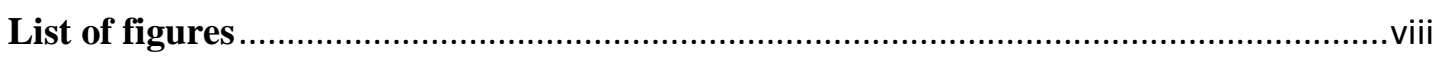

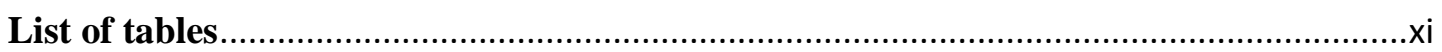

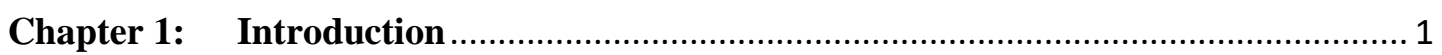

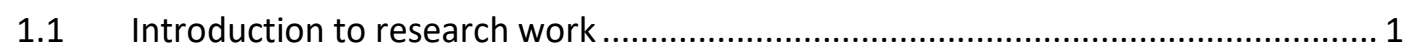

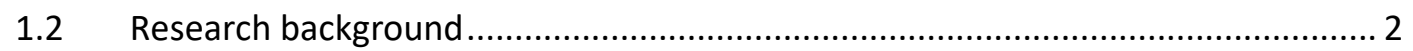

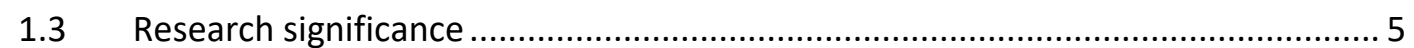

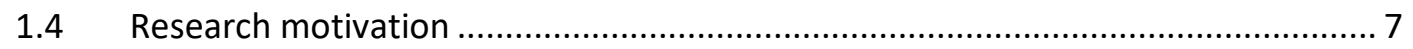

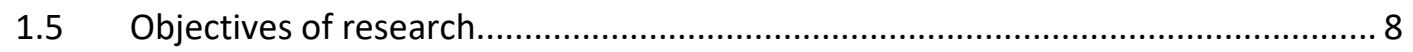

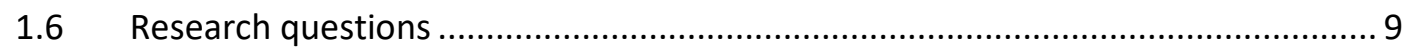

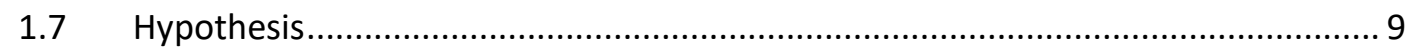

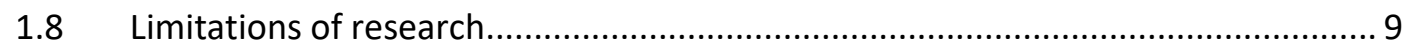

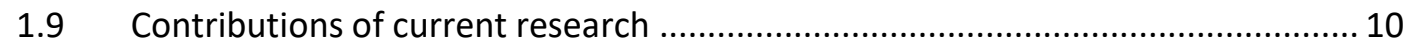

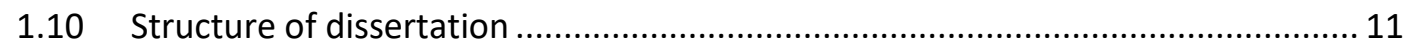

Chapter 2: Theoretical background and literature review of wind energy conversion systems

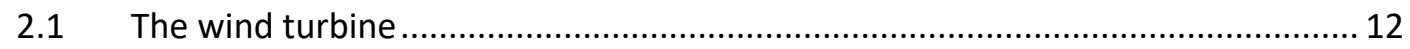

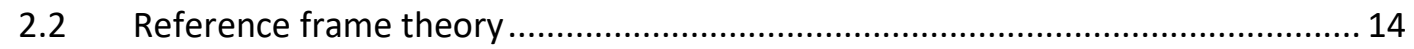

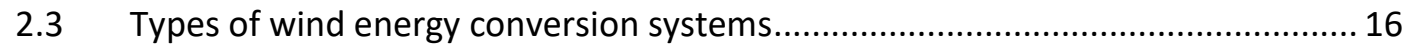

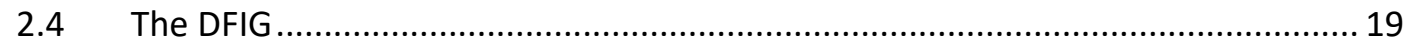

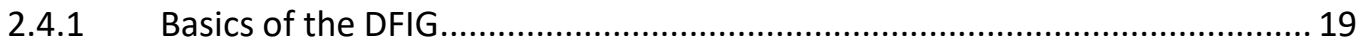

2.4.2 Steady State Analysis of the DFIG ............................................................. 20

2.4.3 Dynamic Modelling of the DFIG in the $\alpha-\beta$ reference frame .......................... 22

2.4.4 Dynamic modelling of the DFIG in the $d-q$ reference frame.......................... 23

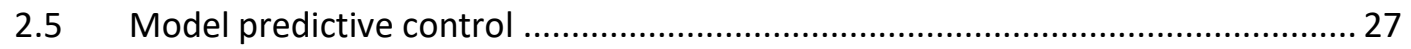

2.5.1 An introduction to model predictive control .............................................. 27

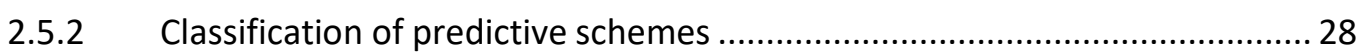

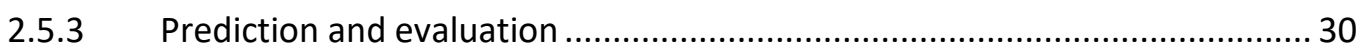

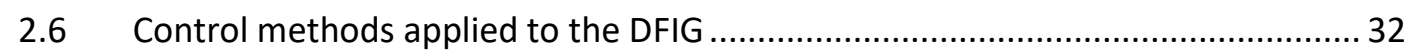

2.7 Review of previous approaches to issues affecting the use of the DFIG ............... 33

2.7.1 Grid synchronization of the DFIG ......................................................... 33 
2.7.2 Improving dynamic and steady state responses of the DFIG....................... 35

2.7.3 Mitigating the effects of unbalanced grid voltages on the DFIG ................... 37

2.7.4 Fault ride through capabilities of the DFIG .............................................. 41

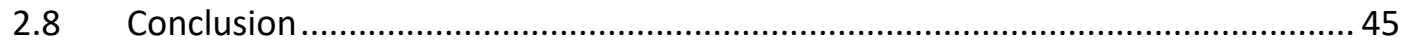

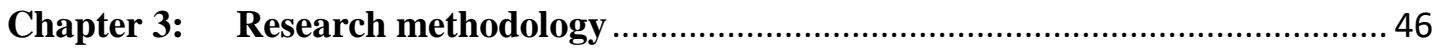

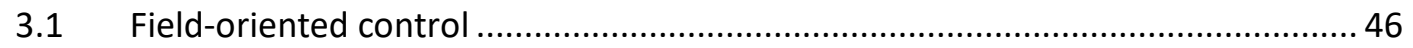

3.2 Direct torque control using the switching table ................................................ 53

3.3 Direct torque control using space vector pulse width modulation ........................56

3.4 Direct power control using the switching table …................................................. 57

3.5 Model predictive current control....................................................................... 59

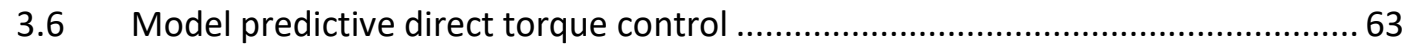

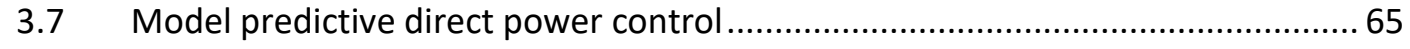

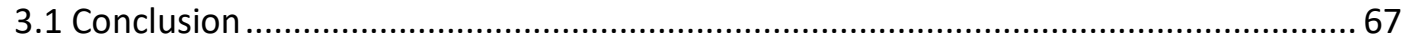

Chapter 4: Performance analysis of conventional control methods applied to the

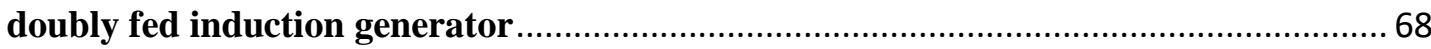

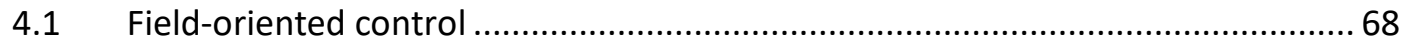

4.2 Direct torque control using the switching table .................................................. 71

4.3 Direct torque control using space vector pulse width modulation ....................... 74

4.4 Direct power control using the switching table ................................................. 77

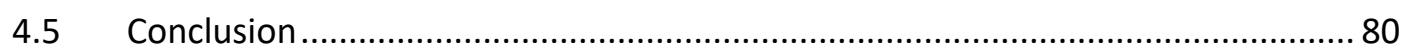

Chapter 5: Performance analysis of model predictive control applied to the control

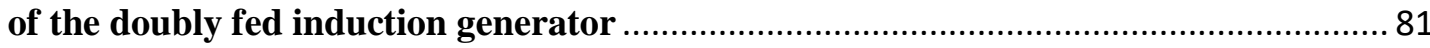

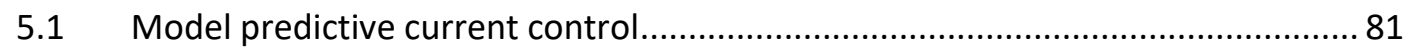

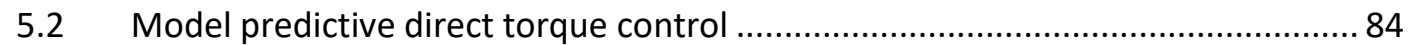

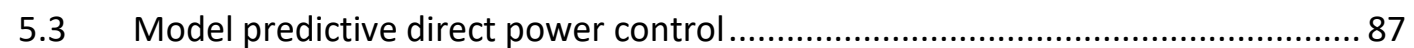

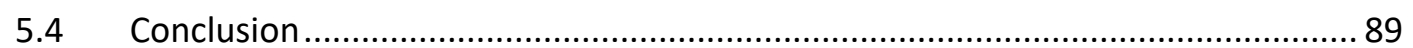

Chapter 6: Conclusion and future scope of work ........................................................ 91

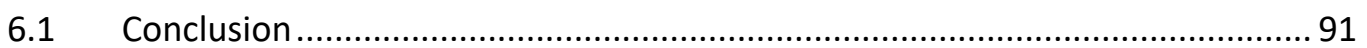

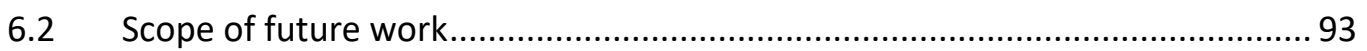

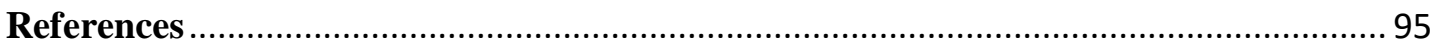

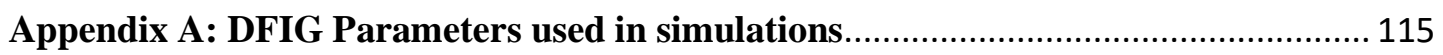

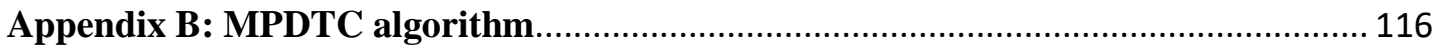




\section{List of figures}

Figure 1-1: General structure of WECS [11] 2

Figure 1-2: Cumulative wind energy capacity across the globe (in GW) from 2013-2019 [20]

Figure 1-3: Percentage contribution to global wind energy capacity for top 10 nations [20].. 6

Figure 1-4: Percentage penetration of wind energy into the electrical grids of various nations

Figure 2-1: Relationship between wind turbine tip speed ratio, power coefficient, and blade pitch [11] 14

Figure 2-2: Vector representation of the different reference frames [49] ............................. 16

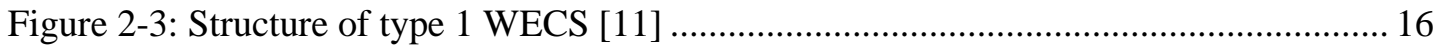

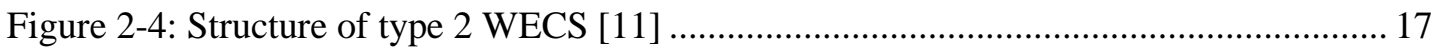

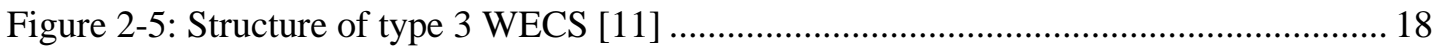

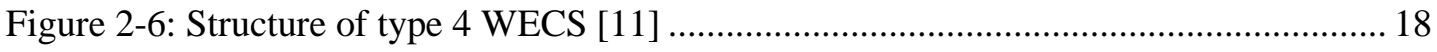

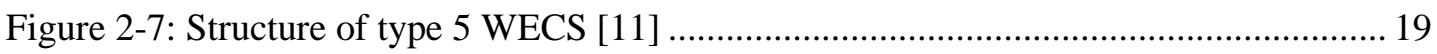

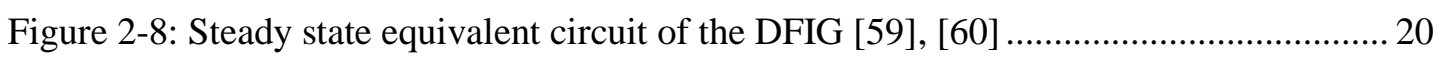

Figure 2-9: Equivalent circuit of DFIG in the d-q reference frame [66],[67] ........................ 25

Figure 2-10: Equivalent circuit of DFIG in the $\alpha-\beta$ reference frame [48] ............................. 26

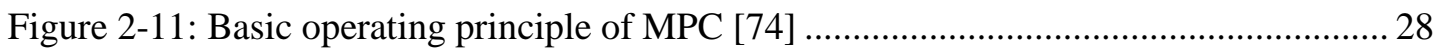

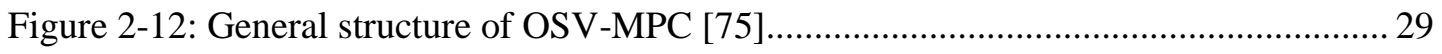

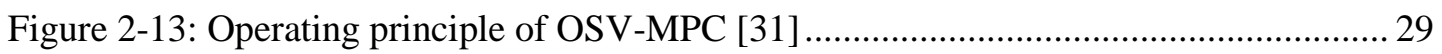

Figure 2-14: Operating principle of the Euler method [79] .................................................. 30

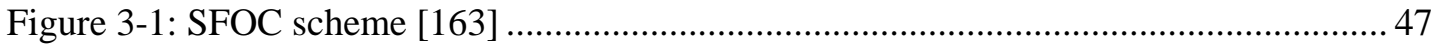

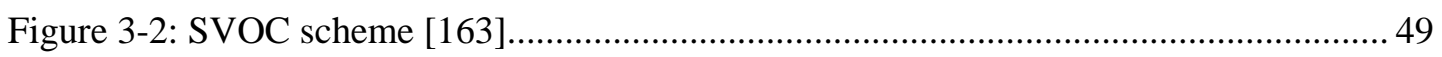

Figure 3-3: Control structure of Indirect FOC [27], [48], [98] ............................................ 51

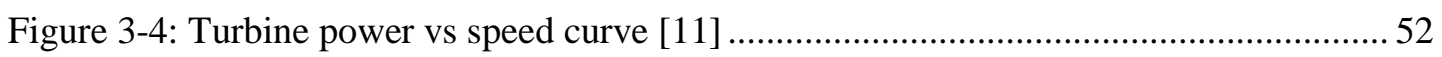

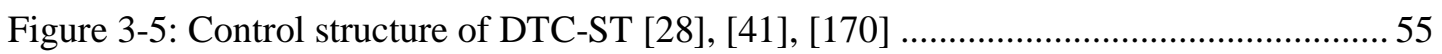

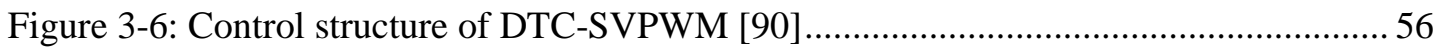

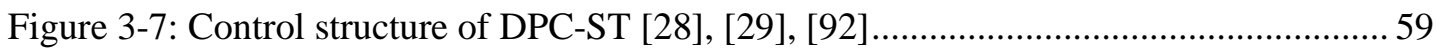

Figure 3-8: Control structure of MPCC using FCS-MPC [93], [94]...................................... 61

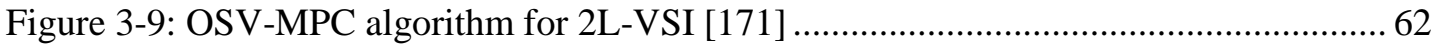

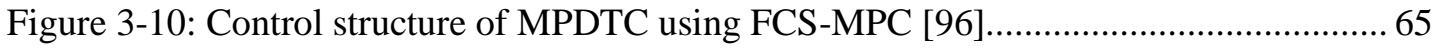

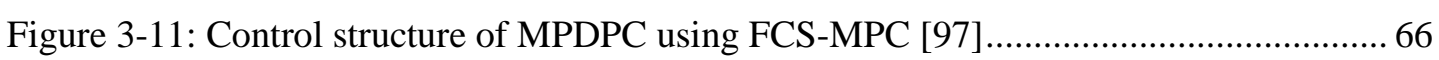

Figure 3-12: Flow chart of research method.......................................66

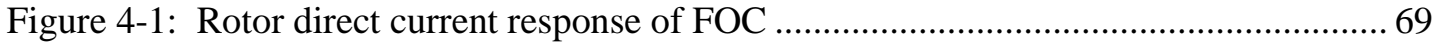


Figure 4-2: Electromagnetic torque response of FOC 69

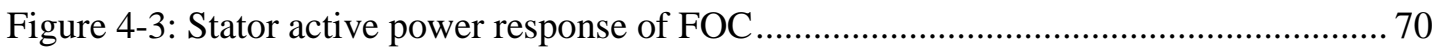

Figure 4-4: Rotor quadrature current response of FOC ……….......................................... 70

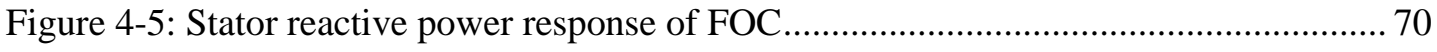

Figure 4-6: Three-phase rotor current response of FOC ....................................................... 70

Figure 4-7: Three-phase stator current response of FOC ...................................................... 71

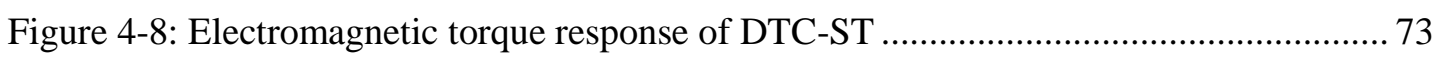

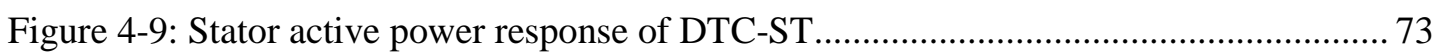

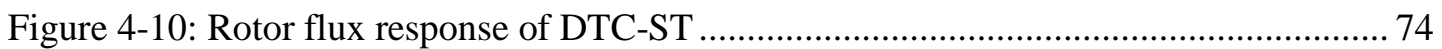

Figure 4-11: Stator reactive power response of DTC-ST ………………………............... 74

Figure 4-12: Three-phase rotor current response of DTC-ST .............................................. 74

Figure 4-13: Three-phase stator current response of DTC-ST ............................................... 74

Figure 4-14: Electromagnetic torque response of DTC-SVPWM ………………................ 76

Figure 4-15: Stator active power response of DTC-SVPWM.............................................. 76

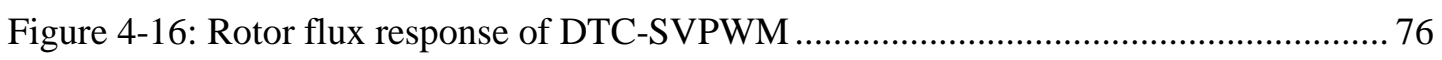

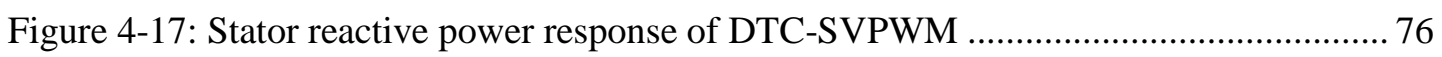

Figure 4-18: Three-phase rotor current response of DTC-SVPWM ….................................... 77

Figure 4-19: Three-phase stator current response of DTC-SVPWM.................................... 77

Figure 4-20: Electromagnetic torque response of DPC-ST ……………………................ 79

Figure 4-21: Stator active power response of DPC-ST ......................................................... 79

Figure 4-22: Stator reactive power response of DPC-ST ....................................................... 79

Figure 4-23: Three-phase rotor current response of DPC-ST ............................................... 79

Figure 4-24: Three-phase stator current response of DPC-ST ............................................. 80

Figure 5-1: Rotor direct current response of MPCC ……………....................................... 82

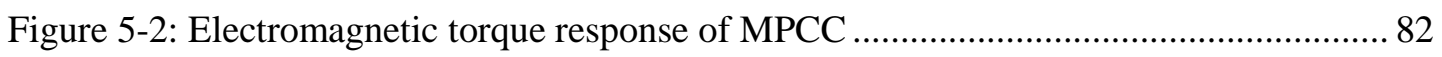

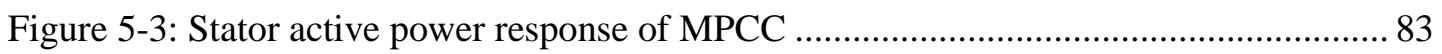

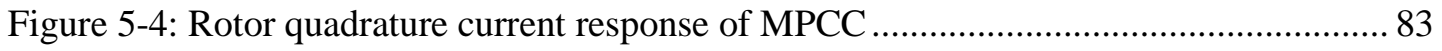

Figure 5-6: Three-phase rotor current response of MPCC................................................... 83

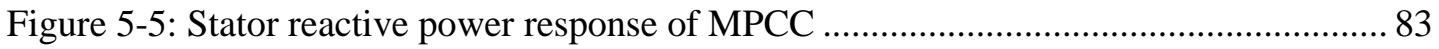

Figure 5-7: Three-phase stator current response of MPCC.................................................... 84

Figure 5-8: Electromagnetic torque response of MPDTC …………………...................... 85

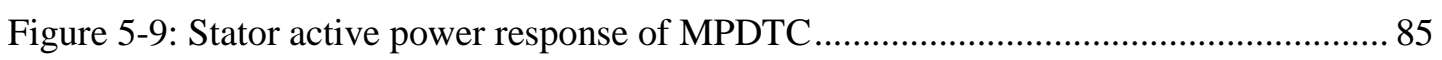

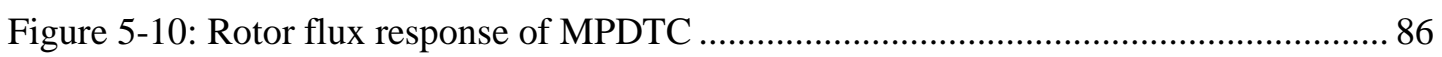

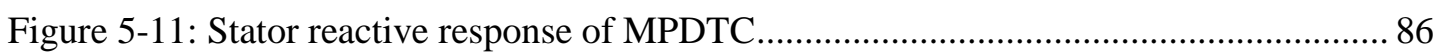

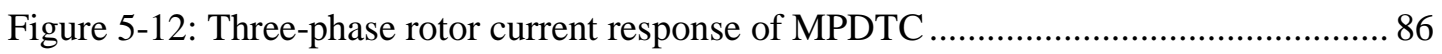

Figure 5-13: Three-phase stator current response of MPDTC ............................................... 86

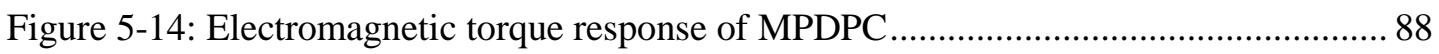




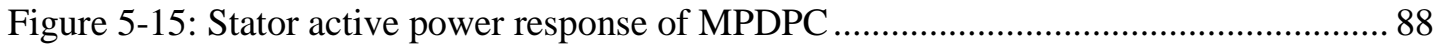

Figure 5-16: Stator reactive power response of MPDPC ....................................................... 89

Figure 5-17: Three-phase rotor current response of MPDPC ………………….................. 89

Figure 5-18: Three-phase stator current response of MPDPC …............................................. 89 


\section{List of tables}

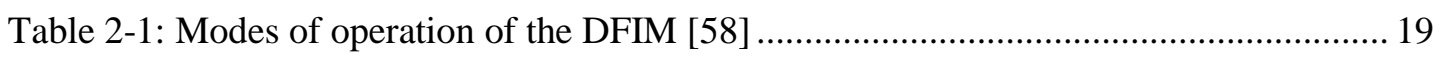

Table 3-1: Rotor voltage generation according to switching states [28]................................ 54

Table 3-2: Sector identification of rotor flux angle [28] ..................................................... 54

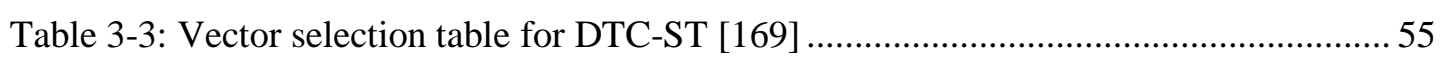

Table 3-4: Sector identification angle of stator flux angle [28] ............................................ 58

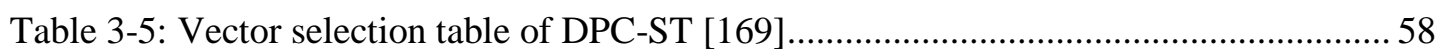




\section{Chapter 1: Introduction}

\subsection{Introduction to research work}

In recent times, there has been an increase in the demand for electrical power. This is due to many factors, such as population growth, urbanisation and increase in demand from industries. This increase in demand puts a strain on the generation system. Furthermore, since majority of current generation systems use coal as their main fuel source, this increase in demand causes an increase in the need for coal. Coal is rapidly becoming a scarce fossil fuel and is estimated to be depleted in the near future. Furthermore, the use of coal in the generation of electrical power emits harmful by-products which damage our precious ozone layer. Is there for these reasons that the world is turning towards the production of electrical energy from sustainable power sources [1], [2], [3]. One such source is the sun, which can effectively be used in small scale electrical power generation [4]. The use of solar panels requires little maintenance but incur large costs due to the use of batteries. Furthermore, each solar panel only produces a few hundred watts of electrical power [5]. This means that a solar farm will be large in size but small in electrical capacity.

Another type of sustainable power source is tidal energy. The natural flow of the sea current can be used to rotate a generator [4], [6]. However, this too has significant disadvantages. The harmful effects on marine life, location limits and extremely high plant construction costs prove to be a big downfall to tidal energy [6]. Geothermal energy is the extraction of heat from under the earth's surface [4]. However, geothermal energy contributes to land instability, is location specific and is expensive. Another sustainable energy source is biomass. Biomass energy refers to energy derived from the burning of plant matter [4]. This remains a strong alternative to coal but is much more expensive and could lead to deforestation.

The final source of sustainable energy is wind energy [4]. Wind energy conversion systems capture wind energy via the use of wind turbines. This captured wind is used to rotate the shaft of a generator. Wind energy conversion systems (WECS) use a small area to produce a large amount of power. They do however have a high initial cost [7]. Furthermore, the intermittent nature of wind energy can prove to be troublesome. WECS deploy the use of highpowered electronic switches to regulate the output of the system [8]. Both synchronous and asynchronous generators are used in WECS [9]. The derivation of electrical energy from WECS is rapidly gaining widespread popularity and seems and attractive option to coal based 
power generation [10]. However, since the electrical energy produced needs to be constant, the varying nature of the wind needs to be accounted for. Efficient and effective generation of electrical power from WECS remains a crucial factor in the alleviation of the current power crisis experienced across the globe.

As can be seen, while production of electrical power from sustainable sources seems to be a way out of the current energy crisis, they all incur large expenses. This is the main drawback of the utilization of sustainable energy sources. Despite its intermittent nature, wind energy seems to be the best sustainable energy source for large scale power generation. Therefore, research in WECS can prove to be highly beneficial. The research undertaken in this project deals with the generation of electrical energy using WECS.

\subsection{Research background}

WECS utilise wind energy to rotate the blades of a wind turbine. The speed of this mechanical rotation is then transformed into a higher speed, usually via the use of a gearbox. This higher rotational motion is fed to the shaft of the generator which, together with some form of electrical control action, produce electrical power that is fed into the electrical grid. This can be seen in figure 1-1 [11]:

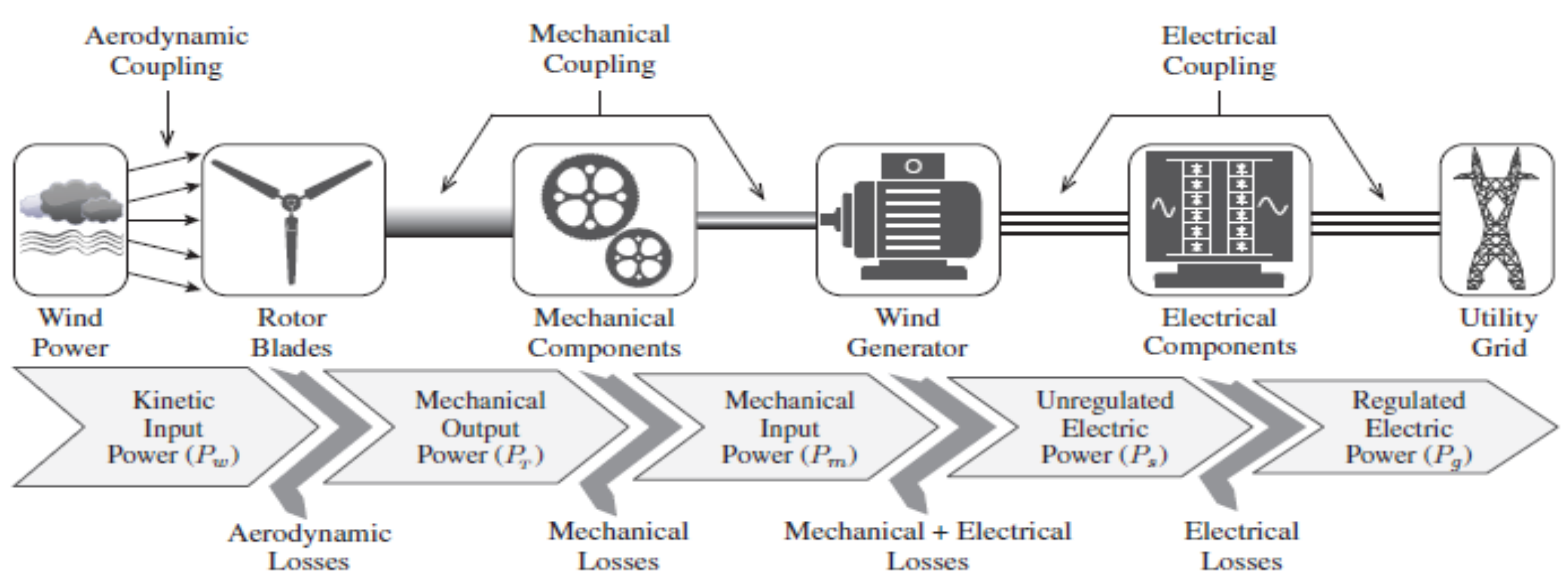

Figure 1-1: General structure of WECS [11]

Wind turbines are produced in large varieties, and can be separated into categories such as [11]:

Low, medium and high-powered turbines

$>$ Pitch regulated based, active stall-based and passive stall-based turbines 
$>$ Vertical and horizontal axis turbines

$>$ Standalone and grid-connected turbines

$>$ Variable and fixed speed turbines

$>$ Onshore and offshore turbines

$>$ Gearless, geared, and semi-geared turbines

$>$ High-speed, medium-speed and low-speed turbines

Low-powered wind turbines are generally wind turbines that are capable of producing up to $30 \mathrm{~kW}$ of power. High-powered wind turbines are wind turbines which produce power in excess of $300 \mathrm{~kW}$. Medium-powered wind turbines are between these. Passive and active stall, and pitch control refers to control of the amount of wind energy that the wind turbine captures. Passive stall is a simple system, used in low and medium powered wind turbine. The wind turbine is designed such that the turbulence on the rotor blades at high speed will cause the blades to lose life force and as a result capture less wind energy. In active stall, the angle of attack of the rotor blades are changed during high wind speeds. The blades are made to face the wind at a more direct angle. After this point, regulation is provided the same as in passive stall. In pitch regulation, the angle of the rotor blades is changed similar to that of active stall. However, at high wind speeds, the rotor blades are angled out of the wind. Active stall and pitch regulation are used in medium and high-powered wind turbines [12], [11]. Geared wind turbines are usually wind turbines that make use of a three-stage gearbox. Semi-geared wind turbines make use of a one or two stage gearbox. In gearless wind turbines, the shaft of the wind turbine is connected to the generator with no interfacing medium. When it comes to the speed rating of wind turbines, there exists three categories. Low-speed wind turbines are capable of operating up to an average wind speed of $7.5 \mathrm{~m} / \mathrm{s}$. This increases to $8.5 \mathrm{~m} / \mathrm{s}$ for medium-speed wind turbines and increases to $10 \mathrm{~m} / \mathrm{s}$ for the high-speed wind turbines. Onshore and offshore wind turbines refer to the location of the wind turbines. Those which are located on land are termed onshore wind turbines whereas those located at sea are termed offshore wind turbined. Onshore wind farms have several advantages over offshore wind farms such as lower construction costs, lower maintenance costs and lower power transmission losses. However, offshore wind farms have advantages over onshore wind farms, such as exposure to stronger and steadier winds and reduced audible and visual pollution [11] .

While the result of rotation of both vertical and horizontal axis wind turbines is the same, there exists significant differences in the structure of these two classifications. Vertical axis wind turbines (VAWT) can be used at lower speeds when compared to horizontal axis wind turbines (HAWT). This allows them to be mounted at a lower height. This reduction in height will 
reduce initial construction costs and reduces the threat that the wind turbines place on birds. VAWT do not have to change their direction depending on the wind [12], [13]. These are all huge advantages over HAWT. However, due to the uneven distribution of wind across the blades, VAWT are less efficient than HAWT. Furthermore, the design of the VAWT subjects the mechanical components to an increased wear and tear [12]. VAWT can further be classified into the Darrieus and Savonius wind turbines [14] .

The mechanical design of WECS is complex and consists of various mechanical components. The mechanical components used in WECS generally consists of a main shaft, a mechanical brake, the rotor hub, rotor blades, rotor bearings, nacelle, pitch drive and yaw drive. The rotor hub converts the rotational motion of the turbine blades into mechanical torque for input to the low-speed shaft. The coupling between the shaft and hub is done via the rotor bearings [11], [15], [16]. The gearbox is responsible for converting the low speed of the main shaft into a higher speed for input to the shaft of the generator. In doing so, the law of conservation of mechanical power is preserved. This means that when the rotational speed is increased, the mechanical torque is decreased. The pitch drive is responsible for controlling the angle of attack of the blades relative to the wind and the yaw drive controls the angle of attack of the entire wind turbine [11]. The nacelle is used to enclose all of the required components and control systems [11], [17]

The electrical design of WECS is also complex in nature and consists of electrical components such as the generator, electrical cables, power converter, step-up transformer and electrical switchgear [11]. The generator converts the mechanical torque which is input to the rotor to electromagnetic torque which produces electrical power. The electrical cables transfer this produced electrical power to a transformer to step up the voltage. This is then sent to the electrical substation. The electrical substation consists of electrical switchgear which provides control over the electrical power. Before being sent into the electrical grid, a step-up transformer increases the voltage produced by the generator into a voltage suitable for injection into the electrical grid [11]. The power converter, which consists of power electronics switches such as IGBT's and power MOSFET's, is used to regulate the output of the generator [18]. This is imperative due to the intermittent nature of the wind speed, hence shaft speed.

Conventional power stations undergo a complex procedure in order to provide mechanical power to the generator. This process involves the heating of water to produce steam, which makes us of coal and boilers. This process is costly and unsustainable. This is where WECS provide a big advantage; the mechanical power is solely provided by the wind with no additional components. It is free and sustainable. However, in order to be considered a source 
of electrical power, WECS need to behave like conventional power plants in all aspects [19]. These aspects are governed by the national grid codes, which vary from country to country.

Despite this variance, grid codes usually consist of the following elements [11]:

$>$ The tolerance of grid frequency and voltage variations

$>$ The quality of power injected into the grid

$>$ The capabilities of the generator to deal with black starts and short circuits

$>$ Fault ride through compliance of the generator

$>$ Both active and reactive power control

These elements are crucial for maintaining the quality of electrical power in the grid as well as preserving stability of the electrical network. The grid codes are usually applicable at the point where the wind farm is connected to the grid. Whilst grid codes are important in all countries, countries such as the UK, Germany, the USA, and China have among the most demanding of grid codes [19].

\subsection{Research significance}

WECS are increasing in capacity, and in 2019 has reached over $650 \mathrm{GW}$ [10]. Figure 1-2 shows the total global installed wind energy capacity [20]. It can be seen that in the last 6 years, there has been a steady increase in the annual cumulative installed wind energy capacity. China is the world leader in installed wind energy capacity, with the United States and Germany closely behind [21]. As of 2019, China has an installed wind energy capacity of 237 MW. The United States fares in at 105.5 MW and Germany at 61.6 MW. There are also various countries around the world like India, France and Spain which have an increasing wind energy capacity [20]. The percentage of wind energy contributions of the top ten countries can be seen in figure 1-3 [20]. Figure 1-4 shows the percentage of penetration of wind energy into the electrical grids of various countries [22]. As can be seen, Europe dominates this area, with Denmark leading this by producing $48 \%$ of its total electrical power by use of wind energy [22]. Despite China and the United States of America leading the list of total cumulative installed wind energy capacity, this only accounts for $11 \%$ and $7 \%$ of their total electrical power respectively [20], [23]. Nevertheless, these countries have had steady growth over the last few years. It can then be said that the world is moving towards electrical power generation by use of WECS. It is therefore imperative that thorough research in the field of control of WECS is carried out. 


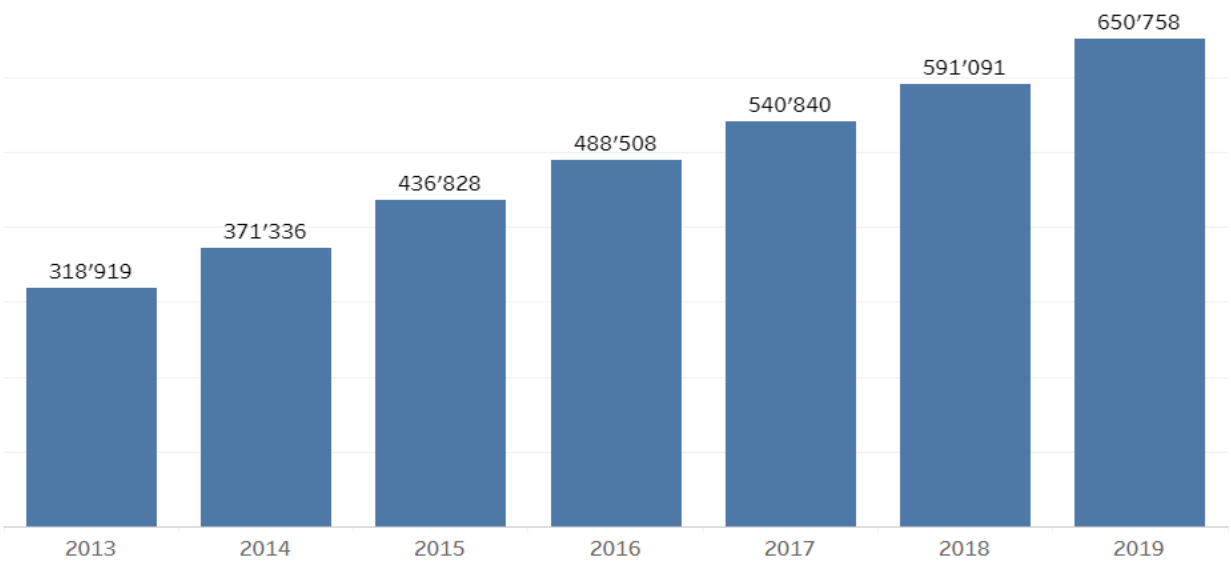

Figure 1-2: Cumulative wind energy capacity across the globe (in GW) from 2013-2019 [20]

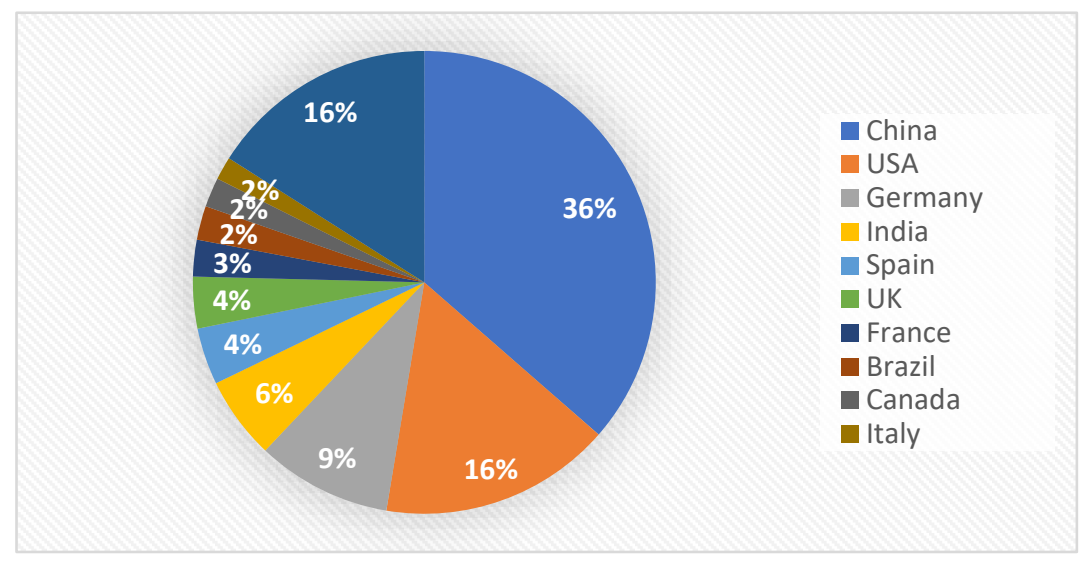

Figure 1-3: Percentage contribution to global wind energy capacity for top 10 nations [20]

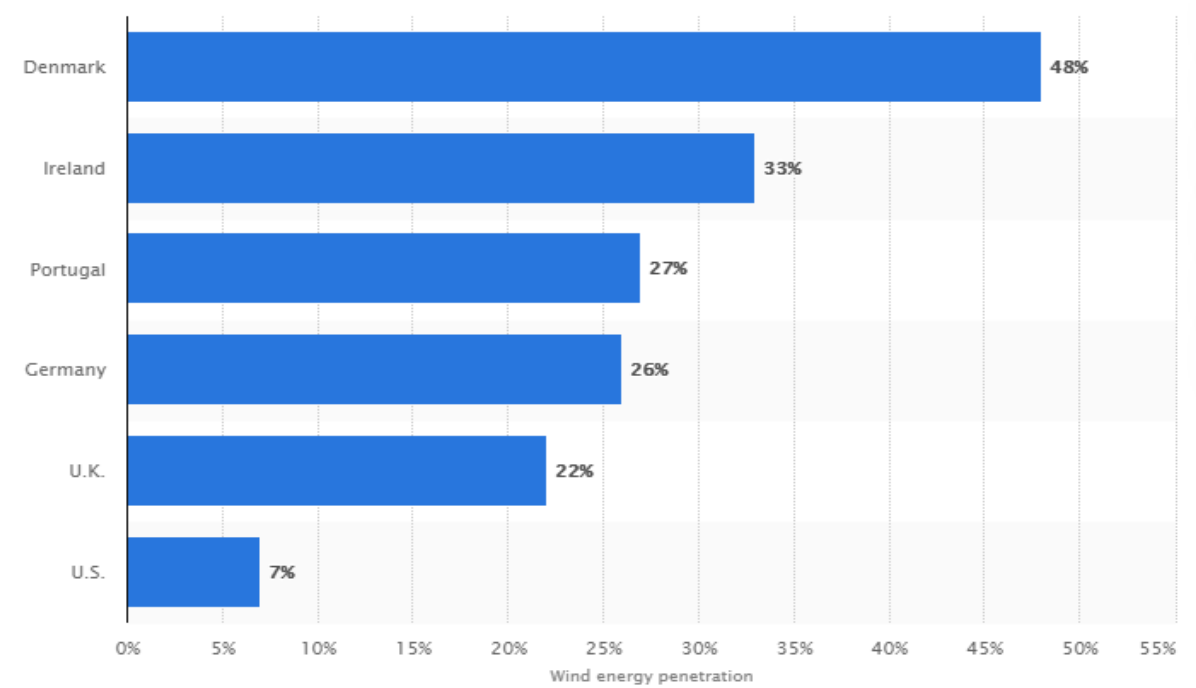

Figure 1-4: Percentage penetration of wind energy into the electrical grids of various nations [22] 


\subsection{Research motivation}

The horizontal axis wind turbines are most commonly used, with the three bladed wind turbine showing dominance in the wind energy industry. When it comes to the use of electrical generators, various examples are seen in wind farms. The conventional synchronous generator remains a robust choice but requires a full-scale converter. This is costly and adds to power losses in the system. The squirrel cage induction machine is a rugged machine which fares well, but only within a limited speed range. This therefore means that a generator with a large speed range and reduction in converter dependency will be well suited for the use of WECS [11].

The doubly fed induction generator, commonly termed DFIG, is an induction generator with a wound rotor. The rotor is connected to the electrical grid by means of a back-to-back converter [24]. It only requires a partially rated converter, making it cheaper and more efficient than the synchronous generator. It also has a higher speed range, making it a better choice than the squirrel cage induction machine [11]. Due to these highly beneficial advantages, the DFIG is seen in majority of WECS [25]. The DFIG however, is not a perfect machine. Unbalances in the grid can severely affect the output of the DFIG [26]. As can be seen in the elements of the grid codes, this could be troublesome and improper care of these aspects will render the DFIG unsuitable for use in WECS.

Despite this disadvantage, the DFIG still remains the best choice for wind energy applications. This therefore means that the control system applied to the DFIG needs to provide strong dynamic and steady state performances, as well as produce acceptable power quality. One method of control of the DFIG is via the control of the rotor current, which conventionally encompasses the utilization of proportional-integral controllers [27]. Although providing acceptable performances, the tuning of the proportional-integral controllers is a complex task. Other control techniques prove to be simpler but do not provide as strong a performance as the conventional rotor current control method [28], [29]. Therefore, a need for a simple control method which provides strong performances is imperative.

This need gives rise to the use of model predictive control in the control of the DFIG. Model predictive control (MPC) has been long used in the process industry but is a fairly new technology in the electrical industry [30]. Based on the premise of the converter having a finite amount of switching states, finite control set model predictive control (FCS-MPC) offers a simple control structure [31]. The issue, however, is the quality of the control performance. This could remain a great drawback as the quality of electrical power injected into the grid needs to be compliant with the national grid codes. This brings rise to the purpose of this 
research. This research provides an investigation into the application of MPC to the control of the DFIG. The research aims to critically evaluate the performance of this control performance with regards to various essential aspects and provide a comprehensive comparison between conventional control methods and control using MPC. Based on the increasing popularity of WECS, in particular DFIG based WECS, successful and effective implementation of MPC applied to the control of the DFIG could provide a competitive alternative to the control of the DFIG and will greatly contribute to the generation of electrical power from sustainable sources.

\subsection{Objectives of research}

The aim of this research is the evaluate the suitability and effectiveness of MPC applied to the control of the DFIG. Initial research needs to be done on the various control methods and their implementation by conventional means. The information gained from this research will be implemented on a suitable software and the control methods will be analysed and evaluated in terms of various aspects. The aspects to be evaluated is steady state ripple, dynamic response, and quality of output. Thereafter, research will be done on MPC and this will be applied to the relevant control strategies by using a suitable software. The results of model predictive based control will be thoroughly evaluated in terms of steady state ripple, dynamic response, and quality of the stator current, and its results will be compared to the conventional methods of control. The research work focuses on large scale electrical power generation which requires the use of a large doubly fed induction generator. This is due to the various advantages of the DFIG when used in WECS.

The aims of this research project are as follows:

1. Provide an in-depth research on WECS, in particular DFIG based WECS. This includes all relevant steady state and dynamic equations of the DFIG.

2. Define the relevant control methods to be applied to the DFIG.

3. Critically evaluate solutions to problems associated with DFIG based WECS.

4. Obtain the relevant structures and equations used in the various control methods. This will be thorough so as to allow an effective investigation to be carried out.

5. Model and implement the various control methods on a suitable simulation software.

6. Critically evaluate the performance of each control method in terms of response time, steady state performance and output quality under different circumstances. 
7. Provide a comparison between all of the implemented control methods.

\subsection{Research questions}

The research undertaken in this project aims to answer the following questions:

1. What are the different control strategies which are used in the control of the DFIG?

2. What is the general structure of the relevant control strategies, implemented both by conventional means and via the use of model predictive control?

3. What are the relevant equations required for execution of the control strategies, both by conventional means and via the use of model predictive control?

4. What information is required for successful execution of each of the control methods?

5. Does the control method require tuning?

6. How well does each control method react to changes?

7. How well does each control method perform at steady state?

8. What is the quality of the stator current of each control method?

9. How does each control method fare against each other in terms of dynamic and steady state response, as well as the quality of stator current?

\subsection{Hypothesis}

1. Based on the basic theory of FCS-MPC, MPC applied to the control of the DFIG will be simple in structure and implementation.

2. Since MPC is based on the estimation of a future value, MPC applied to the control of the DFIG will provide strong dynamic and steady state responses.

3. As the name suggests, MPC will depend primarily on the model of the machine to provide future value estimations.

\subsection{Limitations of research}

The following will not be investigated in this research:

1. Although the output of the DFIG will be constant in frequency, initial grid synchronization will not be implemented in this research. 
2. The grid side converter will not be implemented. Only the rotor side converter will be considered.

3. Despite the DFIG being able to operate at speeds higher and lower than synchronous speed, only speeds lower than synchronous speed will be investigated.

4. Fault ride through compliance is critical in a power system [11]. However, this will not be investigated in this project.

5. Grid unbalances are common occurrences at the site of wind farms and could prove to be problematic as they could interfere with the output quality of the DFIG [26]. Mitigation of such is therefore imperative. However, in this research, the grid is considered as ideal.

6. The wind turbine model is not implemented in this research. The input to the DFIG is taken as a mechanical speed.

\subsection{Contributions of current research}

Although the use of the DFIG in WECS is a relatively new concept, a lot of research has been done in this field. Most of the research deals with conventional control methods, and their improvements or adaptation thereof. This is mostly done with regards to aspects such as the analysis and enhancements of fault ride through capabilities and the mitigation of the harmful effects of voltage unbalances on the operation of DFIG based WECS. Intelligent control methods applied to the DFIG have also been investigated. The effect on transient response and system stability of artificial neural network presents itself in current research. [32], [33]. Fuzzy logic control is another control method that has been applied to the DFIG to improve aspects such as maximum power point tracking and fault protection [34], [35]. When it comes to MPC, not much has been done in the field of electrical power engineering. While there does exists literature on the application of this control method to the DFIG, it is not vast, especially in areas such as fault ride through capabilities and mitigation of voltage unbalances. 


\subsection{Structure of dissertation}

The research work undertaken in this dissertation consists of various sections which are organised as follows:

Chapter 1 introduces the research work undertaken, including the background of the research, research motivation, research limitations and hypothesis. A summary of the intended research is also provided. This chapter provides a thorough introduction to the field of research being undertaken. It provides a comprehensive overview of the use of WECS across the globe.

Chapter two provides an in-depth explanation on the various theoretical aspects regarding WECS. This includes the wind turbine, an explanation of the different types of WECS and an explanation of the implementation of the various control strategies both by conventional means and via the use of MPC. The general theory of MPC is also given. Thereafter, a critical evaluation of solutions to issues concerning the use of the DFIG in WECS is provided.

Chapter 3 describes the relevant theory with regards to the various control strategies, implemented both by conventional means and via the use of MPC. Included in this chapter is the structure of each control method and the equations which govern these control methods. Where relevant, derivation of formulas is provided. This chapter provides the framework for successful implementation of chapters 4 and 5.

Chapter 4 involves the implementation of conventional control methods applied to the DFIG. The simulation scenario for each control method is provided, followed by the results of the experiment and an analysis of the results. The results are analysed in terms of dynamic and steady response, as well as the quality of the stator current. The advantages and disadvantages of each conventional control method are discussed in this chapter.

Chapter 5 is similar in structure to chapter 4 but includes the implementation of MPC to the control of the DFIG. The simulation scenario for each control method is provided, followed by the results of the experiment and an analysis of the results. Once again, the results are analysed in terms of dynamic and steady response as well as the quality of the stator current.

Chapter 6 provides a conclusion to the research work undertaken in this project. Firstly, a comparison between the conventional control methods is discussed. Thereafter, a comparison between the different MPC methods are presented. Finally, a comparison between the relevant conventional and model predictive control methods is critically discussed. The comparisons are given in terms of the steady state and dynamic performances, quality of stator currents and control structures. The final part of the conclusion encompasses a scope for future work to be carried out. 


\section{Chapter 2: Theoretical background and literature review of wind energy conversion systems}

This chapter aims to present the relevant theory with the regards to WECS, as well as a critical evaluation of past approaches to problems associated with the use of the DFIG. The chapter starts by explaining the concepts associated with the wind turbine. It then proceeds to explain reference frame theory and co-ordinate transformations, which is imperative in the control of WECS. The different types of WECS are then briefly explained, followed by an in-depth explanation of the steady state and dynamic modelling of the DFIG. Since the aim of this research is to analyse the effect of MPC applied to the control system of the DFIG, the relevant theory on MPC is provided. The relevant control methods which are applied to the DFIG are briefly discussed, with the final part being a review of approaches used to solve various issues with regards to the use of the DFIG in a power system.

\subsection{The wind turbine}

The wind turbine is the machine responsible for converting wind energy into mechanical torque (energy). The amount of energy captured by the wind turbine is dependent on various factors and is represented as follows [36]:

$P_{M}=\frac{1}{2} C_{p} \times A_{r} \times v^{3} \times \rho$

Where:

- $\quad P_{M}$ is the amount of mechanical power that is extracted by the wind turbine from the wind.

- $A_{r}$ is the area of the rotor turbine blades.

- $v$ is the wind speed in $\mathrm{m} / \mathrm{s}$.

- $\quad p$ is the density of the air.

- $C_{p}$ is the wind turbine's power coefficient. It is dependent on the tip speed ratio of the wind turbine as well as the blade pitch. It has a theoretical maximum of 0.593 [36].

The tip speed ratio can be calculated as follows [37], [38]:

$\lambda=\frac{w_{t} \times r}{v}$

Where:

- $\lambda$ is the tip speed ratio. 
- $w_{t}$ is the angular velocity of the wind turbine.

- $\quad r$ is the radius of the turbine, in metres.

The blade pitch, known as $\beta$, refers to the angle of attack of the rotor blades in reference to the wind. This is useful when the speed of the generator needs to be kept within specified limits. During times of low wind, the blades can be pitched in a way such that more of the blades surface area faces the wind. This will allow more wind energy to be absorbed by the turbine blades and will increase the speed of the generator shaft. During times of high wind speeds, the blades can be pitched such that less of the blades surface area faces the wind. This will allow less wind energy to be absorbed by the turbine blades, thus decreasing the speed of the generator shaft. When the pitch angle is at zero degrees, the entire blade area is facing the wind [11].

The aerodynamic torque captured by the wind turbine is as follows [39]:

$T_{\text {aero }}=\frac{P_{m}}{\Omega_{\text {turbine }}}$

The mechanical torque transferred to the shaft of the generator is calculated as [28]:

$T_{m}=\frac{T_{a e r 0}}{G}$

Hence the speed of the shaft will be [40]:

$$
\Omega_{\text {gen }}=\Omega_{\text {turbine }} \times G
$$

The dynamics of the wind turbine is expressed as [28], [41]:

$J \frac{d \Omega_{g e n}}{d t}+f_{v} \Omega_{m}=T_{m}-T_{e m}$

Where:

$T_{\text {aero }}$ and $T_{m}$ are the aerodynamic and mechanical torques respectively.

$\Omega_{g e n}$ and $\Omega_{\text {turbine }}$ are the speeds of the generator and wind turbine shafts respectively.

$\mathrm{G}$ is the gear ratio.

$J$ is the total system inertia

$f_{v}$ is the friction coefficient.

$T_{e m}$ is the electromagnetic torque of the generator. 
The relationship between the tip speed ratio, power coefficient, and pitch angle are illustrated in figure 2-1 [11]. The power coefficient, $C_{p}$, can be obtained using the following formulae [42]:

$C_{p}(\lambda, \beta)=0.5176\left[116\left(\frac{1}{\alpha}\right)-0.4 \beta-5\right] \exp \left(\frac{-21}{\lambda_{i}}\right) \times 0.0068 \lambda_{i}$

$\frac{1}{\alpha}=\frac{1}{\lambda+0.08 \beta}-\frac{0.035}{1+\beta^{3}}$

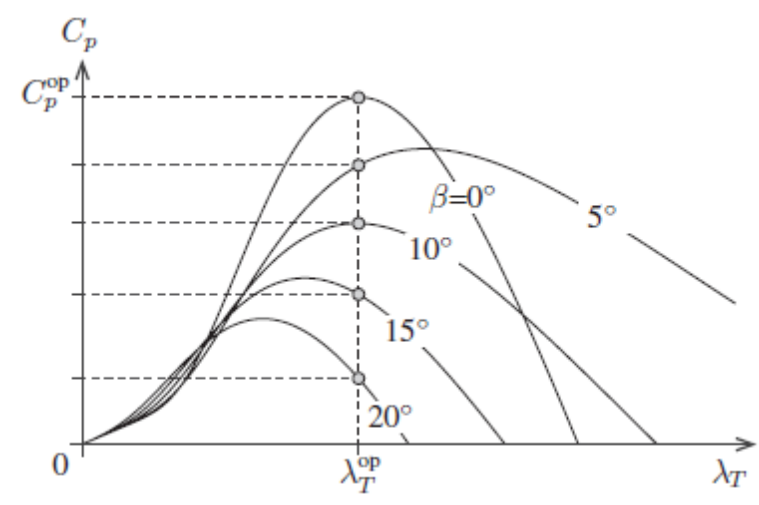

Figure 2-1: Relationship between wind turbine tip speed ratio, power coefficient, and blade pitch [11]

\subsection{Reference frame theory}

Reference frame theory and co-ordinate transformation is extensively used in electrical engineering for the purpose of power systems analysis and control. There exist two types of transforms; the Clark transform, and the Park transform. Clark transform converts a threephase a-b-c quantity into a stationary alpha-beta $(\alpha-\beta)$ quantity. Park transform converts this $\alpha-\beta$ quantity into a rotating direct-quadrature (d-q) quantity. In total, there are four reference frames [43]. They are as follows:

1. a-b-c reference frame: Which is the fundamental reference frame. Time varying threephase currents and voltages are displaced $120^{\circ}$ apart. It has a rotational speed of 0 [44].

2. $\alpha-\beta$ reference frame: This is known as a stationary reference frame. It also has a rotational speed of 0 but now the three phase voltages and currents are expressed as two time-varying components which are orthogonal [44]. 
The transformation from the a-b-c reference frame to the $\alpha-\beta$ reference frame is as follows [45]:

$\left(\begin{array}{l}V_{\alpha} \\ V_{\beta}\end{array}\right)=\left(\begin{array}{ccc}\frac{2}{3} & -\frac{1}{3} & -\frac{1}{3} \\ 0 & \frac{1}{\sqrt{3}} & -\frac{1}{\sqrt{3}}\end{array}\right)\left(\begin{array}{l}V a \\ V b \\ V c\end{array}\right)$

Where $V a, V b$ and $V c$ are phase quantities (not line quantities in the case of three phase voltage and currents)

3. d-q reference frame: This reference frame has a rotational speed equal to that of the synchronous speed. It consists of two dc values which are displaced $90^{\circ}$ apart and rotate at synchronous speed [44]. The transformation from the a-b-c reference frame to the $\mathrm{d}$-q reference frame is as follows [46]:

$\left(\begin{array}{c}V_{d} \\ V_{q} \\ V_{0}\end{array}\right)=\frac{2}{3}\left(\begin{array}{ccc}\operatorname{Sin}\left(\theta_{s}\right) & \operatorname{Sin}\left(\theta_{s}-\frac{2 \pi}{3}\right) & \operatorname{Sin}\left(\theta_{s}+\frac{2 \pi}{3}\right) \\ \operatorname{Cos}\left(\theta_{s}\right) & \operatorname{Cos}\left(\theta_{s}-\frac{2 \pi}{3}\right) & \operatorname{Cos}\left(\theta_{s}+\frac{2 \pi}{3}\right) \\ \frac{1}{2} & \frac{1}{2} & \frac{1}{2}\end{array}\right)\left(\begin{array}{l}V a \\ V b \\ V c\end{array}\right)$

Where $\theta_{s}$ is the angle between the $\alpha$ and $\mathrm{d}$ axes. In a balanced system, $V_{0}$ will $\mathrm{b}$ zero. The $\alpha-\beta$ reference frame to the $d-q$ reference frame transformation is as follows [47]:

$\left(\begin{array}{l}V_{d} \\ V_{q}\end{array}\right)=\frac{2}{3}\left(\begin{array}{cc}\operatorname{Cos}\left(\theta_{s}\right) & \operatorname{Sin}\left(\theta_{s}\right) \\ -\operatorname{Sin}\left(\theta_{s}\right) & \operatorname{Cos}\left(\theta_{s}\right)\end{array}\right)\left(\begin{array}{l}V \alpha \\ V \beta\end{array}\right)$

4. D-Q reference frame: This reference frame has a rotational speed equal to that of the rotor speed and is known as the rotor reference frame. The transformation for the D$\mathrm{Q}$ reference frame is the same as the $\alpha-\beta$ reference frame [48].

The transformation between the D-Q reference frame to the $\mathrm{d}-\mathrm{q}$ reference frame is as follows [48]:

$\left(\begin{array}{l}V_{D} \\ V_{Q}\end{array}\right)=\frac{2}{3}\left(\begin{array}{cc}\operatorname{Cos}\left(\theta_{r}\right) & \operatorname{Sin}\left(\theta_{r}\right) \\ -\operatorname{Sin}\left(\theta_{r}\right) & \operatorname{Cos}\left(\theta_{r}\right)\end{array}\right)\left(\begin{array}{l}V_{d} \\ V_{q}\end{array}\right)$

Where $\theta_{r}$ is the difference in electrical angle between the rotor $\left(\theta_{m}\right)$ and stator $\left(\theta_{s}\right)$

The vector representation of these reference frames is shown in figure 2-2 [49]. 


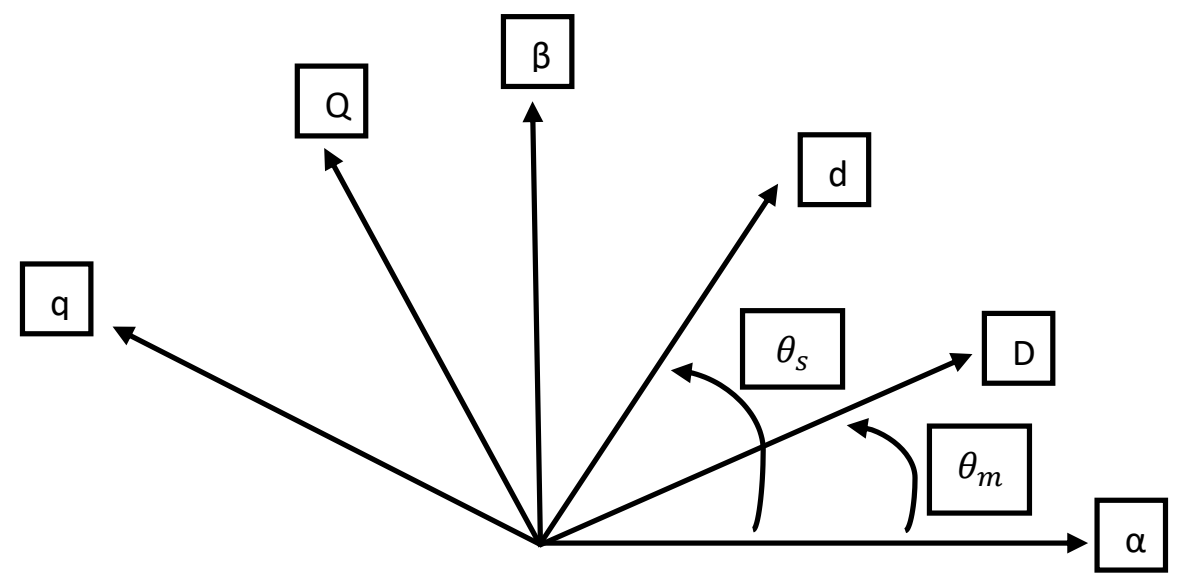

Figure 2-2: Vector representation of the different reference frames [49]

\subsection{Types of wind energy conversion systems}

There exist fives types of WECS. These systems utilize different types of generators. These generators are the squirrel cage induction generator ( $\mathrm{SCIG}$ ), the wound rotor induction generator (WRIG), the DFIG, the permanent magnet synchronous generator (PMSG) and the HTS-synchronous generator (HTS-SG).

Type 1 WECS are simple in structure because they require no additional components to provide grid synchronization and a softer start can be used to limit the inrush current. However, the SCIG requires reactive power [50]. Also, wind speed variance cause problems in grid frequency stabilisation. Furthermore, type 1 WECS produce power over a very small speed range [11]. The structure of type 1 WECS is shown in figure 2-3 [11], [51]:

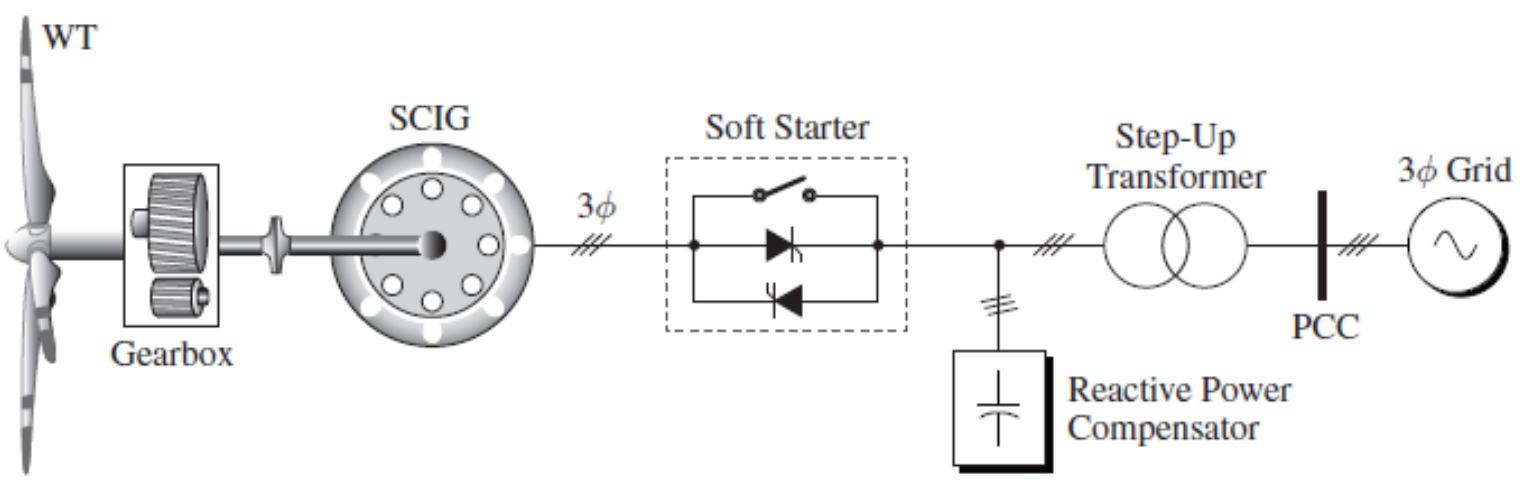

Figure 2-3: Structure of type 1 WECS [11]

Type 2 WECS attempt to mitigate the limited speed range of type 1 WECS. To do so, external resistors are placed in series with the rotor of the machine. The resistors are controlled via a 
power converter which is normally rated at $10 \%$ of the generators rated power. In an asynchronous machine, the value of the torque is an independent value but the speed at which this torque occurs can be varied by varying the rotor resistance of the machine. Hence this type of wind energy conversion system allows for a $10 \%$ variable speed range. The disadvantage, however, is the power loss in the rotor because of the external resistor heat dissipation and the power converters switching losses [11]. The structure of type 2 WECS is shown in figure 2-4 [11], [52]:

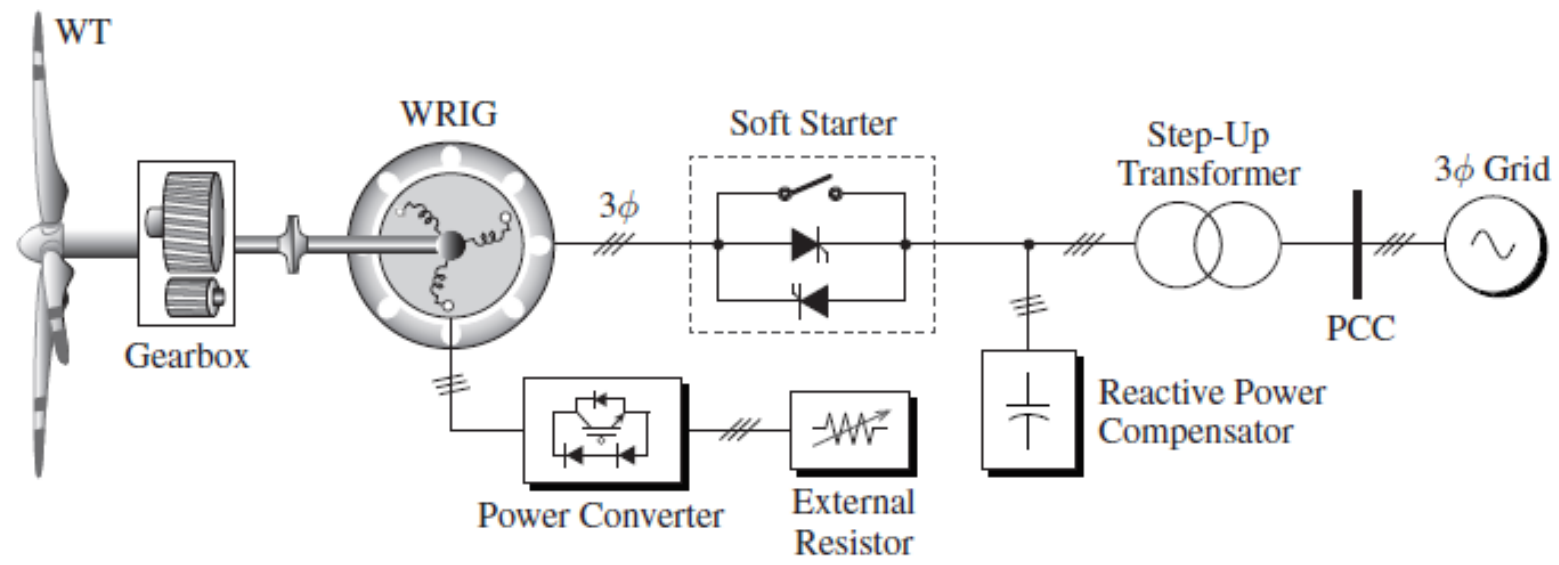

Figure 2-4: Structure of type 2 WECS [11]

Type 3 WECS are an advancement to types one and two. The DFIG is simply a WRIG equipped with a back-to-back converter from the grid to the rotor. The converter allows bidirectional power flow [24], [53], [54],. The converter is usually rated at 30\% of the machines rated power [11]. However, this system has disadvantages as well. For example, fault ride through compliance is complicated because of direct grid connection [11]. The structure of type 3 WECS is shown in figure 2-5 [11], [55].

Type 4 WECS deploys a full-scale converter at the stator of the machine. This means that type 4 WECS can produce power at any wind speed. The machine side converter is responsible for regulating the electromagnetic torque whilst the grid side converter is responsible for regulating the active and reactive power supplied/absorbed to/from the grid. This reactive power control ensures power system stability. However, a full-scale converter is expensive and will yield high switching losses [11], [56]. The structure of type 4 WECS is shown in figure 2-6 [11], [57]. 


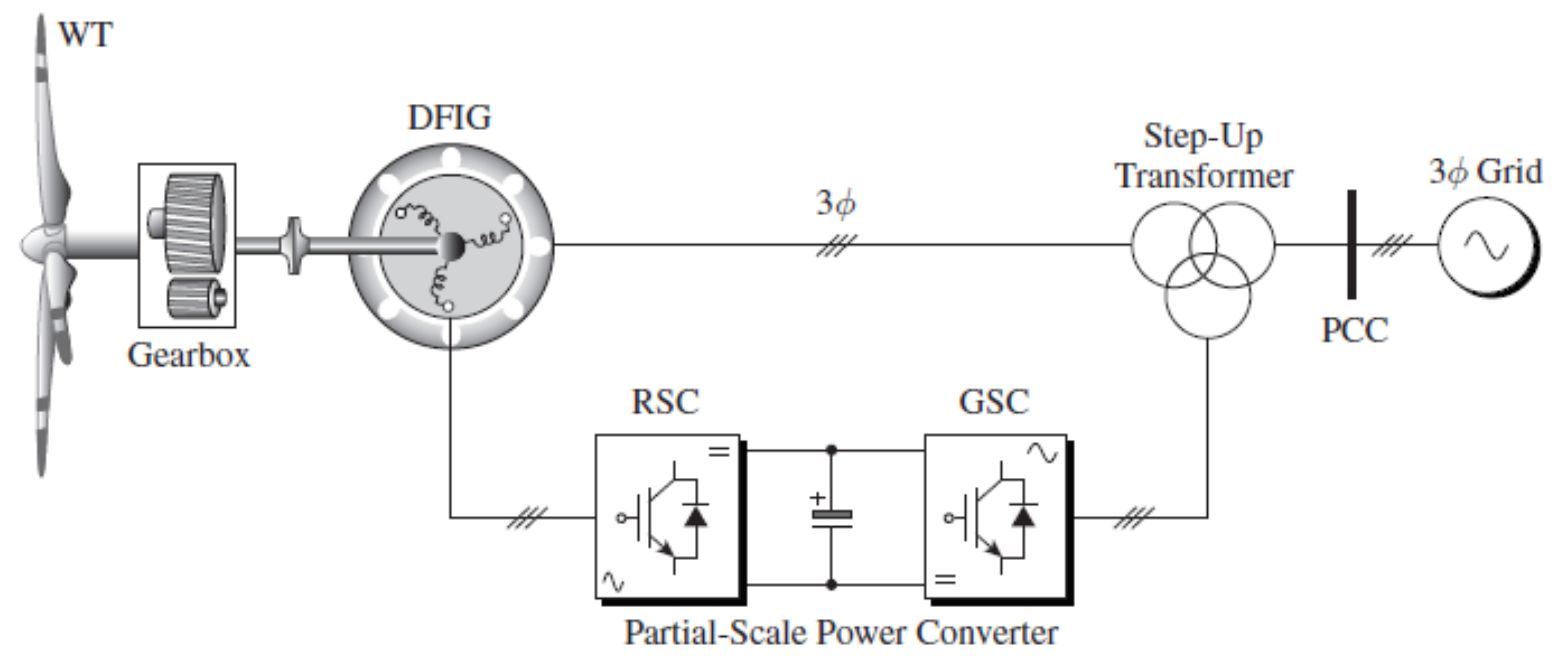

Figure 2-5: Structure of type 3 WECS [11]

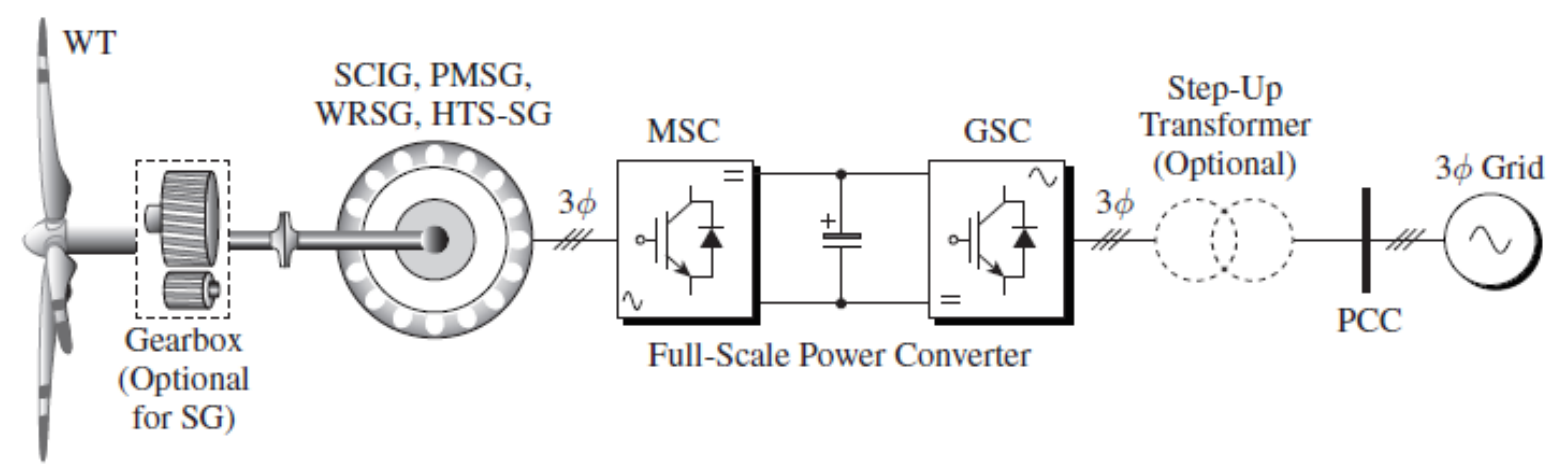

Figure 2-6: Structure of type 4 WECS [11]

Type 5 WECS are complex systems, which makes use of a torque/speed converter to convert the variable speed of the wind into a fixed speed for the generator. Like type 4 , it operates under all ranges of wind speeds. It doesn't require a power converter, so it is more efficient than type 4 . The generator is directly connected to the grid via a synchronizing circuit breaker. However, fault ride through compliance becomes complicated as is it required to be handled only by the excitation system of the wound rotor synchronous generator [11]. The structure of type 5 WECS is as shown in figure 2-7 [11].

Based on the explanations given for the five types of WECS, the DFIG is the most suited for WECS as it poses the perfect balance between cost, efficiency, simplicity, and operating range. It's not as expensive as type 4 , not as complex as type 5, more efficient than type 2 and has a much better operating range than type 1 . 


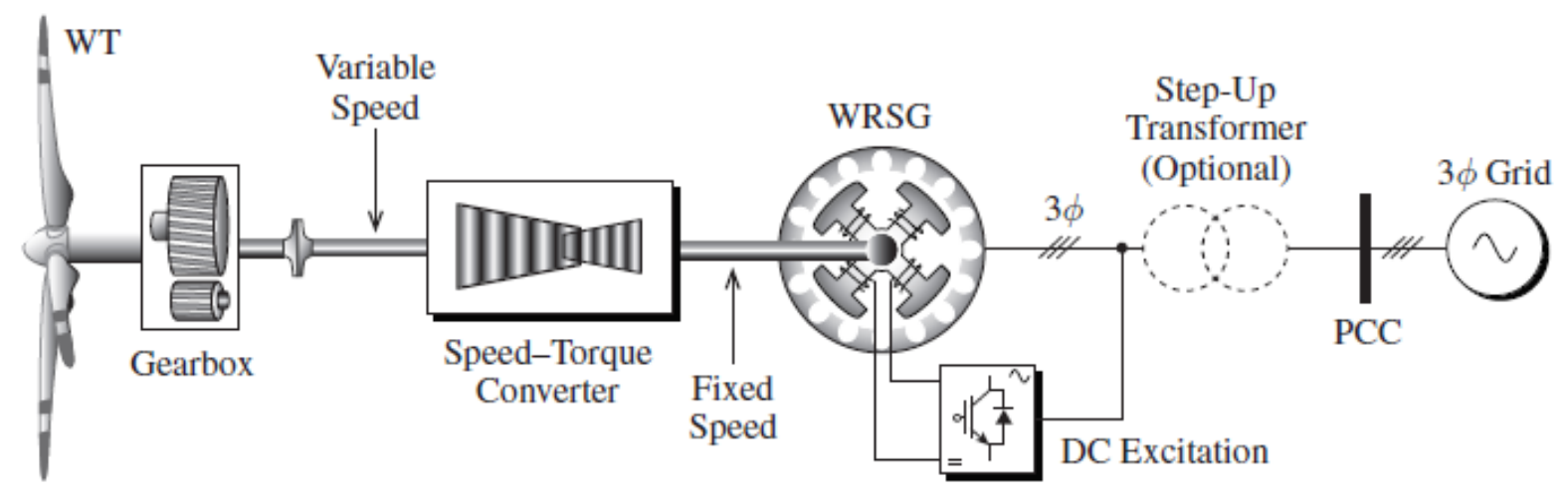

Figure 2-7: Structure of type 5 WECS [11]

\subsection{The DFIG}

\subsubsection{Basics of the DFIG}

The doubly fed induction machine (DFIM) can be operated as a generator and a motor at speeds above and below synchronous speed. The leads to four modes of operation of the DFIM. This can be tabulated as shown in table 2-1 [58]:

Table 2-1: Modes of operation of the DFIM [58]

\begin{tabular}{|c|c|c|c|c|}
\hline Mode & Slip & $\boldsymbol{P}_{\boldsymbol{m}}$ & $\boldsymbol{P}_{\boldsymbol{s}}$ & $\boldsymbol{P}_{\boldsymbol{r}}$ \\
\hline $\begin{array}{c}\text { Motor } \\
\left(T_{e m}>0\right)\end{array}$ & $\mathrm{s}<0$ & $>0$ & $>0$ & $>0$ \\
\hline $\begin{array}{c}\text { Generator } \\
\left(T_{\text {em }}>0\right)\end{array}$ & $\mathrm{s}<0$ & $<0$ & & \\
\hline $\begin{array}{c}\text { Generator } \\
\left(T_{\text {em }}>0\right)\end{array}$ & $\mathrm{s}>0$ & $<0$ & $<0$ & $>0$ \\
\hline $\begin{array}{c}\text { Motor } \\
\left(T_{\text {em }}>0\right)\end{array}$ & $\mathrm{s}>0$ & $>0$ & $>0$ & $<0$ \\
\hline
\end{tabular}

In table 2-1:

- $P_{r}$ is the rotor active power 
- $P_{S}$ is the stator active power

- $P_{m}$ is the mechanical power

Furthermore, positive stator and rotor active power is taken as flowing into the machine, and positive mechanical power is taken as being provided by the machine.

During sub-synchronous operation, the DFIG rotor draws power from the grid so that the mechanical power can be converted into electrical power. During super-synchronous operation, part of the mechanical power is converted to electrical power via the DFIG stator, and part by the DFIG rotor [58]. Furthermore, during sub-synchronous operation, the voltage injected into the rotor of the DFIG is at slip frequency [54]. This is an important aspect of the control of the DFIG.

\subsubsection{Steady State Analysis of the DFIG}

The simplified steady state equivalent model of the DFIG is shown in figure 2-8 [59], [60]:

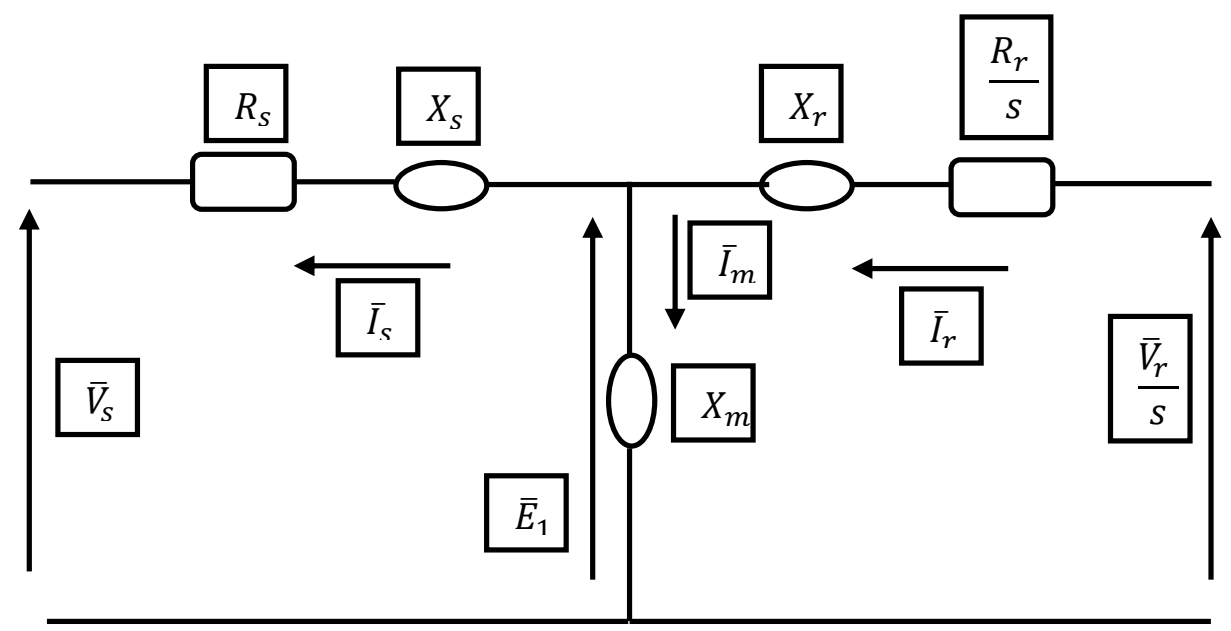

Figure 2-8: Steady state equivalent circuit of the DFIG [59], [60]

In figure 2-8:

- $\bar{V}_{r}, \bar{V}_{s}$ are the rotor and stator voltages respectively

- $\mathrm{s}$ is the slip

- $R_{r}, R_{S}$ are the rotor and stator resistances respectively

- $X_{r}, X_{s}, X_{m}$ are the rotor, stator, and magnetising reactance's respectively

- $\bar{I}_{r}, \bar{I}_{s}, \bar{I}_{m}$ are the rotor, stator, and magnetising currents respectively. 
The steady state currents are expressed as [59], [60]:

$$
\begin{aligned}
& \bar{I}_{s}=\frac{1}{D}\left[D_{A}\left(c X_{m} \sin (\alpha)+\bar{V}_{s} \frac{R_{r}}{s}\right)+D_{B}\left\{\bar{V}_{s}\left(X_{r}+X_{m}\right)-X_{m} \frac{\bar{V}_{r}}{s} \cos (\alpha)\right\}\right] \\
& +j \frac{1}{D}\left[D_{A}\left\{\bar{V}_{s}\left(X_{r}+X_{m}\right)-X_{m} \frac{\bar{V}_{r}}{s} \sin (\alpha)\right\}-D_{B}\left(X_{m} \frac{\bar{V}_{r}}{s} \sin (\alpha)+\bar{V}_{s} \frac{R_{r}}{s}\right)\right] \\
& \bar{I}_{r}=\frac{1}{D}\left[D_{A} \frac{\bar{V}_{r}}{s}\left(R_{r} \cos (\alpha)-\left(X_{r}+X_{m}\right) \sin (\alpha)\right)+D_{B}\left\{\frac{\bar{V}_{r}}{s}\left(\begin{array}{c}
\cos (\alpha)\left(X_{r}+X_{m}\right) \\
+R_{s} \sin (\alpha)
\end{array}\right)-\bar{V}_{S} X_{m}\right\}\right] \\
& +j \frac{1}{D}\left[D_{A}\left(\frac{\bar{V}_{r}}{s}\left(\left(X_{r}+X_{m}\right) \cos (\alpha)+R_{s} \sin (\alpha)-\bar{V}_{s} X_{m}\right)\right)\right. \\
& \left.-\left(D_{B} \frac{\bar{V}_{r}}{s}\left\{R_{s} \cos (\alpha)-\left(X_{r}+X_{m}\right) \sin (\alpha)\right\}\right)\right]
\end{aligned}
$$

The stator active and reactive powers during steady state operation are as follows [56], [57]:

$$
\begin{aligned}
& P_{s}=\operatorname{Re}\left(\bar{V}_{s} \bar{I}_{s}^{*}\right) \\
& P_{S}=\frac{V_{s}^{2}}{D}\left[R_{s} \frac{R_{r}^{2}}{s^{2}}+R_{S}\left(X_{r}+X_{m}\right)^{2}+X_{m}{ }^{2} \frac{R_{r}}{s}\right]-\frac{V_{s} V_{r}}{s D} X_{m}\left[\cos (\alpha) D_{B}-\sin (\alpha) D_{A}\right] \\
& Q_{s}=\operatorname{Im}\left(\bar{V}_{s} \bar{I}_{s}^{*}\right) \\
& Q_{s}=\frac{V_{s} V_{r}}{s D} X_{m}\left[\cos (\alpha) D_{A}-\sin (\alpha) D_{B}\right]+\frac{V_{s}{ }^{2}}{D}\left[\left(X_{r}+X_{m}\right)\left(X_{s} X_{r}+X_{m}\left(X_{s}+X_{r}\right)\right)\right. \\
& \left.+\frac{R_{r}^{2}}{s^{2}}\left(X_{s}+X_{m}\right)\right]
\end{aligned}
$$

The rotor active and reactive powers during steady state operation are given as [59], [60]:

$$
\begin{aligned}
& P_{r}=\frac{V_{r}^{2}}{s^{2} D}\left[R_{s} \frac{R_{s} R_{r}}{s}+\left(X_{s}+X_{m}\right) \frac{R_{r}}{s} X_{s}+X_{m}\left(X_{s} \frac{R_{r}}{s}+X_{m}\left(R_{s}+\frac{R_{r}}{s}\right)\right)\right] \\
& +\frac{V_{s} V_{r}}{s D} X_{m}\left[\cos (\alpha) D_{B}+\sin (\alpha) D_{A}\right] \\
& Q_{r}=\frac{V_{r}^{2}}{s D}\left[\left(X_{r}+X_{m}\right) R_{s}^{2}+\left(X_{s}+X_{m}\right)\left(X_{s} X_{r}+X_{m}\left(X_{s}+X_{r}\right)\right)\right] \\
& +\frac{V_{s} V_{r}}{s D} X_{m}\left[\cos (\alpha) D_{A}+\sin (\alpha) D_{B}\right]
\end{aligned}
$$

And finally, the steady state electromagnetic torque of the DFIG is calculated as [59], [60]:

$$
T_{e m}=-\frac{3 V_{s} V_{r}}{w_{s} s D} X_{m}\left[\begin{array}{l}
\cos (\alpha)\left(\frac{R_{r}}{s}\left(X_{s}+X_{m}\right)-R_{s}\left(X_{r}+X_{m}\right)\right) \\
+\sin (\alpha)\left(\frac{R_{s} R_{r}}{s}+X_{s} X_{r}+X_{m}\left(X_{s}+X_{r}\right)\right)
\end{array}\right]
$$


Where:

- $D_{A}=\frac{R_{s} R_{r}}{s}-\left(X_{r} X_{s}+X_{m}\left(X_{r}+X_{s}\right)\right)$

- $D_{B}=R_{s} X_{r}+\frac{R_{r}}{s} X_{r}+X_{m}\left(R_{s}+\frac{R_{r}}{s}\right)$

- $D=D_{A}{ }^{2}+D_{B}{ }^{2}$

- $w_{S}$ is the synchronous speed of the machine

- $\alpha$ is the angle between the rotor and stator voltages

\subsubsection{Dynamic Modelling of the DFIG in the $\alpha-\beta$ reference frame}

The voltage equations of the DFIG in the $\alpha-\beta$ reference frame are as follows [48]:

$V_{\alpha s}=R_{s} I_{\alpha s}+\frac{d \Phi_{\alpha s}}{d t}$

$V_{\beta s}=R_{s} I_{\beta s}+\frac{d \Phi_{\beta s}}{d t}$

$V_{\alpha r}=R_{s} I_{\alpha r}+\frac{d \Phi_{\alpha r}}{d t}+w_{m} \Phi_{\beta r}$

$V_{\beta r}=R_{S} I_{\beta r}+\frac{d \Phi_{\beta r}}{d t}-w_{m} \Phi_{\alpha r}$

The flux equations are as follows [28], [48]:

$\Phi_{\alpha s}=L_{s} I_{\alpha s}+L_{m} I_{\alpha r}$

$\Phi_{\beta s}=L_{s} I_{\beta s}+L_{m} I_{\beta r}$

$\Phi_{\alpha r}=L_{r} I_{\alpha r}+L_{m} I_{\alpha s}$

$\Phi_{\beta r}=L_{r} I_{\beta r}+L_{m} I_{\beta s}$

The electromagnetic torque can be expressed as follows [48]:

$T_{e m}=\frac{3}{2} \frac{p L_{m}}{L_{s}}\left(\Phi_{\alpha s} I_{\beta r}-\Phi_{\beta s} I_{\alpha r}\right)$

The active and reactive powers of the rotor and stator are shown below [48]:

$$
\begin{aligned}
& P_{S}=\frac{3}{2}\left(V_{\alpha S} I_{\alpha s}+V_{\beta S} I_{\beta S}\right) \\
& Q_{s}=\frac{3}{2}\left(V_{\beta S} I_{\alpha s}-V_{\alpha s} I_{\beta S}\right) \\
& P_{r}=\frac{3}{2}\left(V_{\alpha S} I_{\alpha s}+V_{\beta S} I_{\beta S}\right)
\end{aligned}
$$


$Q_{r}=\frac{3}{2}\left(V_{\beta S} I_{\alpha S}-V_{\alpha s} I_{\beta S}\right)$

\subsubsection{Dynamic modelling of the DFIG in the d-q reference frame}

The voltage equations of the DFIG in the d-q reference frame are as follows [49], [61], [62], [63]:

$V_{d s}=R_{s} I_{d s}+\frac{d \Phi_{d s}}{d t}-w_{s} \Phi_{q s}$

$V_{q s}=R_{s} I_{q s}+\frac{d \Phi_{q s}}{d t}+w_{s} \Phi_{d s}$

$V_{d r}=R_{r} I_{d r}+\frac{d \Phi_{d r}}{d t}-w_{r} \Phi_{q r}$

$V_{q r}=R_{r} I_{q r}+\frac{d \Phi_{q r}}{d t}+w_{r} \Phi_{d r}$

The flux equations are as follows [27], [64]:

$\Phi_{d s}=L_{s} I_{d s}+L_{m} I_{d r}$

$\Phi_{q s}=L_{s} I_{q s}+L_{m} I_{q r}$

$\Phi_{d r}=L_{s} I_{d r}+L_{m} I_{d s}$

$\Phi_{q r}=L_{s} I_{q r}+L_{m} I_{q s}$

The electromagnetic torque is expressed as follows [48]:

$T_{e m}=-\frac{3}{2} \frac{p L_{m}}{L_{s}}\left(\Phi_{d s} I_{q r}-\Phi_{q s} I_{d r}\right)$

The active and reactive powers of the rotor and stator are shown below [65]:

$$
\begin{aligned}
& P_{s}=\frac{3}{2}\left(V_{d s} I_{d s}+V_{q s} I_{q s}\right) \\
& Q_{s}=\frac{3}{2}\left(V_{q s} I_{d s}-V_{d s} I_{q s}\right) \\
& P_{r}=-s P_{s} \\
& Q_{r}=s Q_{s}
\end{aligned}
$$


In (2-22) - (2-47):

- $\quad V_{\alpha s}$ and $V_{\beta s}$ are the alpha and beta components of the stator voltage respectively

- $I_{\alpha s}$ and $I_{\beta s}$ are the alpha and beta components of the stator current respectively

- $\quad V_{\alpha r}$ and $V_{\beta r}$ are the alpha and beta components of the rotor voltage respectively

- $I_{\alpha r}$ and $I_{\beta r}$ are the alpha and beta components of the rotor current respectively

- $\Phi_{\alpha s}$ and $\Phi_{\beta s}$ are the alpha and beta components of the stator flux respectively

- $\Phi_{\alpha r}$ and $\Phi_{\beta r}$ are the alpha and beta components of the rotor flux respectively

- $V_{d s}$ and $V_{q s}$ are the direct and quadrature components of the stator voltage respectively

- $I_{d s}$ and $I_{q s}$ are the direct and quadrature components of the stator current respectively

- $\quad V_{d r}$ and $V_{q r}$ are the direct and quadrature components of the rotor voltage respectively

- $I_{d r}$ and $I_{q r}$ are the direct and quadrature components of the rotor current respectively

- $\Phi_{d s}$ and $\Phi_{q s}$ are the direct and quadrature components of the stator flux respectively

- $\Phi_{d r}$ and $\Phi_{q r}$ are the direct and quadrature components of the rotor flux respectively

- $\quad L_{s}, L_{r}$ and $L_{m}$ are the stator, rotor, and magnetizing inductances respectively

- $w_{S}$ is the electrical speed of the stator (synchronous speed of the machine)

- $w_{m}$ is the electrical speed of the rotor

- $w_{r}$ is the electrical speed of the slip

- $\quad P_{r}$ and $P_{s}$ are the rotor and stator active powers respectively

- $Q_{r}$ and $Q_{s}$ are the rotor and stator reactive powers respectively 
The equivalent circuit of the DFIG in the $d-q$ reference frame as well as in the $\alpha-\beta$ reference frame are shown in figures 2-9 and 2-10 respectively [48], [66], [67]. From figure 2-9, it is seen that the stator direct voltage comprises of the addition of the stator direct voltage drop and the change in the stator direct flux, with the subtraction of the product of the synchronous speed and the stator quadrature flux. This can be seen in equation (2-35). The rotor direct voltage comprises of the addition of the rotor direct voltage drop and the change in rotor direct flux, with the subtraction of the product of the slip electrical speed and rotor quadrature flux. This can be seen in equation (2-37). The stator quadrature voltage comprises of the addition of the stator quadrature voltage drop, change in stator quadrature flux and the product of the synchronous speed and stator direct flux. This can be seen in equation (2-36). The rotor quadrature voltage comprises of the addition of the rotor quadrature voltage drop, change in rotor quadrature flux and the product of the slip electrical speed and rotor direct flux. This can be seen in equation (2-38). With regards to the change in flux, the magnetising inductance as well as the appropriate leakage inductances were considered.
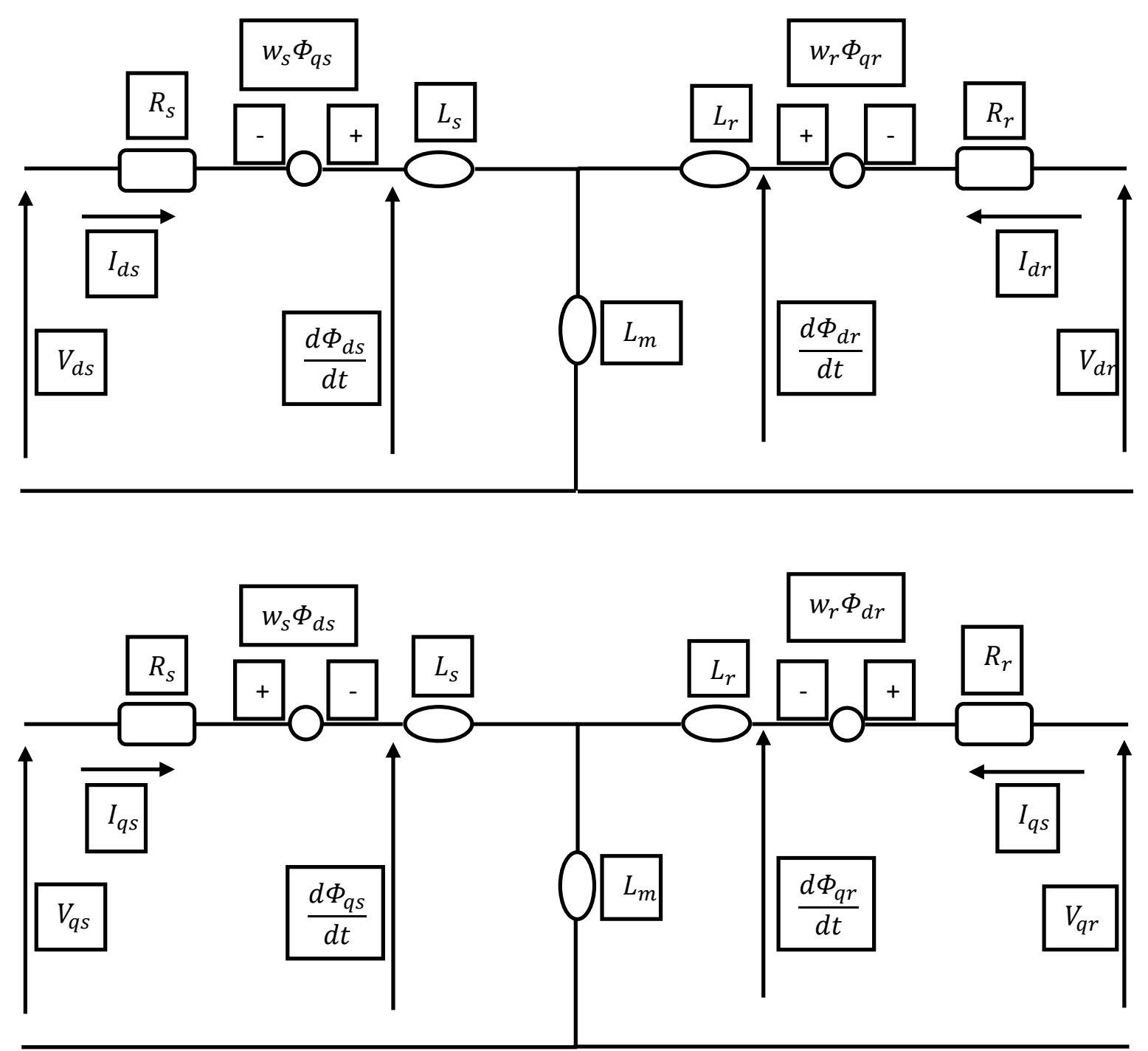

Figure 2-9: Equivalent circuit of DFIG in the d-q reference frame [66],[67] 
From figure 2-10, it is seen that the stator alpha voltage comprises of the addition of the stator alpha voltage drop and the change in the stator alpha flux. This can be seen in equation (2-22). The rotor alpha voltage comprises of the addition of the rotor alpha voltage drop, the change in rotor alpha flux and the product of the rotor electrical speed and rotor beta flux. This can be seen in equation (2-24). The stator beta voltage comprises of the addition of the stator beta voltage drop and the change in stator beta flux. This can be seen in equation (2-23). The rotor beta voltage comprises of the addition of the rotor beta voltage drop and the change in rotor beta flux, with the subtraction of the product of the rotor electrical speed and rotor alpha flux. This can be seen in equation (2-25). With regards to the change in flux (both stator and rotor), the magnetising inductance as well as the appropriate leakage inductances were considered.
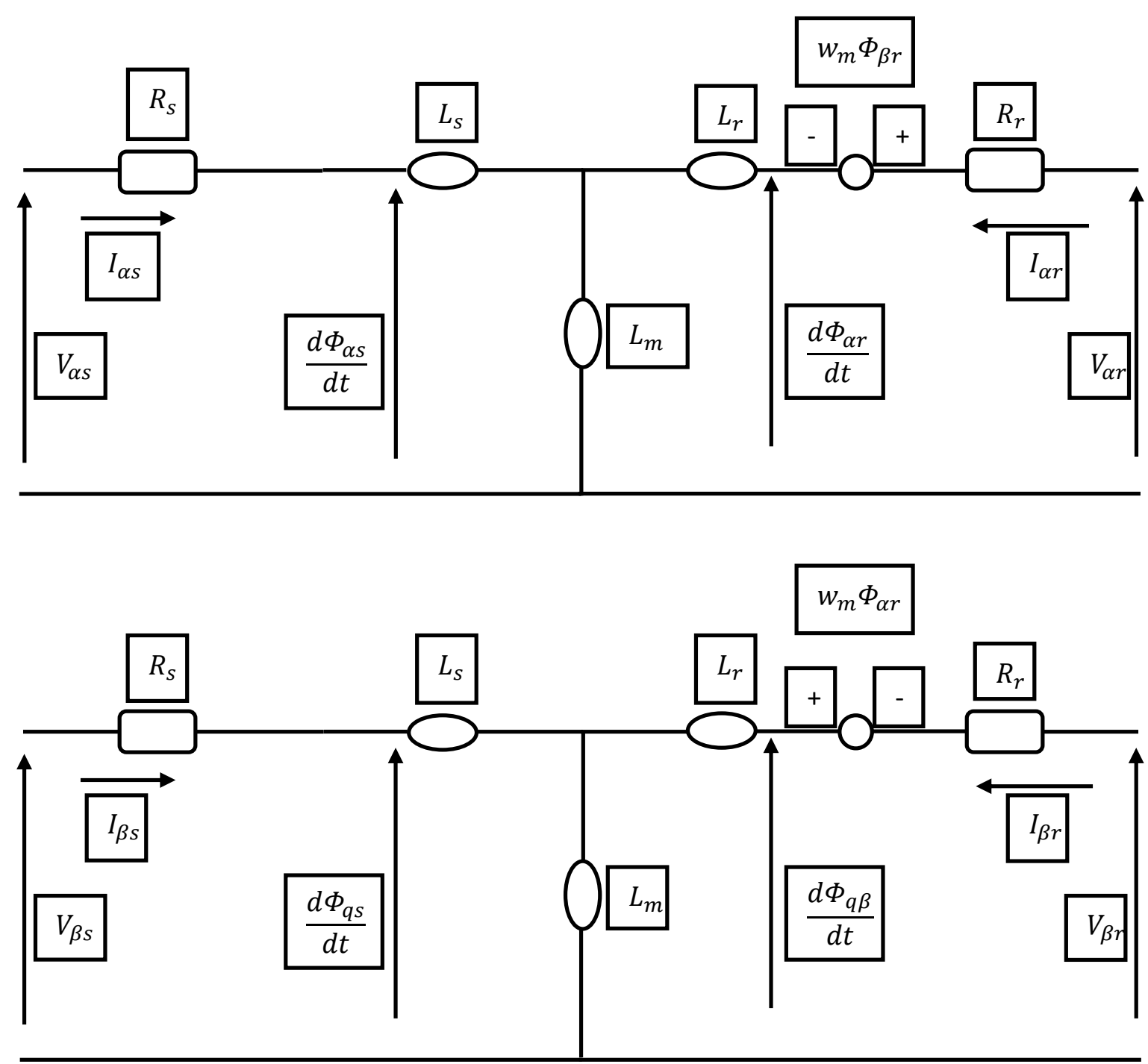

Figure 2-10: Equivalent circuit of DFIG in the $\alpha-\beta$ reference frame [48] 


\subsection{Model predictive control}

\subsubsection{An introduction to model predictive control}

The advancement of control algorithms has drastically improved the performance of control strategies. While some control methods are well established and their performance widely accepted, there has recently been the emergence of new control algorithms which seem promising. Some of the control algorithms that can be applied to control strategies are [44]:

1. Hysteresis control

2. Proportional-integral (pi) control

3. Space vector modulation (svm) control

4. Sinusoidal pulse width modulation (spwm) control

5. Fuzzy logic control

6. Sliding mode control

7. Artificial neural network-based (ANN) control

8. Model predictive control (MPC)

Hysteresis control is known as nonlinear control is the simplest to implement. They directly control the on and off state of switches. They keep the output within a specified bandwidth. A smaller bandwidth will result in a smaller output ripple. However, the bandwidth determines the switching frequency hence should be optimised [44], [68], [69]. Pi control, svm control and spwm control are known as linear control and are known to achieve good response. Fuzzy logic control, sliding mode control, artificial neural network-based control and model predictive control are advanced control techniques which are known to achieve better responses than linear control. In sliding mode control, the control variable is forced along a pre-set trajectory [44]. Sliding mode control offers robustness to parameter variations, external disturbances, nonlinear loads and uncertainties [70]. This is achieved by changing the structure of the control [44]. "Fuzzy logic control is a heuristic approach that easily embeds the knowledge and key elements of human thinking into the design of nonlinear controllers" [47]. A fuzzy logic controller decomposes a complex system into various subsystems in accordance to the human's knowledge about the system [71]. Fuzzy logic controllers do not need an accurate mathematical model of the system and can handle imprecise inputs. [47], [72]. Artificial neural network is a system based on the brain and nervous system. These networks imitate a biological neural network. ANN is based on simulation of the brain and the nervous 
system [73]. A disadvantage of ANN controllers is that they require offline training prior to use [44].

MPC is a control system that can handle the constraints of multiple variables. MPC has been used in the process industry for many years. It is well known that proportional-integral controllers only correct the difference in measurements after it has occurred. The most notable difference between proportional-integral control and MPC is the pre-calculation of signals; this can be both the reference and actual values [30], [74]. The principle of mode predictive control is shown in figure 2-11 [74]. As can be seen from figure 2-11, for a given future time period ( $\mathrm{Np}$ ), the actuating variable is adjusted so that at the end of the future time period, the output is as close to the desired(reference) value as possible. The future time period is called the prediction horizon, or sampling time $\left(T_{S}\right)$.

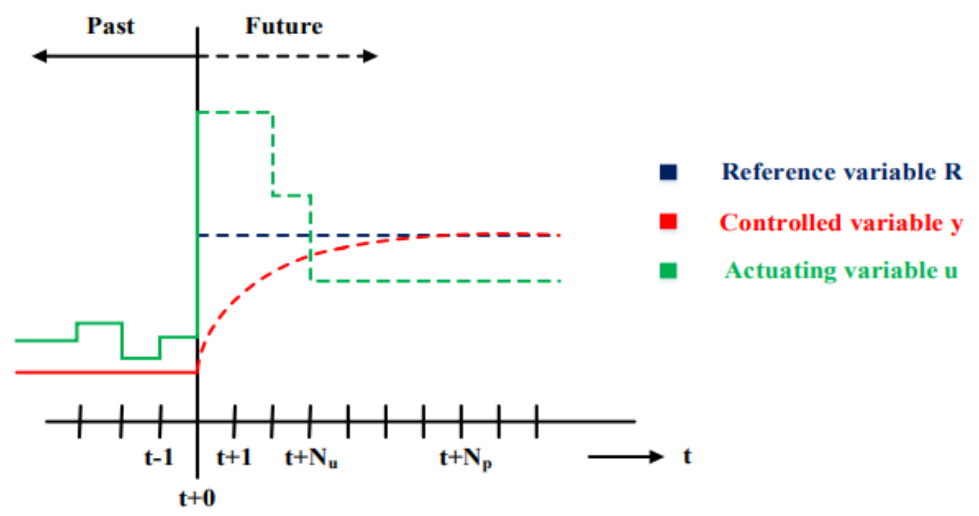

Figure 2-11: Basic operating principle of MPC [74]

\subsubsection{Classification of predictive schemes}

Model predictive control can be classified as finite control set model predictive control (FCSMPC) and continuous control set model predictive control (CCS-MPC) [31], [74]. FCS-MPC considers the discrete nature of the inverter and directly calculates the specific switching states whereas CCS-MPC derives a control variable with a continuous value [74]. CCS-MPC poses a problem in that the nonlinearities in a system makes the method quite complex [74]. CCSMPC utilizes a modulator [74]. On the other hand, FCS-MPC only evaluates a finite set of switching states and chooses the best available switching state/s [31]. This makes the predictive control easier [70]. FCS-MPC doesn't require a modulator [31], [74], [75]. FCSMPC can be further divided into optimal switching vector model predictive control (OSVMPC) and optimal switching sequence model predictive control (OSS-MPC) [76]. In OSVMPC, one vector is applied for the entire sampling period [76]. This is a simple method but 
leads to a variable switching frequency [76], [77] . OSS-MPC attempts to calculate an optimal switching sequence, which makes use of duty cycles. This method provides the benefit of a constant switching frequency but is complicated and places a heavier computational burden [77]. Figure 2-12 shows the general structure of OSV-MPC [75].

In figure $2-12, x^{r e f}$ is the reference value, $x^{k}$ is the measured signal at time $\mathrm{t}=\mathrm{k}$ (present time), $x^{(k+1)}$ is the value of the predicted signal after a specific horizon and $S_{\text {opt }}$ is the optimal switching state [71].

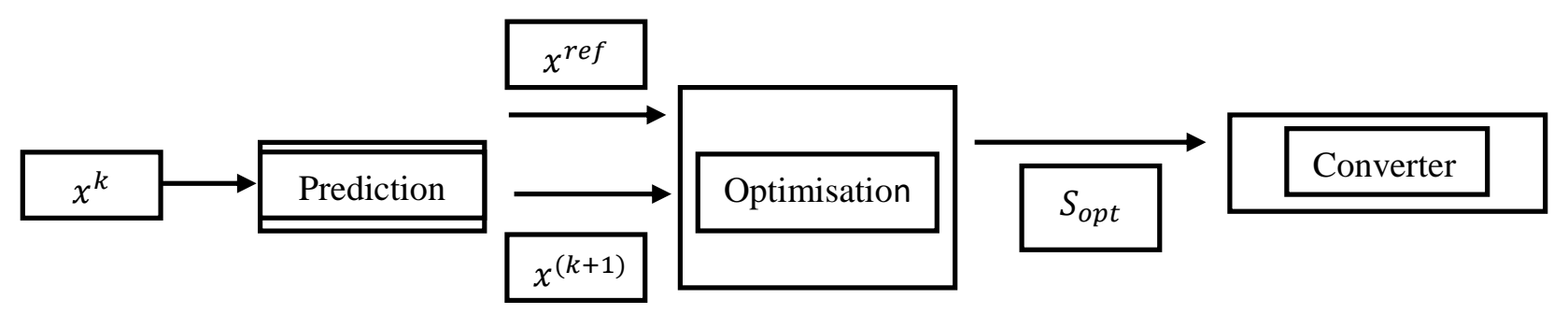

Figure 2-12: General structure of OSV-MPC [75]

The output of the previous figure can be seen in figure 2-13 [31]:

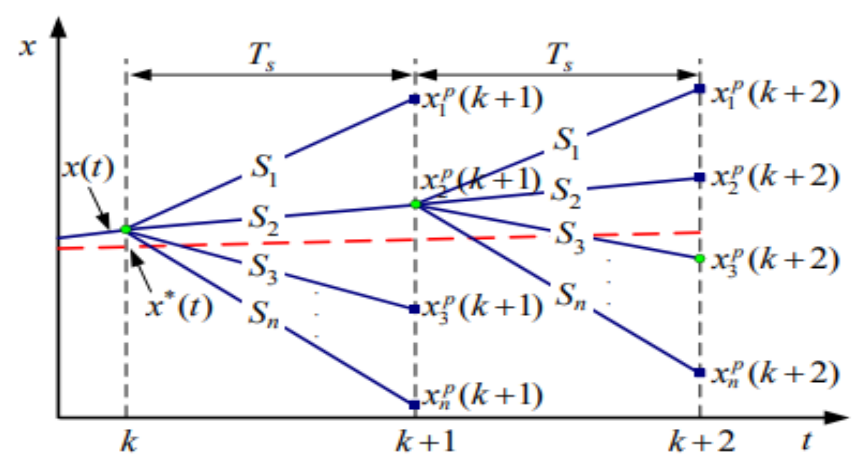

Figure 2-13: Operating principle of OSV-MPC [31]

Consider figure 2-13. Between time horizon $\mathrm{k}$ and $\mathrm{k}+1$ (known as the sampling period), the switching state $\mathrm{S} 2$ will bring the measured value the closest to the reference value. Between time horizon $\mathrm{k}+1$ and $\mathrm{k}+2$, switching state $\mathrm{S} 3$ will do the same. This is the basic operating principle of OSV-MPC [31], [78]. For a given time period, the switching state which produces the smallest error between the reference and predicted values is implemented. 


\subsubsection{Prediction and evaluation}

Perhaps the most imperative part of MPC is the prediction of future values. The is majorly computed using the Euler method. The principle behind the Euler method is to utilize the tangent line through the solution curve (some initial point) to obtain an approximation of some future value. Consider figure 2-14 [79]:

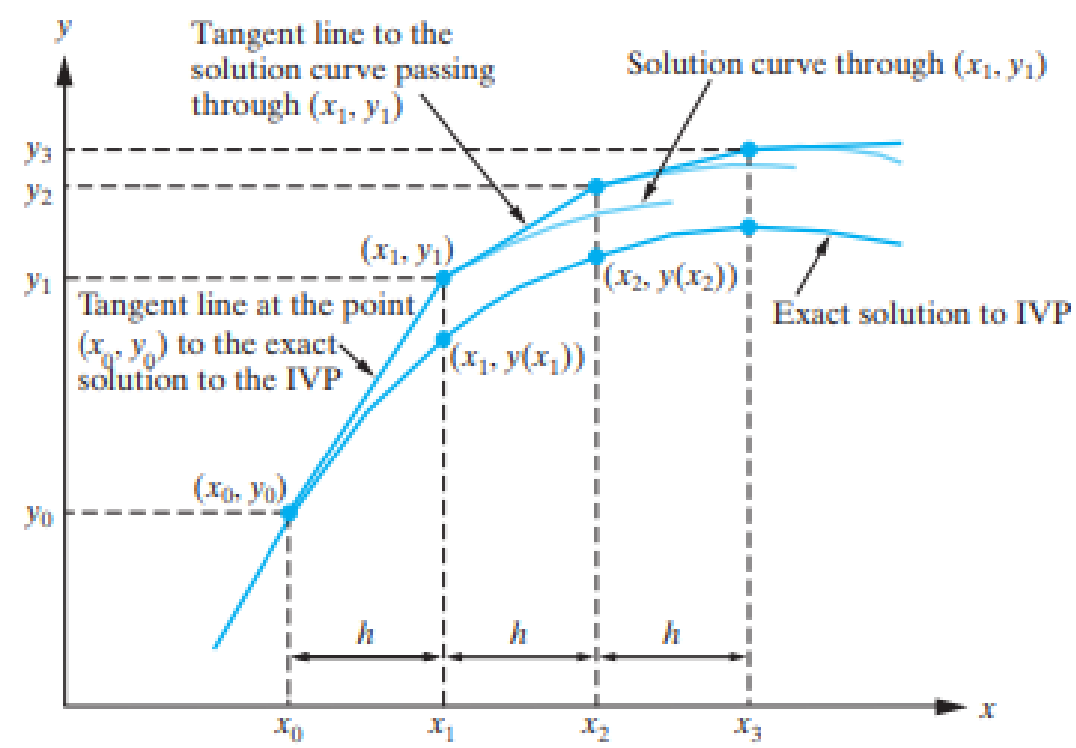

Figure 2-14: Operating principle of the Euler method [79]

The equation of the tangent line through the initial point of $\left(x_{0}, y_{0}\right)$ is [79]:

$y(x)=y_{0}+f\left(x_{0}, y_{0}\right)\left(x-x_{0}\right)$

Where $\mathrm{x}$ is some point after $x_{0}$

If $x=x_{1}$, the Euler approximation to the exact solution at $x_{1}$ is yielded [79]:

$y_{1}=y_{0}+f\left(x_{0}, y_{0}\right)\left(x_{1}-x_{0}\right)$

Making $\left(x_{1}-x_{0}\right)=h$, we get:

$y_{1}=y_{0}+h f\left(x_{0}, y_{0}\right)$

The approximation at a value $x=x_{2}$ is [79]:

$y_{2}=y_{1}+h f\left(x_{1}, y_{1}\right)$

Where now $h=x_{2}-x_{1}$

The general approximation formula for this method is [79], [80], [81]: 
$y_{k+1}=y_{k}+h f\left(x_{k}, y_{k}\right)$

Where $h=x_{k+1}-x_{k}$

This approximation is known as the forward Euler approximation method. It is an explicit method. In cases where the stability requirements of the explicit method impose strict conditions on the step size (h), implicit methods can be used. One such method is the backward Euler method and is described as [80], [81], [82]:

$y_{k+1}=y_{k}+h f\left(x_{k+1}, y_{k+1}\right)$

Another explicit method that can be used is called the midpoint method as is as follows [80], [83]:

$y_{k+1}=y_{k-1}+h f\left(x_{k}, y_{k}\right)$

In FCS-MPC, switching state/s is determined via the use of a cost function. The switching state/s which yields the smallest cost function will be implemented. The cost function, $\mathrm{g}$, is defined can be defined in three possible ways [78], [80]:

$g=\left|x^{r e f}-x^{(k+1)}\right|$

$g=\left(x^{r e f}-x^{(k+1)}\right)^{2}$

$g=\frac{1}{T_{S}} \int_{0}^{T_{S}}\left(x^{r e f}-x^{(k+1)}\right)$

Equation (2-56) provides a better dynamic and steady state response when compared to (255), but at the cost of a larger switching frequency. Furthermore, it provides a simpler execution than (2-57). The cost function defined in (2-57) provides a more accurate reference tracking than (2-55) and (2.56) [78]. However, it is not as simple as the others. Based on the objectives of this research, equation (2-56) seems the best choice to be implemented in this project.

Note that (2-55) - (2-57) only considers a single variable. Consider a multivariable system with the variables $x$ and $a$. The cost function will now read [78], [80]:

$g=\left(x^{r e f}-x^{(k+1)}\right)^{2}+\left(a^{r e f}-a^{(k+1)}\right)^{2}$

Where there are more than one terms in the cost function, weighting factors can be introduced in the cost function [84] to signify importance to certain aspects of the system, or to reduce the effects of coupling [78]. 


\subsection{Control methods applied to the DFIG}

There are three main control strategies which are implemented to achieve control of the DFIG.

These strategies are [11]:

1. Rotor current control

2. Direct torque control

3. Direct power control

Field-Oriented Control (FOC) provides individual control of the stator reactive and active powers. It does so by applying an appropriate voltage vector to the rotor of the machine. This is either done by control of the stator power directly (which are expressed in terms of the rotor currents) or indirectly via control of the rotor current [27]. FOC based on the indirect control of the stator powers is the more popular type. The variables, either the rotor currents or stator powers, are regulated via the use of proportional-integral controllers and along with a compensation term, form the required rotor voltage. In order to ensure that this voltage is at slip frequency, co-ordinate transformation is required. A modulator is also required. As can be seen, this is a complex control method [27], [48], [49], [85], [86].

Direct torque control (DTC) works by directly controlling the electromagnetic torque and rotor flux. This is accomplished by firstly approximating the rotor flux and electromagnetic torque, comparing it to the reference values, and then applying an appropriate voltage to the rotor in order to reduce the difference between the actual and reference values. Conventional DTC is implemented in two methods; via the use of hysteresis controllers and a switching table (DTCST) or via the use of pi controllers and space vector pulse width modulation (DTC-SVPWM) [28], [87], [88], [89], [90]. The switching table method is simple but has various disadvantages These are [88], [90], [91]:

1. Non-constant switching frequency

2. High flux and torque ripples

3. The requirement of a high sampling frequency

4. Flux and current deformation because of rotor flux vector zone location change

DTC-SVPWM offers a constant switching frequency and produces less torque and flux ripple as compared to the look up table method. However, this method is more complex than the switching table method as it requires the tuning of proportional-integral controllers. This method is similar to FOC [89], [90]. Direct power control (DPC) is a control method which directly control the stator active and reactive powers. It is most commonly implemented in the 
same manner as DTC-ST, preserving the same advantages and disadvantages [29], [92]. It is commonly known as DPC-ST.

The use of MPC is an alternative to these conventional control methods. MPC is void of proportional-integral and hysteresis controllers. The predictive alternative to FOC is called the model predictive current control (MPCC) method. OSV-MPC is generally used for the control of three-phase machines [76]. Considering MPCC, the decoupled rotor current values at the next sampling instant are determined for the various possible switching states of the converter [93], [94]. Model predictive direct torque control (MPDTC) and model predictive direct power control (MPDPC) work in the same manner, the predicted values being the rotor flux and electromagnetic torque in the former, and the stator reactive and active powers in the latter [11], [95], [96], [97].

\subsection{Review of previous approaches to issues affecting the use of the DFIG}

\subsubsection{Grid synchronization of the DFIG}

Owing to the intermittent nature of the wind speed, the speed of the rotor varies greatly, meaning that synchronization of the DFIG to the grid needs to be computed in real time. In FOC and DTC-SVPWM, this is achieved by applying a voltage of slip frequency to the rotor [27]. This will preserve the frequency and phase of the output, irrespective of the rotor speed. DTC-ST uses the rotor reference flux angle and DPC-ST uses the slip angle to transform the stator flux value so that the switching vector chosen will preserve the phase and frequency of the stator voltage [28], [29]. If grid synchronisation is was achieved prior, then the slip angle can be extracted in three ways. The first method is to convert the stator voltage (which is equal to the grid voltage) from a-b-c to $\alpha-\beta$ and then use the inverse tan function to obtain the stator angle. The angle of the rotor is obtained via the use of an encoder and the difference between these two angles produces the slip angle. In the second method, the stator angle is obtained via integration of the constant stator electrical speed and the rotor angle is obtained via the use of an encoder. In the third method, the stator angle is obtained via the use of the inverse tan function and the rotor angle is obtained via integration of the rotor electrical speed. [27], [98].

The process of initial grid connection is complex, as synchronization requires that the DFIG stator voltage to simultaneously have same magnitude, phase, and frequency of the grid [99]. In [99] a method of direct torque control with grid synchronization is discussed. This method creates a rotor flux reference by passing the difference between the reference and measured 
stator voltage via a proportional-integral controller. A reference synchronous speed is also defined by passing the difference between the grid and stator flux values through another proportional-integral controller. This reference speed is compared to the measured synchronous speed and the difference passed to a final proportional-integral controller, the result being the reference electromagnetic torque. Although proven to achieve fast and soft grid synchronization, this method is complex due to the use of three proportional-integral controllers. A virtual torque approach is proposed in [100]. This method follows the same principle as DTC-ST but contains an additional component for grid synchronization. It is known that the electromagnetic torque of the DFIG is a function of the rotor and stator flux magnitudes and the angle between them. To match the grid phase and frequency, a virtual torque of zero is used as the reference. To match grid voltage magnitude, the rotor flux reference is defined in terms of the grid voltage and grid speed. Once synchronization is complete, the flux and torque reference values are returned to their normal values. The main advantage of this method is its voidance of stator values. Furthermore, unlike [99], there is no need for complex tuning of proportional-integral controllers. Almost identical to [100], a virtual power approached is presented in [101]. In this method, a virtual stator reactive and active power is defined. This method makes use of the fact that the rotor flux and stator flux are collinear during an open circuit. The virtual reactive and active powers are written in terms of a virtual flux, the rotor flux, and the angle between the two. The virtual flux is computed using the grid voltage and speed. At first, the DFIG is open circuited. The virtual powers are set to zero, forcing the rotor flux to be identical to the virtual (grid) flux. Since during an open circuit the stator flux is collinear with the rotor flux, a virtual power reference of zero would mean that the stator flux is collinear with the grid flux. The amplitude is matched the same way as in [100].

FCS-MPC in its standard procedure will not achieve grid synchronization of the DFIG. The standard cost function only includes the direct variables in question (rotor currents in MPCC, rotor flux and electromagnetic torque in MPDTC and stator reactive and active power in model MPDPC). In [102], a modification to the cost function of the MPDTC method is provided. This method computes the difference between the stator flux angle and the angle of the predicted rotor flux. This difference is then added to the standard cost function. As evident, it is a simple procedure and exhibits excellent dynamic and steady state responses to grid connection. A combined approach is tested in [103]. This method uses MPDPC to regulate the stator reactive and active powers but adopts a virtual torque method like the method explained in [100] to achieve grid synchronization. The method works by first predicting the future virtual torque and rotor flux values and comparing them to their references. This will achieve grid synchronization of the DFIG. After this is done, the reference values are switched 
to the required stator reactive and active powers. In addition to this an, in-depth analysis of the effect of the rotor voltage vector on the rotor flux in shown in [103]. The results of this paved the way for a method for rotor flux position estimation without the use of a sensor. This method increases the reliability of the grid synchronization process.

Furthermore, like the virtual power method shown in [101], a method for MPDPC with grid synchronization is shown in [104]. In this method, a virtual stator reactive and active power is defined in terms of the rotor and grid flux. The virtual power reference is set to zero and a comparison is made between this and the predicted virtual active and reactive power values. Once grid synchronization is accomplished, the method follows the conventional MPDPC procedure. A similar approach is discussed in [105], but unlike in [104], this method considers only the stator apparent power. The stator apparent power reference is once again set to zero. A comparison is then made between this value and a predicted stator apparent power, which is defined in terms of a predicted rotor and grid flux. The aim of the approach outlined in [105] is to produce a lower average switching frequency during the synchronization process. Considering the predictive current control method of controlling the DFIG, synchronization can be done according to the method outlined in [106].The converter used in the control of the DFIG is the indirect matrix converter, as compared to the well-established two-level voltage source inverter (2L-VSI). Considering that the stator voltage depends on the amplitude and phase of the rotor and stator currents, this method obtains the required rotor current amplitude and phase via a modified stator voltage equation. An auxiliary angle is defined in [106], which is used to further adjust the rotor current reference phase. The method then proceeds to calculate the predicted rotor currents. Utilizing an indirect matrix converter, this method predicts the rotor current twenty-four times as compared to the eight when using the 2L-VSI. The final part is the cost function, which is left standard.

\subsubsection{Improving dynamic and steady state responses of the DFIG}

Owing to the DFIG being directly connected to the grid, a major aspect of controlling the DFIG is an acceptable dynamic response to the varying wind speeds. The aim of control in this aspect is to reach steady state value as quickly as possible, with as little overshoot and ripple as possible. Despite their simplicity over the conventional FOC, DTC-ST and DPC-ST are known to produce high levels of ripple. This is highly undesirable in a power system. An improved switching table is presented in [107]. It will be shown later that in the DTC-ST method, the rotor flux will lie in one of six sectors, each sector of magnitude 60 degrees. In [107] the sector number is increased from six to twelve, each sector now a magnitude of 30 
degrees. The possible switching states is also increased from eight to twelve. The increased number of available switching states will increase the accuracy of the method. However, it is unknown what effect this increase in rotor flux angle sectors will have on the quality of the stator current waveforms. The same approached was adopted in [108] for the DPC-ST method. In this case, no discernible improvement in the stator current waveforms were shown.

In [109], a new DTC method is proposed. This method applies three voltages vectors per sampling period. This is two active vectors, followed by a zero vector. The strategies proposed in [110] and [111] use two voltage vectors instead of three, but since these were applied to an induction machine operated as a motor, it is not necessarily suitable for application to a DFIG. The method in [109] follows a similar structure to the DTC-ST method (with regards to hysteresis controllers and a switching table) but uses two switching tables. The switching tables are similar in structure but slightly different in terms of vector selected. Another advantage of this method is the constant switching frequency, which will reduce harmonics. However, the stator current waveforms were unbalanced.

Considering conventional MPC, a more effective approached was suggested in [96] for MPDTC. The method predicts the next state of the variables using the standard (Euler) method but introduces another term into the cost function. First the electromagnetic torque slope (between current and predicted value) in each sample time is calculated. This value is then used to calculate the electromagnetic torque surface, which is in terms of the sample time, measured electromagnetic torque and referential electromagnetic torque. The electromagnetic torque surface is added to the cost function, with an appropriate weighting factor.

It has been stated that the two-vector control method may not be suitable for application to the DFIG when using the DTC-ST method. However, this is not true for the DPC-ST method. In [112], a double vector control is used to control the stator reactive and active power of the DFIG as well as present a reduction in power ripple. This method predicts the future value of the stator reactive and active powers and compares them to the respective references. As with OSV-MPC based MPDPC, the switching state corresponding to the lowest cost function is implemented. However, as opposed to the conventional OSV-MPC based MPDPC, the duration of this switching state is not for the entire sampling period, but rather for a part of. The duration of application of the selected vector is dependent on the difference between the predicted power values and their references, as well as their rates of change. For the remainder of the sampling period, a zero vector is implemented. The strategy discussed in [113] involves the application of three voltage vectors; and whilst it does provide better steady state performance and a reduction in sampling frequency compared to [112], it is much more complex in nature. 
However, the cost function in [112] utilises squares with no weighting factor which, as explained in [114] and [115], results in mutual interference when controlling active and reactive powers. This mutual interference increases as the variations in reactive and active power increase. This can deteriorate the control dynamics of the pulse width modulation converter. An improvement to [112] was stated in [116]. This proposed solution defined a weighting factor for each square of the cost function given in [112]. The defined weighting factors were functions of the reference powers, predicted powers and the rated stator active and reactive powers. This method ensured a reduction in mutual interference. To further reduce the ripples in the reactive and active powers, an approach was stated in [117]. Like [112] and [116], this method utilises the application of two voltage vectors, but instead of this always being an active and a zero vector, the proposed scheme allows the use of two active vectors. The time duration of each applied is calculated in the same way as explained in [116]. The same applies for the predicted stator reactive and active powers. Since the first applied vector is succeeded by either an active or zero vector, the number of possible outcomes is twelve. This is more than the eight used in [112]. When compared to [112] and [116], it was shown than the method explained in [117] achieved better steady state performance.

\subsubsection{Mitigating the effects of unbalanced grid voltages on the DFIG}

Wind farms are usually situated in areas where the grid is weak, hence the unpleasant effects of unbalanced grid voltages are frequently seen in the operation of the DFIG. Unbalances in the grid could lead to uneven stator winding heating, as well as power and torque pulsations at double frequency. This pulsation would adversely affect the steady state operation of the DFIG. Furthermore, the electromagnetic torque pulsations would cause damage to the mechanical components of the generator. This grid voltage unbalance could also result in the DFIG producing distorted stator currents, which may not be compliant with grid codes [26], [118]. Based on the Fortescue theorem, a balanced system will contain no negative sequence components i.e., only positive sequence components exist. Hence it can be seen that in order to mitigate the effects of an unbalanced grid voltage, the components of negative sequence nature should be zero [119]. Most of the literature presents mitigations that include both rotor side converter (RSC) as well as the grid side converter (GSC) control. This review, however, will only focus on the schemes based on the control of the RSC.

The established solution to this is to decompose the system currents into negative and positive sequences in the synchronous reference frames. This is shown in [120], [121], [122], [123], [124], [125], [126] which control the positive sequence current with dual current controllers, 
and the negative sequence with another two current controllers. This is known as the dual vector control, and although proven to achieve acceptable performance against unbalanced grid voltages, this decomposition must be done from measured signals. This could result in a time delay, phase and magnitude errors and a decreased system stability [124]. A solution to this is to use a proportional-integral-resonant (PI-R) controller, as shown in [127], [128], [129]. The PI-R regulator consists of the conventional proportional-integral controller, but with a resonant pole. The aim is the obtain an infinite gain at the resonant frequency. In [130], the positive synchronous reference frame is used to design the PI-R controller. This would mean that the positive sequence currents, voltages, and flux values appear as dc values and the components of negative sequence nature appear as double frequency ripples. The proportionalintegral controller controls the dc quantities, and the $\mathrm{R}$ controller is used to control the double frequency signals. Hence no sequence de-composition is required. However, the use of a resonant controller increases the complexity of these control algorithms

A similar method is introduced in [131], the controllers named main and auxiliary controllers. The negative synchronous reference frame is used to implement the auxiliary controller, with the negative sequence current extracted. This method works well, but the negative sequence current reference was not considered in the main controller. In [132], this has been improved and the designed showed a better performance. Still, however, sequence decomposition was partially required. If distorted network conditions are to be considered, then an improvement to this method, proposed in [133], can be considered. The method uses a similar structure as [131] and [132] but uses two resonant controllers. Since the fifth and seventh harmonics pulsate like ac components at two and six times the synchronous frequency respectively, the dual resonant controllers are tuned at double and six times the grid frequency respectively. This simple adjustment to the method proposed in [133] yielded a strong reduction in the effects of common harmonics in a system [134]. However, the use of two resonant controllers increases the complexity of the algorithm. In [135], a scheme which is void of the dual vector of the PI-R application is presented. This method decomposes the stator voltage and sets the stator reactive and active power double frequency oscillating terms to zero. This results in the extraction of the reference stator flux values, which are then used to calculate the reference rotor currents. It only uses the standard two proportional-integral controllers and is void of resonant controller tuning. However, in the tests conducted, only a 5\% voltage unbalance was considered. Furthermore, despite the stator currents improving in terms of distortion, they were unbalanced.

When dealing with the effects of unbalanced networks on the DFIG, most of the research has been done in the field of current control. Very little literature is presented on DTC and DPC. In [136], a DTC scheme for voltage unbalances is presented. This method is like [127]-[129] 
in that it makes use of a PI-R controller to reduce the torque oscillations. In an unbalanced voltage, the electromagnetic torque has a dc value and an oscillating value. The proportionalintegral controller regulates the dc value, and the resonant controller regulates the oscillating value. The proportional-integral controller output is a steady angle, and the resonant controller output is a double frequency component of torque angle. When these angles are added, the steady state errors for both the double frequency and steady state components of the torque are forced to zero. The addition of the stator electrical angle to this value provides the reference rotor voltage angle. The proportional-integral controller for the rotor flux produces the magnitude of the reference rotor voltage vector. This resultant polar form is then transformed to the stator then rotor reference frame. Despite its efficacy, the use of resonant controllers makes the control algorithm complex

The strategy explained in [137] aims to directly control the reactive and active power reference using the DPC-ST method. In [137], three possible solutions to an unbalanced grid voltage are presented. In the first one, a power reference is defined by decomposing the stator reactive and active powers and setting the oscillating terms (which pulsate at two times the grid frequency) to zero. In the second method, which is like the first method, the active power reference is defined in terms of the electromagnetic torque (with the active power oscillating components still equated to zero). In the final proposed method, an oscillating term from the stator active power and electromagnetic torque is added to a stator power reference considering no voltage unbalance. Method 3 is the best as it requires no sequence decomposition, thereby increasing the systems stability and dynamic response time.

However, in an unbalanced grid voltage, the stator reactive and active powers comprise of three terms viz. the average value, the double frequency value and a term oscillating at synchronous frequency. The proposed method in [137] only accounts for the first two, and not the component oscillating at synchronous frequency. This is addressed in [138], which uses two resonant controllers tuned at synchronous and two times the synchronous frequency to get rid of the two oscillating terms. The method also presents a new phase locked loop method to track the positive sequence components of the stator voltage; it uses a resonant controller which is tuned at twice the grid frequency in order to provide compensation for the error in phase angle between the positive sequence stator voltage and unbalanced grid voltage. This will reduce the negative sequence component effect on the phase locked loop, allowing the phase angle and frequency of the positive sequence component to be tracked without the requirement of sequence composition. Furthermore, the method presented in [138] makes use of a constant switching frequency, an important aspect in control which is not presented in [137]. However, the control algorithm doesn't reduce the electromagnetic torque pulsations. The proposed strategy in [139] uses the same theory derived in [137] but makes use of a four 
switch three phase inverter instead of the conventional six switches. The four switches result in an unbalanced voltage that, when placed in proper combination, can emulate the eight switching states of a conventional six switch inverter. A new switching table is implemented in [139]. Although the higher voltage rating of the switches will increase power losses, the omission of two switches reduces power losses by $33.33 \%$.

Whilst the concept of MPC is well established and used extensively in the process industry, it is relatively new control method in power systems. This would explain the lack of literature when it comes to mitigating the effects of an unbalanced grid using MPC. A method is proposed in [140] which uses the MPDPC method. This method consists of a power compensator added to the original power reference to prevent distorted stator currents. This method is like the method presented in [137], where the double frequency term is made equal to zero. Despite its efficacy, the use of a notch filter means the control algorithm is still complex. In [138], it was stated that the stator reactive and active powers are comprised of three values: one dc value, one double frequency value and one value oscillating at grid frequency. These terms will be named S0, S1 and S2 respectively. In [118], just like [137], S1 is made to be zero. The method presented in [118] defined a power references in terms of S0 and S2, for both the stator reactive and active power reference values. Since the negative sequence value is much smaller than the positive sequence value, accurate extraction is difficult. In this method, no negative sequence current is required, thus greatly increasing the reliability of this method. In a study conducted in [141] it is shown that the predictive power control strategy outlined in [112] provides a good response against grid voltage unbalances, with no modification of control structure required. In another strategy given in [142], a modified MPDPC approach is tested against grid unbalances. The method adds a compensation term to the reference reactive and active powers. It is now known that the stator reactive and active power consists of three terms. The power compensator is a factor of the third value, or $\mathrm{S} 2$ as defined previously. It is worth mentioning that $\mathrm{S} 2$ comprises of a reactive and active power value. Consider the active power value as S21 and the reactive power value as S22. The factor used in these two should add up to two. If $\mathrm{m}$ is the factor applied to S21 and $n$ applied to $S 22$ then the sum of $m$ and $n$ should be two. The value of $m$ and $n$ would depend on what's being achieved. To make the power follow the reference values whilst the stator current contains (harmful) third harmonics, then $\mathrm{m}$ and $\mathrm{n}$ should equal 0 . To obtain sinusoidal stator current, $\mathrm{m}$ and $\mathrm{n}$ should each be one. To eliminate reactive power ripples and obtain asymmetric but sinusoidal stator current then $\mathrm{m}$ and $\mathrm{n}$ should be 2 and 0 respectively. To eliminate active power ripples and obtain asymmetric but sinusoidal stator current then $\mathrm{m}$ and $\mathrm{n}$ should be 0 and 2 respectively. This method proved to be effective but can only address one issue at a time. Furthermore, sequence decomposition is still required. 
A combination of MPCC with a direct matrix converter is presented in [143]. The method defines the controller in the stationary reference frame, different to the synchronous reference frame used most of the time. It was shown that the use of the stationary reference frame greatly reduces the computational complexity of the system. The method follows a general predictive current control pattern and creates a rotor voltage which opposes the stator unbalanced voltage, thereby blocking the circulation of harmonic currents in the stator of the DFIG and resulting in sinusoidal stator voltages and currents during a grid unbalance. A predictive torque control considering voltage unbalance is proposed in [144]. This method is a continuation of [109], where three rotor voltage vectors are applied. The proposed method defined the active power and electromagnetic torque in terms of the harmonics present in the system. It known that harmonics oscillate, hence the proposed strategy compared this electromagnetic torque and active power to a dc value. This forces the oscillating components to zero. However, the control algorithm was only tested on a $5 \%$ voltage unbalance.

\subsubsection{Fault ride through capabilities of the DFIG}

During a grid fault, connected generators disconnect from the grid. Depending on the amount of generating systems that are disconnected, the system stability can be compromised. Furthermore, in some cases, it is imperative to supply reactive power to the grid in order to reestablish the required grid voltage. It therefore remains important that generating systems remain connected and operational in the electrical grid and supply the required power to allow the grid to return to normal operating conditions. This is termed fault ride through and is categorised into three scenarios [11], [145]:

Zero voltage ride through- which is the termed used when the grid voltage becomes zero

$>$ Low voltage ride through- which is when the grid voltage is between $15 \%-25 \%$ of its nominal value

$>$ High voltage ride through-which occurs when the voltage of the grid is above $110 \%$ of its rated value

Because of electromagnetic induction, the DFIG is highly sensitive to grid faults. Since wind energy has been, and will be, increasing throughout the world, it is important to address this issue. The aim is to not only to protect the DFIG from the harmful effects of the grid fault, but also to control the DFIG in such a way that it provides reactive power to the grid during the fault. The most common form of voltage disturbances is the voltage dip, which can have disastrous effects on the wind energy conversion system. Firstly, due to the magnetic coupling 
of the machine, a transient overcurrent can occur in the rotor windings. This could damage the converter switches. Secondly, the unbalanced flow of reactive and active power in the converter could lead to a high dc link voltage [146], [147], [148], [149], [150].

A common method to overcome these harmful effects is to short circuit the rotor with a set of resistors. This is known as the conventional crowbar method. This accomplishes the task of protecting the wind energy conversion system but does not assist in the production of reactive power [151]. The resumption of normal operating conditions is also not feasible using this method. In [152], a method has been proposed to connect a set of resistors between the RSC and the machine. The resistors are controlled by thyristors, meaning that the resistors can be turned on and off when required. This method prevents overcurrent's in the rotor windings due to the magnetic coupling and allows the DFIG to remain in connection to the grid. Furthermore, it allows reactive power to be supplied to the grid, assisting in voltage restoration. The method also takes only a few hundred milliseconds to restore normal operation. In [151], the vector control method is used to achieve fault ride through. The method not only considers the value of the peak rotor current, but also the rotor voltage required to restrain the rotor current to within its acceptable limits. The method also provides an analysis on the effect of the dc link voltage on fault behaviour. The methods explained in [151] and [152] work well, but do not consider the fact that the crowbar resistance has the potential to cause severely high dc link voltages, which can cause damage. In [153], the optimum crowbar resistance is calculated, and a new technique to place the RSC in parallel with the GSC is investigated. The method completely detaches the dc link from the RSC, thereby protecting it. It also provides reactive power to the grid via both the RSC and GSC. Active power generation is also resumed quickly and smoothly. Another solution is given in [154], which is based on the counteraction of the negative and zero sequence current components in the stator by applying the required rotor voltage. A similar approach is given in [155] with regards to counteraction of the stator voltage, but this method synthesizes the required rotor voltage without the need for any sequence decomposition. This greatly increases the response time and reliability of the proposed control strategy. A simple but powerful method is explained in [156], which utilises generator demagnetization to prevent the large stator and rotor current. The method provides a fast but smooth demagnetization and requires very little addition to existing control methods. A method proposed in [157] is like the methods proposed in [152] and [156]. Like [152] the crowbar is controlled by thyristors, allowing the DFIG to remain connected to the grid and ensures quick restoration of normal operation, all while reducing the rotor inrush current. Like [156], it makes use of generator demagnetization to reduce stator and rotor inrush currents. However, whereas [156] uses the established FOC, the method explained in [157] makes uses of power errors instead of current errors. This method is 
superior to [156] as the FOC method has a large dependency on systems parameters, whereas the method explained in [156] does not.

Owing to the nonlinear dynamic nature of the DFIG, a linear controller cannot work effectively under large voltage sags. The method in [158] proposes the use of a nonlinear controller to mitigate the effects of voltage sags on the DFIG. The method combines the use of a proportional-integral and Lyapunov-based auxiliary control. The aim of the control strategy is to provide a compensation for the rotor back emf, thereby preventing any damage to the RSC and dc link. Since just compensating for the rotor back emf can lead to reduced stator dynamics, another control method is investigated in [159]. This method compensates for the rotor back emf and stabilises the stator of the machine. Although proven to be an effective method, it is complex. Based on the integral backstepping control method outlined in [159], which is an alternative to proportional-integral control, a method in [149] is introduced. This method utilises the control structure of the integral backstepping control method explained in [159] to control the rotor and grid side converters. The integral backstepping method is used to provide the required rotor voltage to counteract the disturbances caused by grid voltage sags and is used in the GSC to prevent large tolerances in the dc link. This method was proven to provide a smooth response as well as effective control of reactive and active powers. The method proposed in [160] consists of passive and active low voltage ride through compensators. It is known that conventional crowbars are placed in parallel between the rotor side converter and rotor terminals of the DFIG. However, the passive compensator explained in [160] consists of a set of three resistors connected to the stator of the DFIG, in parallel with bidirectional switches. During normal operating conditions, the switches are closed, and the resistors become an open circuit (since the resistance of the alternate path is much lower than that of the resistors). During a voltage sag, the switches are open and the current flows through the calculated parallel resistors. This increase in stator resistance increases the transient resistance of the rotor, which will reduce the generally high current in the rotor due to the voltage sag. This would also allow the RSC to remain in operation during the fault. The active compensator aims to enhance the stator flux damping. The compensator uses proportionalintegral controllers to convert the oscillating transient response of the DFIG during the fault into a strongly damped and bounded exponential response. This method is simple but yields a powerful mitigation response to the harmful effects of grid voltage sags.

The methods outlined in [150]-[160] were proved to successfully mitigate the harmful effects of grid voltage sag, as well as maintain generator connection to the grid and in some cases, provide the required reactive power. However, these methods work well during symmetrical voltage sags, which are commonly not the case. Their effectiveness was not investigated under the effect of unbalanced voltage sags. This such scenario is investigated in [161]. This method 
is based on the research provided in [160] but uses asymmetrical stator resistors. The resistors are only activated in the phases with the unbalanced voltage. Furthermore, the RSC is controlled so that despite the negative sequence currents in the stator, the stator experiences no unbalanced voltages. This means that the undamped negative sequence oscillations of the DFIG is removed. Furthermore, this method addresses the issue of reactive power generation via the control of the GSC. This method requires very little modifications to the method proposed in [160], but has strong practical applications due to its simplicity, effectiveness and low cost.

When considering MPC in mitigating harmful voltage sag effects, there hasn't been much done. One approach is suggested in [145], which adopts the same procedure as the conventional MPCC, but with an addition to counter voltage sags. The rotor current direct component, which is controlled to achieve the desired stator active power and electromagnetic torque, is multiplied by a factor which is a function of the magnitude of the grid voltage before and during the fault. In this way, the surplus energy in the rotor during the fault is stored in the rotor inertia. The multiplication factor is always less than 1 , hence the rotor current $d$ component is always expected to decrease during a fault. This will decrease the amount of active power delivered during the fault but will prevent damage to the converter from high currents and will allow the DFIG to remained connected to the grid during the fault. The method uses OSV-MPC, meaning that the switching state corresponding to the lowest error between reference and actual values in implemented. The method also applies control to the GSC to keep the dc link voltage within an acceptable range. Compared to the conventional crowbar, this method is superior in terms of performance and grid reliability. The proposed scheme in [162] makes use of another type of MPC, called explicit model predictive control. The aim of this method is to provide successful generator demagnetization for generator low voltage right through enhancement. Generally, demagnetization is achieved via a constant rotor current scaling factor, which is inefficient for varying grid faults. The advantage of the method proposed in [162] allows varying degrees of rotor current scaling, thereby improving the systems capabilities during different magnitudes of faults. Furthermore, explicit model predictive control requires only offline based calculations, reducing the burden of the control method. 


\subsection{Conclusion}

This chapter provided the theoretical framework and literature review of WECS; in particular DFIG based WECS. The power flow of the DFIG was described, and the dynamic and steady state modelling of the DFIG was provided. The theory of operation of MPC, in particular FCSMPC, was explained. An introduction to the control methods was also provided, with an indepth explanation provided in the next chapter. Lastly, a critical evaluation of previous approaches to various issues regarding the use of the DFIG is provided. From this evaluation, it is seen that MPC was not extensively explored in the field of electrical power engineering. Furthermore, considering the mitigation of the effects of an unbalanced grid, most of the research was only done with regards to current control; not much was done using DTC and DPC. 


\section{Chapter 3: Research methodology}

This chapter serves to provide the methodology of the control methods used in the control of the DFIG. These control methods were introduced in chapter 2 and will be explained in detail in this chapter. Four conventional control methods and three MPC strategies will be explained in this chapter. The four conventional control methods are FOC, DTC-ST, DTC-SVPWM and DPC-ST. The three MPC methods are MPCC, MPDTC and MPDPC. For all seven control methods the relevant equations, look up tables and functional block diagrams will be provided. The control methods discussed in this chapter aim to preserve grid synchronization, but do not address other issues such as mitigating the effects of voltage unbalances, reducing harmonic distortion and the supply of reactive power to the grid during faults. The information provided in this chapter forms the basis for conducting the investigation, which will be shown in subsequent chapters.

\subsection{Field-oriented control}

FOC is a control method that makes use of co-ordinate transformation and proportionalintegral controllers. FOC is classified in two categories: direct FOC and indirect FOC. In direct FOC, the stator reactive and active powers are defined in terms of the rotor currents and directly passed through proportional-integral controllers. However, this is not well documented in literature, meaning that it is not the common method of FOC. It will therefore not be analysed in this scope of work. In indirect FOC, stator power control is achieved via control of the rotor direct and quadrature currents. This will be within the scope of this work and will be analysed further [85], [86].

To accomplish indirect FOC, the three-phase rotor current is first transformed into its direct and quadrature $(\mathrm{d}-\mathrm{q})$ co-ordinates. The difference between these values and their respective references are sent to individual proportional-integral controllers. The output of the proportional-integral controllers is added to two individual coupling terms and the result is the respective reference rotor voltages. These rotor voltages are applied to the rotor via a modulator with a predefined switching frequency. To accomplish this rotor voltage application, the direct and quadrature reference rotor voltages need to be converted into their natural frame counterparts. To preserve grid synchronization of the DFIG, this co-ordinate transformation is done by use of the slip angle. The grid angle can be obtained from the stator voltage or synchronous electrical speed (assuming grid synchronization was achieved prior), but the rotor angle requires an encoder or tachometer to track the rotor angle [27], [48], [49]. 
There exist two possible methods to execute FOC. They are named stator voltage-oriented control (SVOC) and stator flux-oriented control (SFOC). In SVOC, the rotor direct current is responsible for regulating the stator active power and the rotor quadrature current is responsible for regulating the stator reactive power. In SFOC, the rotor direct current is responsible for regulating the stator reactive power whereas the rotor quadrature current is responsible for regulating the stator active power. The type of control execution is determined based on whether the stator flux or stator voltage is aligned with the direct axis [48], [163].

If the stator direct flux is aligned with the direct axis, SFOC is being performed. In this case, the stator direct flux is made to align with the direct axis, meaning that the stator flux is wholly comprised of the stator direct flux. This makes the stator quadrature flux equal to zero. Due to the 90-degree phase difference between the stator flux and stator voltage, the stator voltage is aligned with the quadrature axis. This means that the stator voltage is wholly comprised of the stator quadrature voltage, making the stator direct voltage equal to zero [85], [164], [165]. This can be observed in figure 3-1 [163]:

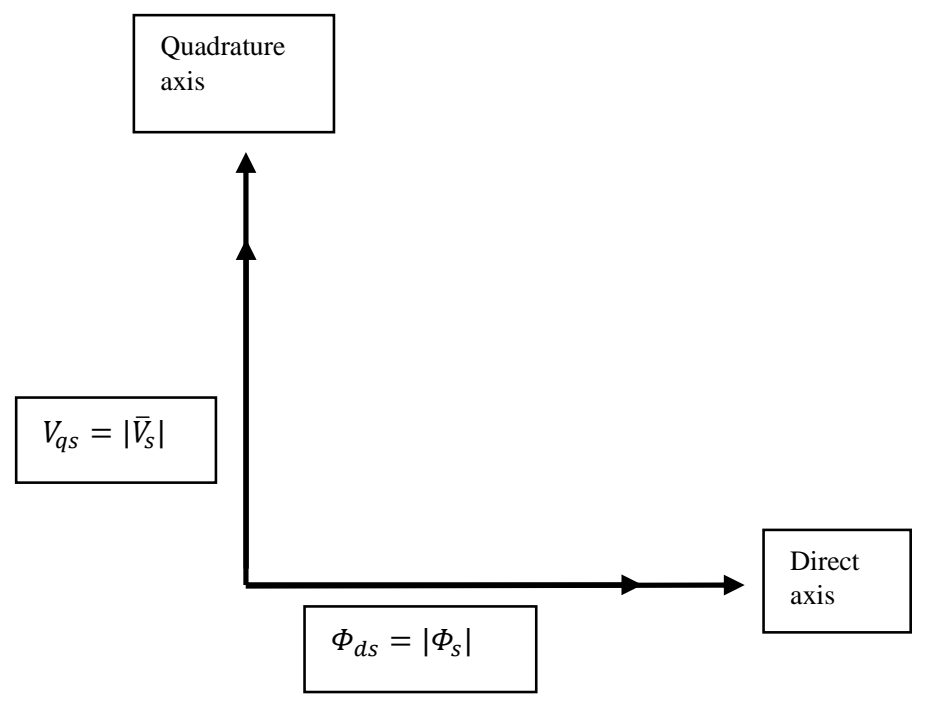

Figure 3-1: SFOC scheme [163]

Considering this, the stator flux equations can be written as [85]:

$$
\begin{aligned}
& \Phi_{d s}=\Phi_{s}=L_{s} I_{d s}+L_{m} I_{d r} \\
& \Phi_{q s}=0=L_{s} I_{q s}+L_{m} I_{q r}
\end{aligned}
$$

Rewriting these, making the stator currents the subject of the formula yields [85]:

$$
I_{d s}=\frac{\Phi_{s}}{L_{s}}-\frac{L_{m}}{L_{s}} I_{d r}
$$




$$
I_{q s}=-\frac{L_{m}}{L_{s}} I_{q r}
$$

Using these expressions for the stator current, the rotor flux can be expressed as [85]:

$$
\begin{aligned}
& \Phi_{d r}=\left(L_{r}-\frac{L_{m}^{2}}{L_{s}}\right) I_{d r}+\frac{L_{m} \Phi_{s}}{L_{s}} \\
& \Phi_{q r}=\left(L_{r}-\frac{L_{m}^{2}}{L_{s}}\right) I_{q r}
\end{aligned}
$$

Substituting these into the rotor voltage equations, the following is obtained [27], [48], [85]:

$$
\begin{aligned}
& V_{d r}=R_{r} i_{d r}+\sigma L_{r} \frac{d i_{d r}}{d t}-\sigma L_{r} i_{q r} w_{r} \\
& V_{q r}=R_{r} i_{d r}+\sigma L_{r} \frac{d i_{q r}}{d t}-\left(\sigma L_{r} i_{d r}+\frac{L_{m} \Phi_{s}}{L_{s}}\right) w_{r}
\end{aligned}
$$

Where:

- $\sigma=1-\frac{L_{m}^{2}}{L_{s} L_{r}}$

- $w_{r}$ is the slip electrical angular velocity

The electromagnetic torque can be defined as [93]:

$T_{e m}=\frac{3}{2} \frac{p}{w_{s}} \frac{L_{m}}{L_{s}}\left(-I_{q r} V_{q s}+R_{s} I_{q s} I_{q r}+R_{s} I_{d s} I_{d r}-I_{d r} V_{d s}\right)$

The stator active power is proportional to the electromagnetic torque and can be expressed as:

$$
P_{s}=\frac{3}{2} \frac{L_{m}}{L_{s}}\left(-I_{q r} V_{q s}+R_{s} I_{q s} I_{q r}+R_{s} I_{d s} I_{d r}-I_{d r} V_{d s}\right)
$$

The stator reactive power can be expressed as [85], [160], [161]:

$$
Q_{s}=\frac{3}{2} V_{q s}\left(\frac{V_{q s}-R_{S} I_{q s}}{w_{s} L_{s}}-\frac{L_{m}}{L_{s}} I_{d r}\right)
$$

Equations (3-7) - (3-11) form the basis of indirect FOC using SFOC. In (3-10), it is seen that if the stator resistance is neglected, the stator active power is dependent on the rotor quadrature current. In (3-11), it is seen that the stator reactive power is dependent on the rotor direct current. The last terms in (3.7) and (3.8) are known as the coupling terms and are added at the output of the proportional-integral controllers.

If the stator voltage is aligned with the direct axis, SVOC is being performed. In this case, the direct stator voltage is aligned with the direct axis, meaning that the stator voltage is wholly comprised of the stator direct voltage. This makes the quadrature rotor voltage equal to zero. Due to the 90-degree phase difference between the stator flux and stator voltage, the stator 
flux is made to align with the quadrature axis. This means that the stator flux is wholly comprised of the quadrature stator flux, making the direct stator flux equal to zero. In this case, the quadrature stator flux is a negative value [85], [166]. This can be seen in figure 3-2 [163]:

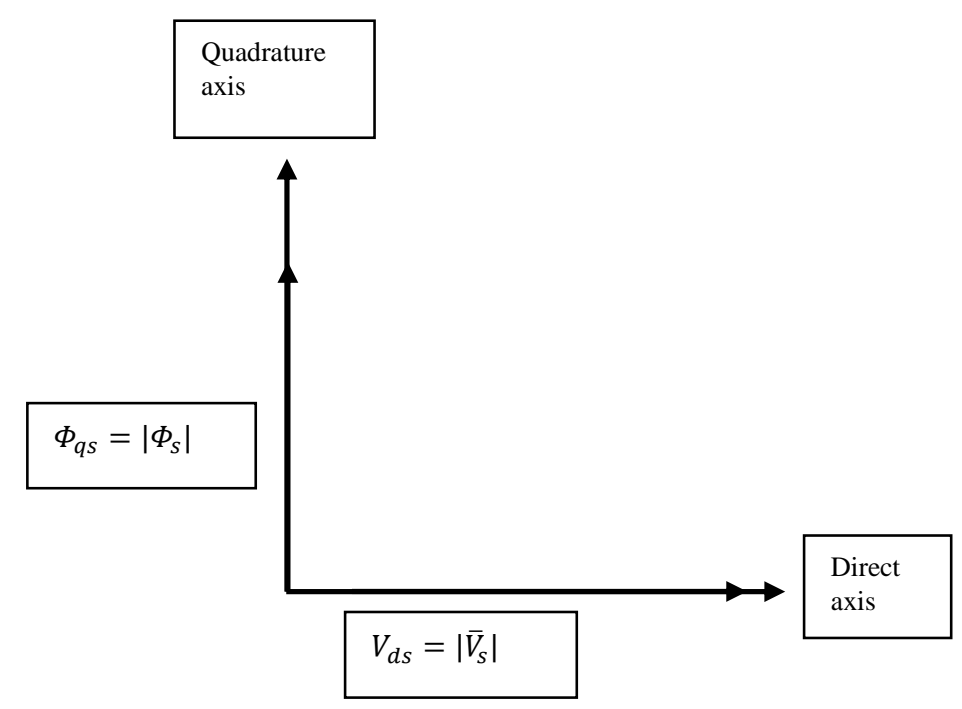

Figure 3-2: SVOC scheme [163]

Considering this, the stator flux equations can be written as:

$\Phi_{d s}=0=L_{s} I_{d s}+L_{m} I_{d r}$

$\Phi_{q s}=-\Phi_{s}=L_{s} I_{q s}+L_{m} I_{q r}$

Rewriting these, making the stator currents the subject of the formula yields:

$$
\begin{aligned}
& I_{d s}=-\frac{L_{m}}{L_{s}} I_{d r} \\
& I_{q s}=-\frac{\Phi_{s}}{L_{s}}-\frac{L_{m}}{L_{s}} I_{q r}
\end{aligned}
$$

Using these expressions for the stator current, the rotor flux can be defined as:

$$
\begin{aligned}
& \Phi_{d r}=\left(L_{r}-\frac{L_{m}^{2}}{L_{s}}\right) I_{d r} \\
& \Phi_{q r}=\left(L_{r}-\frac{L_{m}^{2}}{L_{s}}\right) I_{q r}-\frac{L_{m} \Phi_{s}}{L_{s}}
\end{aligned}
$$

Substituting these into the rotor voltage equations, the following is obtained [163]:

$$
\begin{aligned}
& V_{d r}=R_{r} I_{d r}+\sigma L_{r} \frac{d I_{d r}}{d t}-w_{r}\left(\sigma L_{r} I_{q r}-\frac{L_{m} \Phi_{s}}{L_{s}}\right) \\
& V_{q r}=R_{r} I_{q r}+\sigma L_{r} \frac{d I_{q r}}{d t}+w_{r} \sigma L_{r} I_{d r}
\end{aligned}
$$


The electromagnetic torque can be defined as [85]:

$T_{e m}=\frac{3}{2} \frac{p}{w_{s}} \frac{L_{m}}{L_{s}}\left(R_{s} I_{q S} I_{q r}+R_{s} I_{d s} I_{d r}-I_{d r} V_{d s}\right)$

The stator active power is proportional to the electromagnetic torque and can be expressed as:

$P_{s}=\frac{3}{2} \frac{L_{m}}{L_{s}}\left(R_{s} I_{q s} I_{q r}+R_{S} I_{d s} I_{d r}-I_{d r} V_{d s}\right)$

The stator reactive power can be defined as [85]:

$Q_{s}=\frac{3}{2} \frac{L_{m}}{L_{s}} V_{d s}\left(I_{q r}-\frac{R_{s} I_{d s}}{w_{s} L_{m}}+\frac{V_{d s}}{w_{s} L_{m}}\right)$

Equations (3-18) - (3-22) form the basis for indirect FOC using SVOC. In (3-21), it is seen that if the stator resistance is neglected, the stator active power is dependent on the rotor direct current. In (3-22), it is seen that the stator reactive power is dependent on the rotor quadrature current. The last two terms in (3-18) and (3-19) are known as the coupling terms and are added at the output of the proportional-integral controllers. Indirect FOC can be accomplished in two ways. The first method is called indirect FOC with power loop. In this method, the difference in the measured and reference stator powers are passed through proportional-integral controllers. From this, depending on the orientation chosen, the reference direct and quadrature rotor currents are obtained. The difference between the measured and reference rotor currents are then passed through proportional-integral controllers and, together with the coupling terms, form the reference rotor voltage to be applied to the DFIG rotor. This is a complex method, utilizing four proportional-integral controllers. The second method is called indirect FOC without power loop. This method derives the reference rotor currents directly from the equations presented in (3-10) - (3-11) or (3-21) - (3-22). The difference in the measured and reference rotor currents are then passed through proportional-integral controllers and together with the coupling terms, form the reference rotor voltage to be applied to the DFIG rotor [27]. This method is simpler than its power loop counterpart as it only uses two proportional-integral controllers. The control structure of indirect FOC without power loop is shown in figure 3-3. The orientation shown is SVOC [27], [48], [98]. In the control structure shown in figure 3-3, $c 1$ and $c 2$ are the coupling terms which are obtained from (3-18) and (3-19) respectively and $\theta_{s}, \theta_{m}$ and $\theta_{r}$ are the stator, rotor and slip electrical angles respectively. Furthermore, the slip angle extraction is shown for the SVOC method. For the SFOC method, the same method is used, but the resultant angle $\theta_{r}$ has $90^{\circ}$ subtracted from it [85]. 


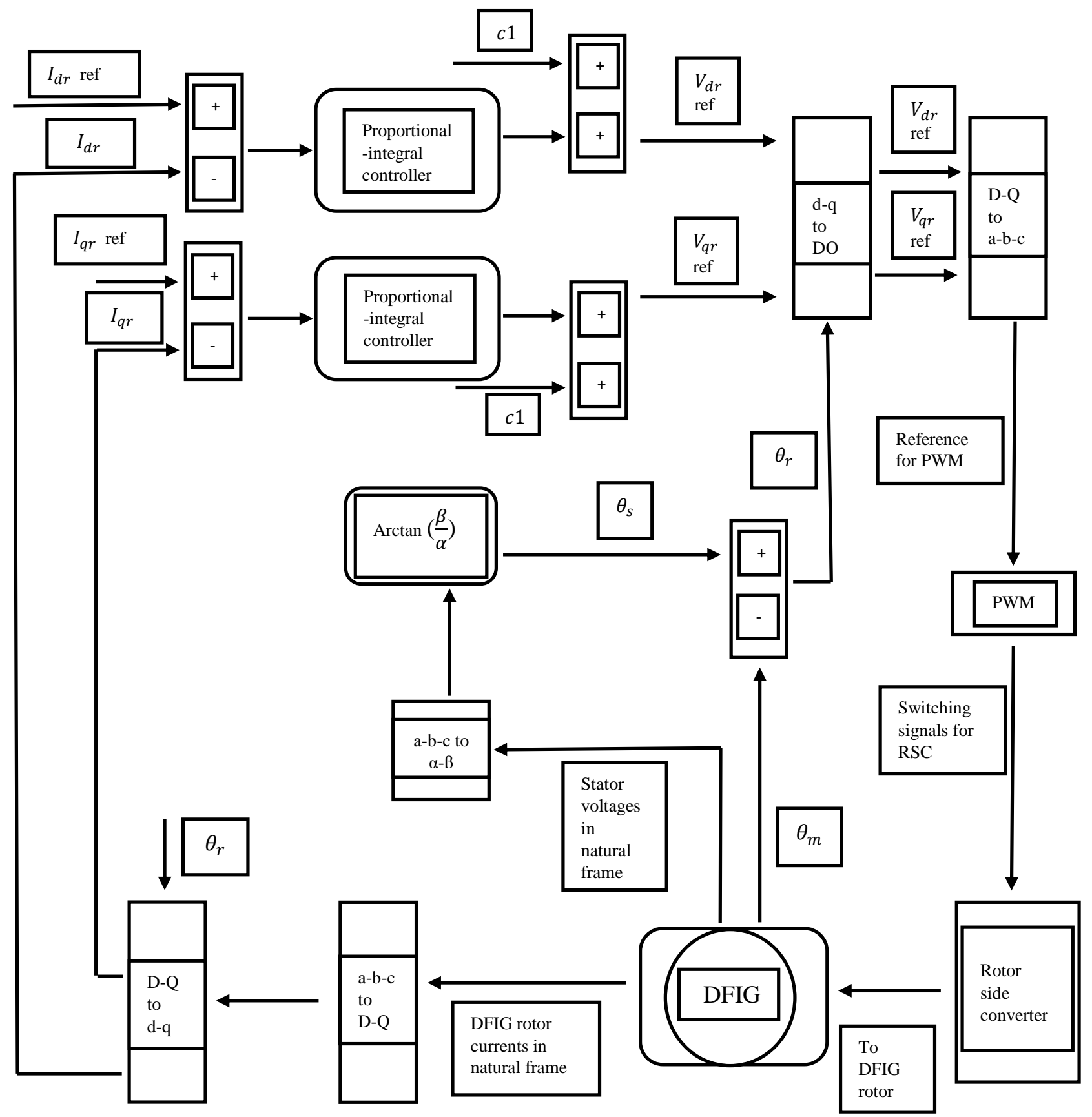

Figure 3-3: Control structure of Indirect FOC [27], [48], [98]

As explained earlier, the reference current for stator active power control is dependent on the reference stator active power. Consider figure 3-4 [11]. 


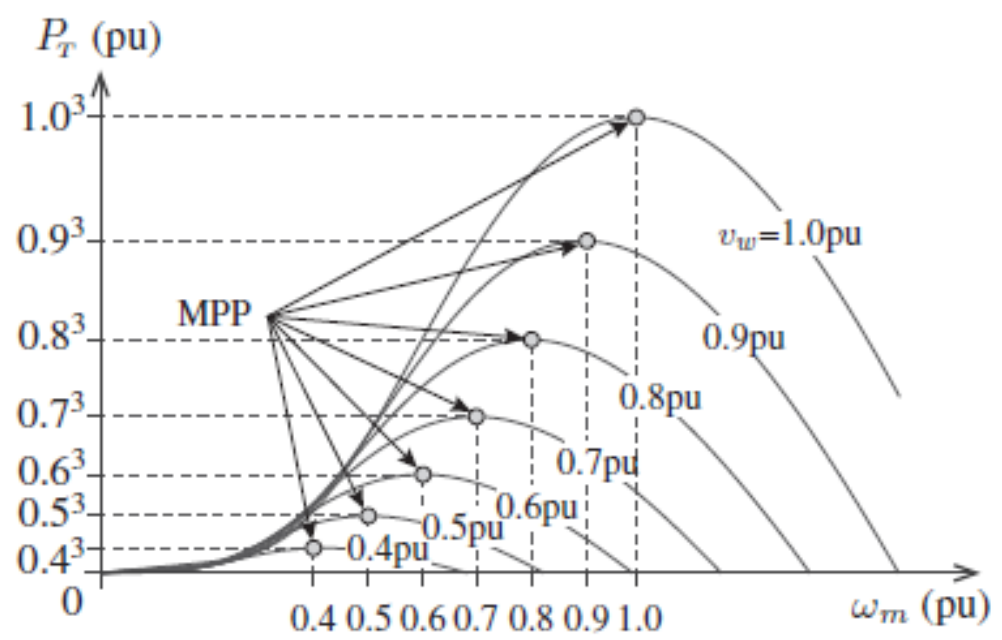

Figure 3-4: Turbine power vs speed curve [11]

From figure $3-4$, it is seen that the power available by the wind turbine is dependent on the wind speed and the speed of the machine rotor. The turbine power is proportional to the stator active power hence to obtain the reference stator power, the wind speed is first needed. This wind speed is then used in a look up table like figure 3-4 to obtain the required rotor speed. A proportional-integral controller is then used to provide regulation of the machine rotor speed [48]. As can be seen, this method is complex. If the maximum possible stator active power is required to be delivered to the grid at all times, a method known as the optimal torque control method can be used. It is known that the electromagnetic torque of a machine is directly proportional to the stator active power. Hence obtaining the value of the maximum electromagnetic torque will result in the maximum stator active power being obtained. Since the electromagnetic torque is approximately equal to the mechanical torque, the reference electromagnetic torque can be expressed as follows [11]:

$T_{e m} r e f=\frac{1}{2} \times \rho \times \pi \times r_{T}{ }^{5} \times \frac{C_{p}{ }^{o p}}{\left(\lambda_{T}^{o p}\right)^{3} \times r_{g b}{ }^{3}} \times w_{m}{ }^{2}$

Where $C_{p}{ }^{o p}$ and $\lambda_{T}^{o p}$ are the optimal power coefficient and tip speed ratio values respectively. The expression $\frac{1}{2} \times \rho \times \pi \times r_{T}{ }^{5} \times \frac{C_{p}{ }^{o p}}{\left(\lambda_{T}{ }^{o p}\right)^{3} \times r_{g b^{3}}}$ is a constant, meaning that the reference electromagnetic torque is only dependant on the square of the machine rotor speed. This method is much simpler than the speed control method, but only can be used when the maximum power is expected to be delivered.

The dc bus voltage, $V_{d c}$, is calculated as follows [167]:

$V_{d c}=\sqrt{2} \times s_{\max } \times u \times V_{r}$ 
Where $u$ is the ratio between the stator and rotor voltages respectively and $s_{\max }$ is the maximum slip of the machine.

\subsection{Direct torque control using the switching table}

DTC-ST is a control method whereby the DFIG rotor flux and electromagnetic torque are controlled directly. In this control method, the errors between the reference and measured rotor flux and electromagnetic torque are passed through hysteresis controllers. The electromagnetic torque requires a three-level hysteresis controller, and the rotor flux requires a two-level hysteresis controller. The hysteresis controllers produce an appropriate output. One output will be as a result of the electromagnetic torque difference and one as a result of the rotor flux difference. The rotor flux angle is also required for this control method. The rotor flux in the rotor reference frame (D-Q) is estimated via use of the rotor voltages and currents in the same reference frame. From this, the angle of the rotor flux is determined. The output of the hysteresis controllers, as well as the angle of the rotor flux, determines the switching state of the rotor side converter [28], [88]. The switching states give rise to the appropriate rotor voltage vector, as seen in table 3-1, Table 3-1 considers a 2L-VSI, where $\boldsymbol{S}_{\boldsymbol{a}}, \boldsymbol{S}_{\boldsymbol{b}}$ and $\boldsymbol{S}_{\boldsymbol{c}}$ are the converter switching states [28]. The rotor flux is calculated using the following formulae [41], [168]:

$\Phi_{D r}(t)=\int_{0}^{t}\left(V_{D r}-R_{r} I_{D r}\right) d t$

$\Phi_{Q r}(t)=\int_{0}^{t}\left(V_{Q r}-R_{r} I_{Q r}\right) d t$

$\Phi_{r}=\sqrt[2]{\left(\Phi_{D r}^{2}+\Phi_{Q r}{ }^{2}\right)}$

The angle of the rotor flux is calculated as:

$\angle \Phi_{r}=\tan ^{-1}\left(\frac{\Phi_{Q r}}{\Phi_{D r}}\right)$

Where:

- $\Phi_{D r}$ and $\Phi_{Q r}$ are the components of the rotor flux in the rotor reference frame

- $V_{D r}$ and $V_{Q r}$ are the components of the rotor voltage in the rotor reference frame

- $I_{D r}$ and $I_{Q r}$ are the components of the rotor current in the rotor reference frame

The rotor flux angle is divided into six sectors, which can be seen in table 3-2 [28]. 
Table 3-1: Rotor voltage generation according to switching states [28]

\begin{tabular}{|c|c|c|c|c|c|}
\hline $\boldsymbol{S}_{\boldsymbol{a}}$ & $\boldsymbol{S}_{\boldsymbol{b}}$ & $\boldsymbol{S}_{\boldsymbol{c}}$ & Vector & $\boldsymbol{V}_{\boldsymbol{\alpha r}}$ & $\boldsymbol{V}_{\boldsymbol{\beta r}}$ \\
\hline 0 & 0 & 0 & $V_{0}$ & 0 & 0 \\
\hline 1 & 0 & 0 & $V_{1}$ & $\frac{-2 V_{d c}}{3}$ & 0 \\
\hline 1 & 1 & 0 & $V_{2}$ & $\frac{V_{d c}}{3}$ & $\frac{V_{d c}}{\sqrt{3}}$ \\
\hline 0 & 1 & 0 & $V_{3}$ & $\frac{-V_{d c}}{3}$ & $\frac{V_{d c}}{\sqrt{3}}$ \\
\hline 0 & 1 & 1 & $V_{4}$ & $\frac{-2 V_{d c}}{3}$ & 0 \\
\hline 0 & 0 & 1 & $V_{5}$ & $\frac{-V_{d c}}{3}$ & $\frac{-V_{d c}}{\sqrt{3}}$ \\
\hline 1 & 0 & 1 & $V_{6}$ & $\frac{V_{d c}}{3}$ & $\frac{-V_{d c}}{\sqrt{3}}$ \\
\hline 1 & 1 & 1 & $V_{7}$ & 0 & 0 \\
\hline
\end{tabular}

Table 3-2: Sector identification of rotor flux angle [28]

\begin{tabular}{|c|c|}
\hline Rotor flux angle & Sector \\
\hline$-\frac{\pi}{6} \leq \angle \Phi_{r}<\frac{\pi}{6}$ & 1 \\
\hline$\frac{\pi}{6} \leq \angle \Phi_{r}<\frac{\pi}{2}$ & 2 \\
\hline$\frac{\pi}{2} \leq \angle \Phi_{r}<\frac{5 \pi}{6}$ & 3 \\
\hline$\frac{5 \pi}{6} \leq \angle \Phi_{r}<\frac{7 \pi}{6}$ & 4 \\
\hline$\frac{7 \pi}{6} \leq \angle \Phi_{r}<-\frac{\pi}{2}$ & 5 \\
\hline$-\frac{\pi}{2} \leq \angle \Phi_{r}<-\frac{\pi}{6}$ & \\
\hline
\end{tabular}

Table 3-3 shows the relationship between the rotor flux sector, rotor flux hysteresis controller output and electromagnetic torque hysteresis control output [169]. In table 3-3, $\boldsymbol{E}_{\boldsymbol{f}}$ and $\boldsymbol{E}_{\boldsymbol{t}}$ are the outputs of the rotor flux and electromagnetic torque hysteresis controllers respectively and $\mathrm{k}$ is the sector. From table 3-3, it is seen that there exists a scenario where the output of the electromagnetic torque hysteresis controller is not zero, but the selected vector is a zero vector $\left(V_{0}\right.$ or $\left.V_{7}\right)$. In such a scenario, the voltage vector $V_{0}$ is changed to $V_{6}$, whereas the voltage 
vector $V_{7}$ is changed to $V_{1}$. This is as a result of adding and subtracting one revolution from the sector respectively. There also exists a scenario where the rotor voltage vector chosen is $V_{-1}$ or $V_{8}$. These vectors are out of range. In such a scenario, $V_{-1}$ is changed to $V_{5}$ and $V_{8}$ is changed to $V_{2}$. This is also as a result of adding and subtracting one revolution from the sector respectively

Table 3-3: Vector selection table for DTC-ST [169]

\begin{tabular}{|c|c|c|c|}
\hline & $\boldsymbol{E}_{\boldsymbol{t}}=1$ & $\boldsymbol{E}_{\boldsymbol{t}}=0$ & $\boldsymbol{E}_{\boldsymbol{t}}=-1$ \\
\hline $\boldsymbol{E}_{\boldsymbol{f}}=1$ & $V_{k-1}$ & $V_{7}, V_{0}$ & $V_{k+1}$ \\
\hline $\boldsymbol{E}_{\boldsymbol{f}=-1}$ & $V_{k-2}$ & $V_{7}, V_{0}$ & $V_{k+2}$ \\
\hline
\end{tabular}

The final part of this control strategy is the calculation of the bandwidth of the hysteresis controllers. This is generally difficult to define. However, a good method to follow is to define the bandwidth of the rotor flux as 5.5\% of the machines rated rotor flux and $17 \%$ of the machines rated electromagnetic torque [169]. The reference electromagnetic torque can be obtained via either of the methods explained in 3.1. The control structure DTC-ST table is shown in figure 3-5 [28], [41], [170]:

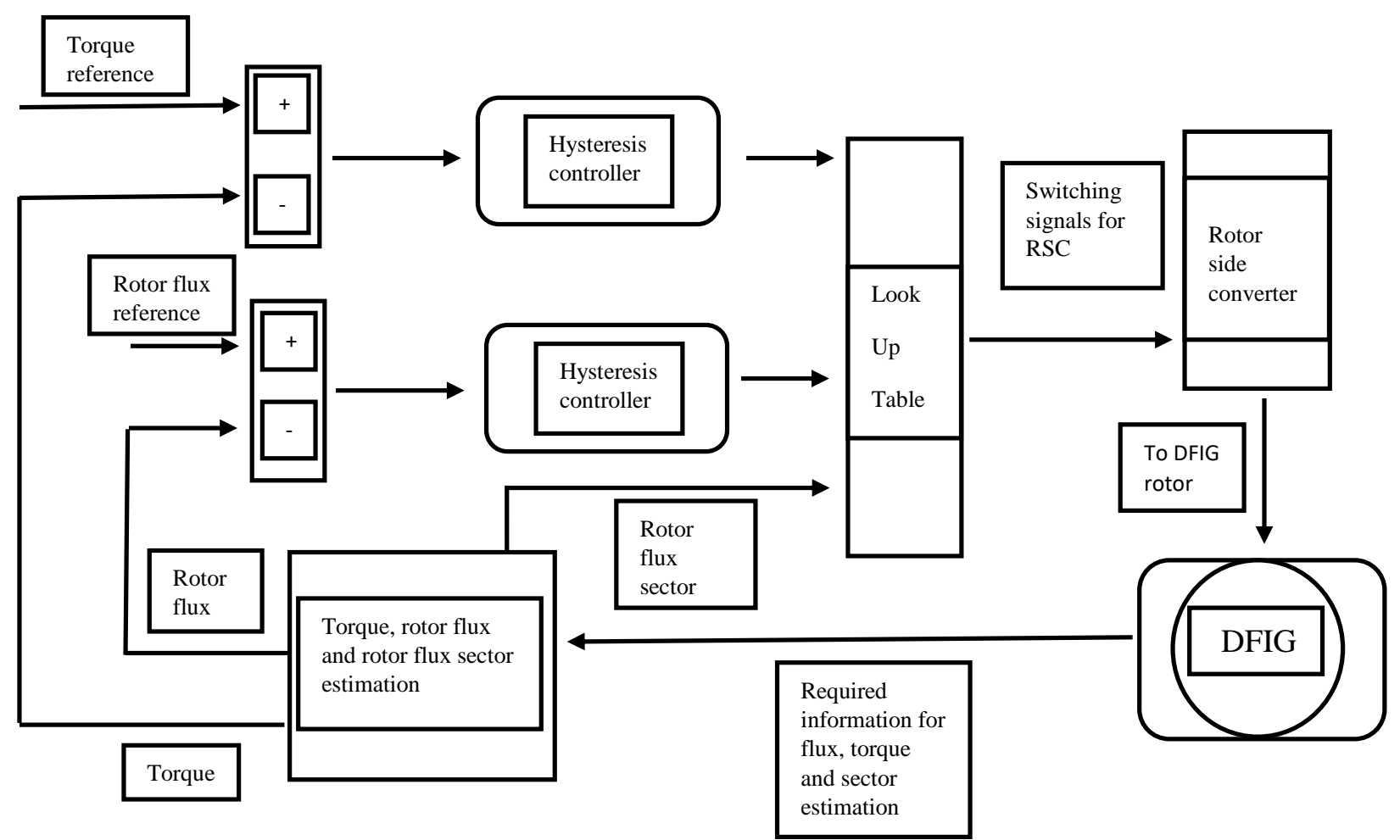

Figure 3-5: Control structure of DTC-ST [28], [41], [170] 


\subsection{Direct torque control using space vector pulse width modulation}

DTC-SVPWM is an alternative control method to DTC-ST. The electromagnetic torque and rotor flux are directly controlled. The control method makes use of two proportional-integral controllers; one for control of the rotor flux and one for control of the electromagnetic torque. The output of the proportional-integral controllers produces the reference rotor voltage to be applied to the rotor of the DFIG [89], [90]. To preserve grid synchronisation, this reference rotor voltage is then transformed using the slip angle and passed through a modulator, which produce the switching signals for the converter [27]. Either the direct or quadrature rotor voltage can be used to control either the electromagnetic torque or rotor current. If the slip angle is extracted using the stator flux angle, the direct rotor voltage controls the rotor flux and the quadrature rotor voltage controls the electromagnetic torque. The opposite is true if the stator voltage angle is used to extract the slip angle. The reference electromagnetic torque can be obtained from the methods explained in 3.1. The two electromagnetic torque values are negated before their differences are estimated. The control structure of DTC-SVPWM is seen in figure 3-6 [90]. In figure 3-6, the slip angle is extracted using the stator voltage angle.

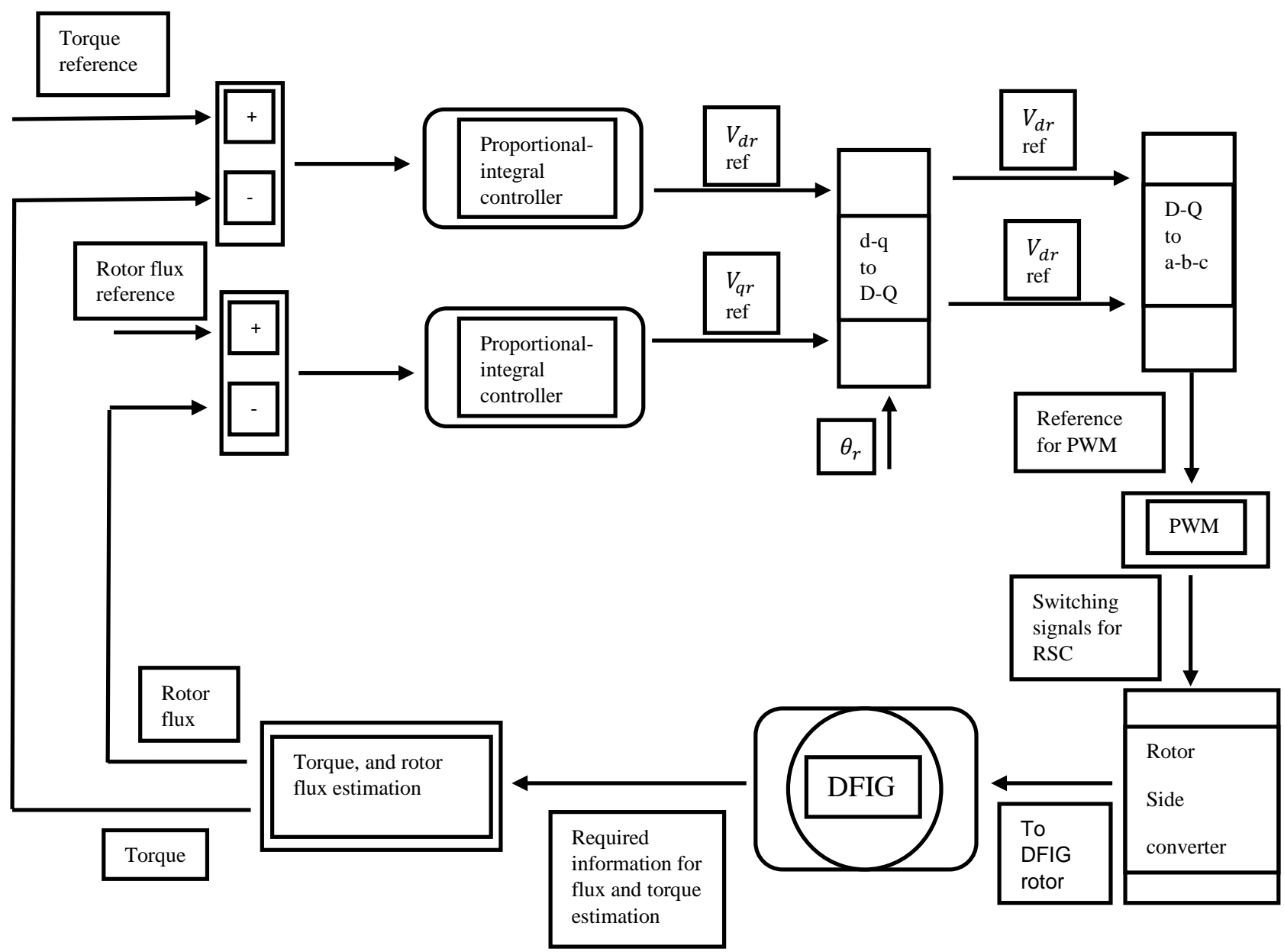

Figure 3-6: Control structure of DTC-SVPWM [90] 


\subsection{Direct power control using the switching table}

DPC-ST is almost identical to DTC-ST. In DPC-ST, the stator reactive and active powers are directly controlled via the use of hysteresis controllers. In this control method, the difference between the reference and measured stator reactive and active powers are passed through hysteresis controllers. The active power requires a three-level hysteresis controller, and the reactive power requires a two-level hysteresis controller. The hysteresis controllers produce an appropriate output. One output will be as a result of the reactive power difference and one as a result of the active power difference. The output of the hysteresis controllers, together with the flux sector, provides the appropriate switching state [28], [29], [88], [92]. There exist two methods of execution of DPC-ST. This includes the use of either the rotor flux position or the stator flux position [29]. The method using the stator flux position will be discussed further. The three-phase stator flux is transformed from the synchronous reference frame into the rotor reference frame and from this the stator flux angle is calculated. This requires knowledge of the slip angle [29], [92].

The value of the stator flux in the synchronous frame can be estimated as follows [93]:

$$
\begin{aligned}
& \Phi_{d s}=\frac{V_{q s}-R_{s} I_{q s}}{w_{s}} \\
& \Phi_{q s}=-\frac{V_{d s}-R_{s} I_{d s}}{w_{s}}
\end{aligned}
$$

These flux values are then converted from the synchronous reference frame to the rotor reference frame via the use of the slip angle. Thereafter, the angle of the stator flux in the rotor reference frame is calculated as:

$\angle \Phi_{S}=\tan ^{-1}\left(\frac{\Phi_{Q S}}{\Phi_{D S}}\right)$

Where $\Phi_{D s}$ and $\Phi_{Q s}$ are the stator flux co-ordinates in the rotor reference frame. The stator flux angle is divided into six sectors, which can be seen in table 3-4 [28]. Table 3-5 shows the relationship between the stator flux sector, stator reactive power hysteresis controller output and stator active power hysteresis controller output [169]. In table 3-5, $\boldsymbol{E}_{\boldsymbol{q}}$ and $\boldsymbol{E}_{\boldsymbol{p}}$ are the outputs of the stator reactive power and stator active power hysteresis controllers respectively and $\mathrm{k}$ is the sector. From table $3-5$, it is seen that there exists a scenario where the output of the stator active power hysteresis controller is not zero, but the selected vector is a zero vector $\left(V_{0}\right.$ or $\left.V_{7}\right)$. In such a scenario, the voltage vector $V_{0}$ is changed to $V_{6}$, whereas the voltage vector $V_{7}$ is changed to $V_{1}$. This is as a result of adding and subtracting one revolution from the sector respectively. There also exists a scenario where the rotor voltage vector chosen is 
$V_{-1}$ or $V_{8}$. These vectors are out of range. In such a scenario, $V_{-1}$ is changed to $V_{5}$ and $V_{8}$ is changed to $V_{2}$. This is also as a result of adding and subtracting one revolution from the sector respectively.

Table 3-4: Sector identification angle of stator flux angle [28]

\begin{tabular}{|c|c|}
\hline Stator flux angle & Sector \\
\hline$-\frac{\pi}{6} \leq \angle \Phi_{S}<\frac{\pi}{6}$ & 1 \\
\hline$\frac{\pi}{6} \leq \angle \Phi_{S}<\frac{\pi}{2}$ & 2 \\
\hline$\frac{\pi}{2} \leq \angle \Phi_{S}<\frac{5 \pi}{6}$ & 3 \\
\hline$\frac{5 \pi}{6} \leq \angle \Phi_{S}<\frac{7 \pi}{6}$ & 4 \\
\hline$\frac{7 \pi}{6} \leq \angle \Phi_{S}<-\frac{\pi}{2}$ & 5 \\
\hline$-\frac{\pi}{2} \leq \angle \Phi_{S}<-\frac{\pi}{6}$ & 6 \\
\hline
\end{tabular}

Table 3-5: Vector selection table of DPC-ST [169]

\begin{tabular}{|c|c|c|c|}
\hline & $\boldsymbol{E}_{\boldsymbol{p}}=1$ & $\boldsymbol{E}_{\boldsymbol{p}}=0$ & $\boldsymbol{E}_{\boldsymbol{p}}=-1$ \\
\hline $\boldsymbol{E}_{\boldsymbol{q}}=1$ & $V_{k-2}$ & $V_{7}, V_{0}$ & $V_{k+2}$ \\
\hline $\boldsymbol{E}_{\boldsymbol{q}}=-1$ & $V_{k-1}$ & $V_{7}, V_{0}$ & $V_{k+1}$ \\
\hline
\end{tabular}

The final part of this control method is the calculation of the bandwidth of the hysteresis controllers. This is generally difficult to define. The reference stator active power can be obtained by using either of the methods shown in 3.1. Since the stator active power is proportional to the electromagnetic torque, the reference stator active power is defined as follows:

$P_{s}^{r e f}=T_{e m}{ }^{r e f} \times \frac{w_{s}}{p}$

Where $w_{s}$ is the synchronous speed and $p$ is the number of pole pairs. The control structure of DPC-ST is shown in figure 3-7 [28], [29], [92]. 


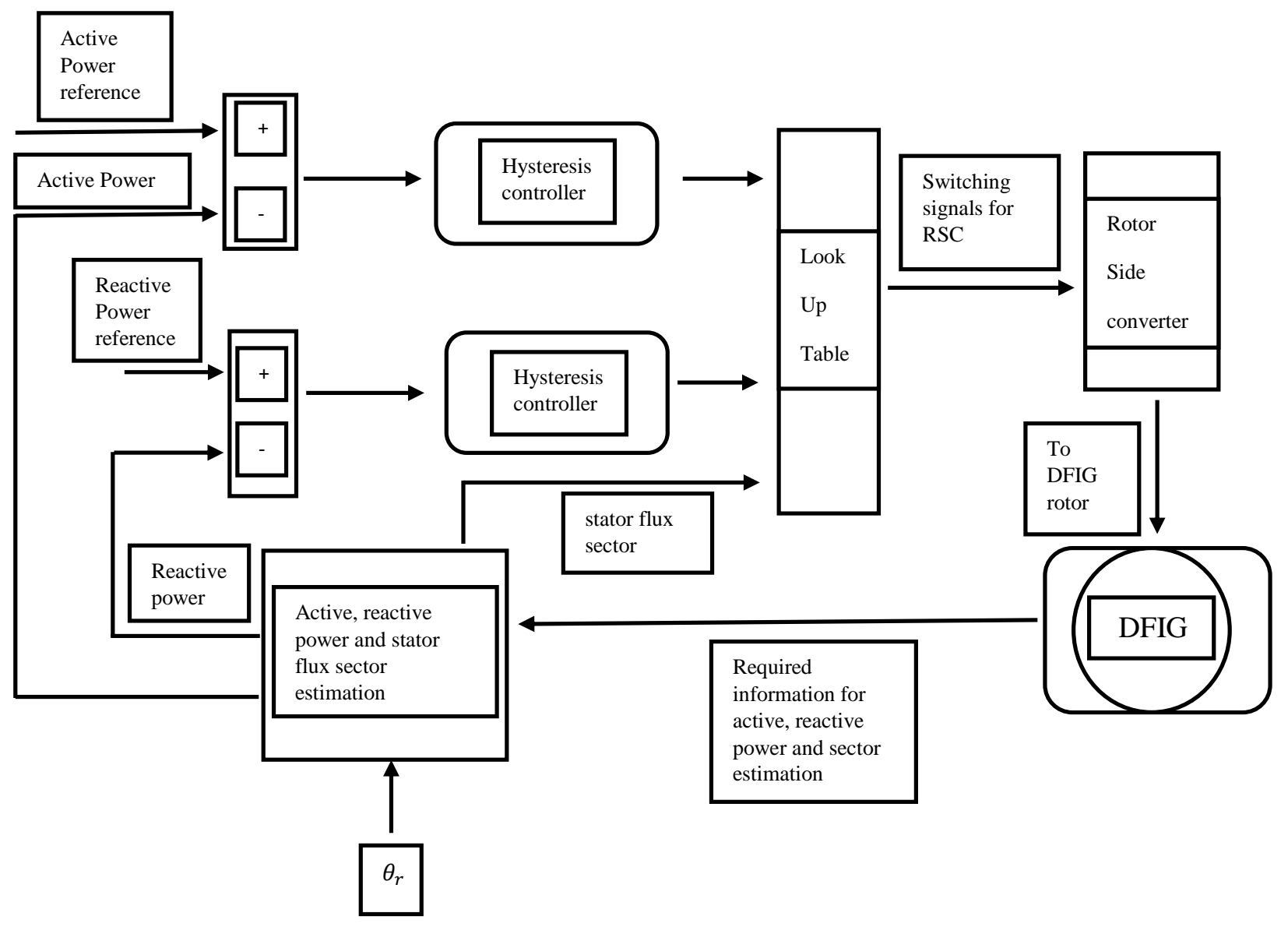

Figure 3-7: Control structure of DPC-ST [28], [29], [92]

\subsection{Model predictive current control}

MPCC is a control method which regulates the stator reactive and active power of the DFIG via control of the rotor currents. Since the RSC has a finite amount of switching states, FCSMPC is the best type of MPC to be used in the control of the DFIG. Due to its simplicity, OSV-MPC will be discussed further and used in this research. Furthermore, a 2L-VSI will be considered and used in this research. MPCC can be implemented in two ways; indirect MPCC and direct MPCC. Indirect MPCC estimates the next state rotor currents via computation of the next state stator currents and rotor fluxes. Direct MPCC directly estimates the next state rotor currents. Direct MPCC will be discussed in this chapter [93], [94]. Direct MPCC approximates the direct and quadrature rotor currents at the next sampling instant. and compares them with their reference values. It then estimates a cost function for each of the eight possible switching states. The switching state corresponding to the smallest cost function is implemented [93], [94]. 
Using the forward Euler approximation, the rotor direct and quadrature currents at the next sampling instant is given by [93]:

$$
\begin{aligned}
& I_{d r}{ }^{k+1}=I_{d r}{ }^{k}+T_{S}\left(\frac{d}{d t} I_{d r}{ }^{k}\right) \\
& I_{q r}{ }^{k+1}=I_{d r}{ }^{k}+T_{S}\left(\frac{d}{d t} I_{q r}{ }^{k}\right)
\end{aligned}
$$

The change in rotor current can be expressed as [93]:

$$
\left(\begin{array}{l}
\frac{d}{d t} I_{d r}{ }^{k} \\
\frac{d}{d t} I_{q r}{ }^{k}
\end{array}\right)=A_{1}\left(\begin{array}{c}
I_{d s}{ }^{k} \\
I_{q s}{ }^{k} \\
I_{d r}{ }^{k} \\
I_{q r}{ }^{k}
\end{array}\right)+A_{2}\left(\begin{array}{c}
V_{d s}{ }^{k} \\
V_{q s}{ }^{k} \\
V_{d r}{ }^{k} \\
V_{q r}{ }^{k}
\end{array}\right)
$$

Where:

$$
\begin{aligned}
& A_{1}=\left(\begin{array}{cccc}
R_{s} L_{m} & -w_{m}{ }^{k} L_{s} L_{m} & -R_{r} L_{s} & -w_{m}{ }^{k} L_{r} L_{s}+k_{\Phi} \\
w_{m}{ }^{k} L_{s} L_{m} & R_{s} L_{m} & w_{m}{ }^{k} L_{r} L_{s}-k_{\Phi} & -R_{r} L_{s}
\end{array}\right) \\
& A_{2}=\left(\begin{array}{cccc}
-L_{m} & 0 & L_{s} & 0 \\
0 & -L_{m} & 0 & L_{s}
\end{array}\right)
\end{aligned}
$$

By combining (3-35) with (3-33) and (3-34), the rotor direct and quadrature currents at the next sampling period is given as [93].

$$
\left(\begin{array}{c}
I_{d r}{ }^{k+1} \\
I_{q r}{ }^{k+1}
\end{array}\right)=A_{3}\left(\begin{array}{c}
I_{d s}{ }^{k} \\
I_{q s}{ }^{k} \\
I_{d r}{ }^{k} \\
I_{q r}{ }^{k}
\end{array}\right)+A_{4}\left(\begin{array}{c}
V_{d s}{ }^{k} \\
V_{q s}{ }^{k} \\
V_{d r}{ }^{k} \\
V_{q r}{ }^{k}
\end{array}\right)
$$

Where:

$$
\begin{aligned}
A_{3} & =\left(\begin{array}{cccc}
R_{s} L_{m} T_{s} & -w_{r}{ }^{k} L_{s} L_{m} T_{s} & 1-R_{r} L_{s} T_{s} & -w_{r}{ }^{k} L_{r} L_{s} T_{s}+k_{\Phi} \\
w_{r}{ }^{k} L_{s} L_{m} T_{s} & R_{s} L_{m} T_{s} & w_{r}{ }^{k} L_{r} L_{s} T_{s}-k_{\Phi} & 1-R_{r} L_{s} T_{s}
\end{array}\right) \\
A_{4} & =\left(\begin{array}{cccc}
-L_{m} T_{s} & 0 & L_{s} T_{s} & 0 \\
0 & -L_{m} T_{s} & 0 & L_{s} T_{s}
\end{array}\right) \\
k_{\Phi} & =w_{s} \sigma L_{s} L_{r} T_{s}
\end{aligned}
$$

Note that the superscripts $\mathrm{k}$ and $\mathrm{k}+1$ represent the current and next states respectively.

The rotor voltage in the direct-quadrature reference frame is [93]:

$$
\left(\begin{array}{l}
V_{d r}{ }^{k} \\
V_{q r}{ }^{k}
\end{array}\right)=v_{d c}\left(\begin{array}{l}
s_{d r}{ }^{k} \\
s_{q r}{ }^{k}
\end{array}\right)
$$


Where:

$$
\left(\begin{array}{c}
s_{d r}{ }^{k} \\
s_{q r}{ }^{k}
\end{array}\right)=\left(\begin{array}{cc}
\cos \left(\theta_{r}\right) & \sin \left(\theta_{r}\right) \\
-\sin \left(\theta_{r}\right) & \cos \left(\theta_{r}\right)
\end{array}\right) \times \frac{2}{3}\left(\begin{array}{ccc}
1 & -\frac{1}{2} & -\frac{1}{2} \\
0 & \frac{\sqrt{3}}{2} & -\frac{\sqrt{3}}{2}
\end{array}\right)\left(\begin{array}{l}
S_{a} \\
S_{b} \\
S_{c}
\end{array}\right)
$$

The switching states $S_{a}, S_{b}$ and $S_{c}$ can be found in table 3-1.

Upon completion of estimation of the rotor voltage and next state rotor currents, the cost function is defined as:

$g=\left(I_{d r}{ }^{r e f}-I_{d r}{ }^{k+1}\right)^{2}+\left(I_{q r}{ }^{r e f}-I_{q r}{ }^{k+1}\right)^{2}$

The algorithm of OSV-MPC is seen in figure 3-9 [171]. In figure 3-11, the next state variables are the rotor direct and quadrature currents. Furthermore, $g(j)$ is the cost function of the $j^{\text {th }}$ switching state. The term $g_{o p}$ is the optimal (smallest) cost function and $j_{o p}$ is the switching state that brings about this optimal cost function. Like FOC, MPCC can also be executed using SVOC or SFOC. Once again, in SVOC, the direct rotor current is used to control the stator active power and the quadrature rotor current is used to control the stator reactive power. The opposite is true for SFOC. The direct and quadrature reference rotor currents are obtained as shown in 3.1 [93]. The control structure of MPCC using FCS-MPC is seen in figure 3-8 [93], [94].

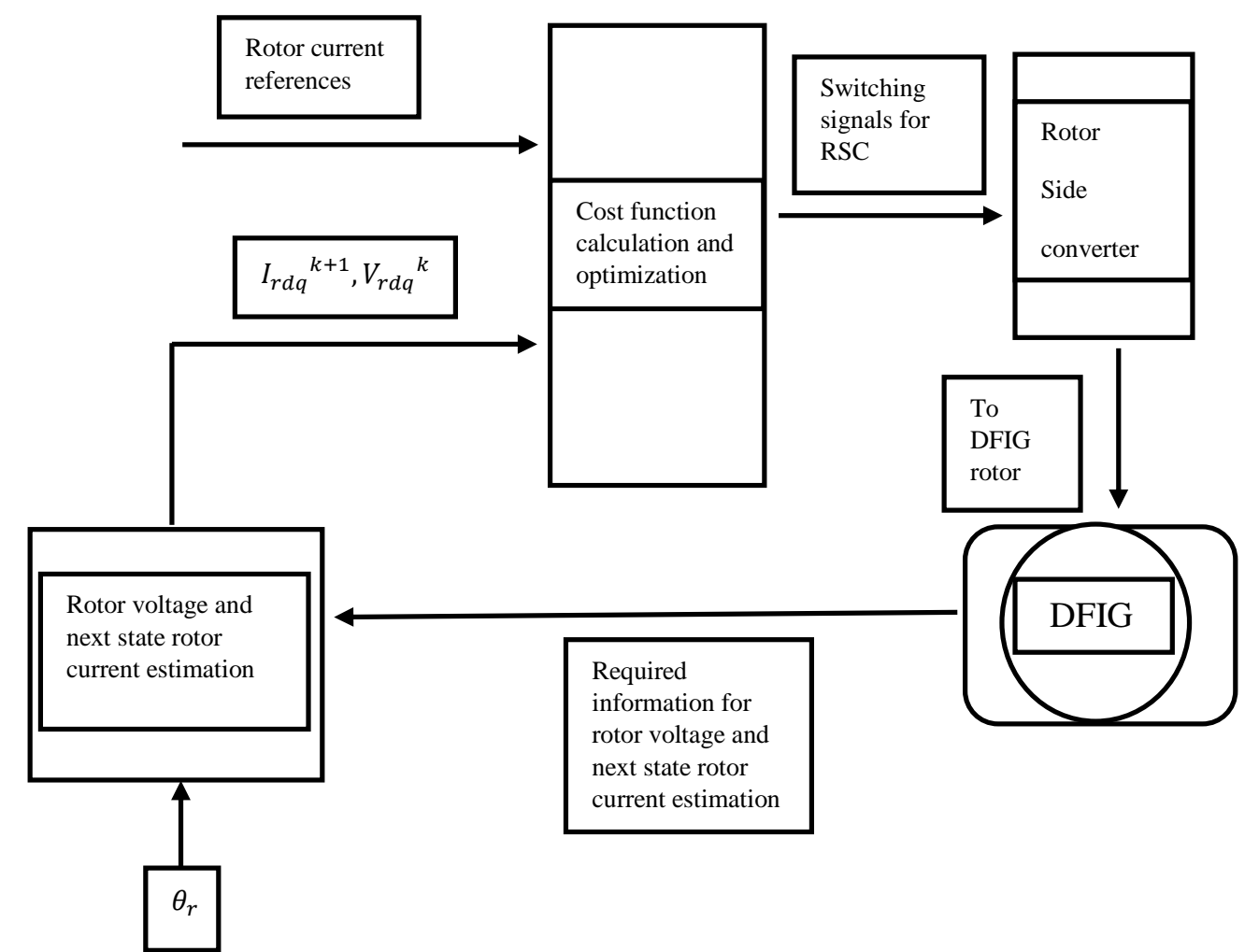

Figure 3-8: Control structure of MPCC using FCS-MPC [93], [94] 


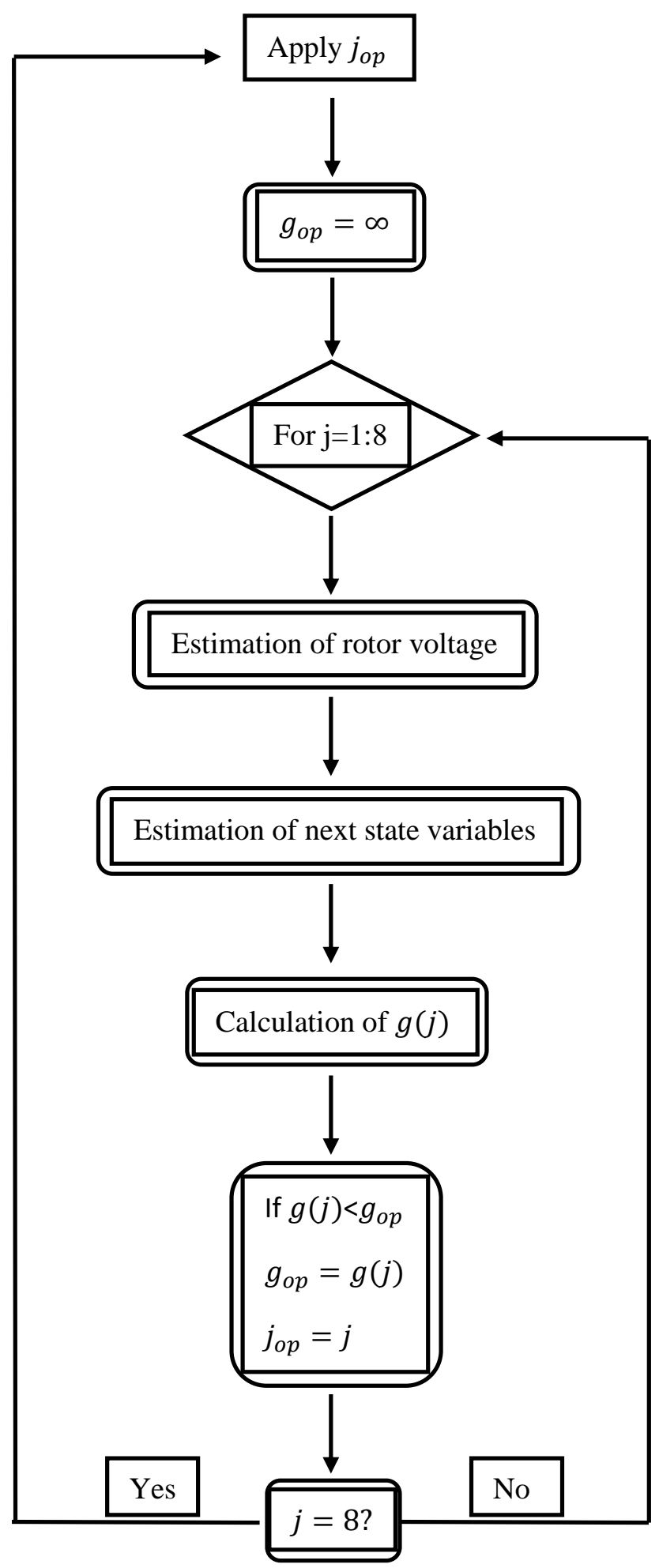

Figure 3-9: OSV-MPC algorithm for 2L-VSI [171] 


\subsection{Model predictive direct torque control}

MPDTC is almost identical to MPCC, the difference being that now the rotor flux and electromagnetic torque are directly controlled. The electromagnetic torque can be represented as follows:

$T_{e m}=\frac{3}{2} p\left(\Phi_{d s} I_{q s}-\Phi_{q s} I_{d s}\right)$

From (3-40), as well as the stator flux equations defined in (3-29) and (3-30), it is seen that estimation of the next state direct and quadrature stator currents will allow the estimation of the next state electromagnetic torque to be computed. The stator direct and quadrature currents at the next sampling instant is given as [93]:

$$
\begin{aligned}
& I_{d s}{ }^{k+1}=I_{d s}{ }^{k}+T_{s}\left(\frac{d}{d t} I_{d s}{ }^{k}\right) \\
& I_{q s}{ }^{k+1}=I_{q s}{ }^{k}+T_{s}\left(\frac{d}{d t} I_{q s}{ }^{k}\right)
\end{aligned}
$$

The change in the direct and quadrature stator currents is as follows [93]:

$$
\left(\begin{array}{l}
\frac{d}{d t} I_{d s}{ }^{k} \\
\frac{d}{d t} I_{q s}{ }^{k}
\end{array}\right)=A_{5}\left(\begin{array}{l}
I_{d s}{ }^{k} \\
I_{q s}{ }^{k} \\
I_{d r}{ }^{k} \\
I_{q r}{ }^{k}
\end{array}\right)+A_{6}\left(\begin{array}{c}
V_{d s}{ }^{k} \\
V_{q s}{ }^{k} \\
V_{d r}{ }^{k} \\
V_{q r}{ }^{k}
\end{array}\right)
$$

Where:

$$
\begin{aligned}
A_{5} & =\left(\begin{array}{cccc}
-R_{s} L_{r} & w_{m}{ }^{k} L_{m}{ }^{2}+k_{\Phi} & R_{r} L_{m} & w_{m}{ }^{k} L_{m} L_{r} \\
-w_{m}{ }^{k} L_{m}{ }^{2}-k_{\Phi} & -R_{s} L_{r} & -w_{m}{ }^{k} L_{m} L_{r} & R_{r} L_{m}
\end{array}\right) \\
A_{6} & =\left(\begin{array}{cccc}
L_{r} & 0 & -L_{m} & 0 \\
0 & L_{r} & 0 & -L_{m}
\end{array}\right)
\end{aligned}
$$

By combining (3-43) with (3-42) and (3-41), the direct and quadrature stator currents at the next sampling instant in derived [89]:

$$
\left(\begin{array}{c}
I_{d s}{ }^{k+1} \\
I_{q s}{ }^{k+1}
\end{array}\right)=A_{7}\left(\begin{array}{c}
I_{d s}{ }^{k} \\
I_{q s}{ }^{k} \\
I_{d r}{ }^{k} \\
I_{q r}{ }^{k}
\end{array}\right)+A_{8}\left(\begin{array}{c}
V_{d s}{ }^{k} \\
V_{q s}{ }^{k} \\
V_{d r}{ }^{k} \\
V_{q r}{ }^{k}
\end{array}\right)
$$


Where:

$$
\begin{aligned}
A_{7} & =\left(\begin{array}{cccc}
1-R_{s} L_{r} T_{s} & w_{m}{ }^{k} L_{m}{ }^{2} T_{s}+k_{\Phi} & R_{r} L_{m} T_{s} & w_{m}{ }^{k} L_{m} L_{r} T_{s} \\
-w_{m}{ }^{k} L_{m}{ }^{2} T_{s}-k_{\Phi} & 1-R_{s} L_{r} T_{s} & -w_{m}{ }^{k} L_{m} L_{r} T_{s} & R_{r} L_{m} T_{s}
\end{array}\right) \\
A_{8} & =\left(\begin{array}{cccc}
L_{r} T_{s} & 0 & -L_{m} T_{s} & 0 \\
0 & L_{r} T_{s} & 0 & -L_{m} T_{s}
\end{array}\right)
\end{aligned}
$$

The rotor flux at the next sampling instant is given by [93]:

$$
\begin{aligned}
& \Phi_{d r}{ }^{k+1}=\Phi_{d r}{ }^{k}+T_{s}\left(\frac{d}{d t} \Phi_{d r}{ }^{k}\right) \\
& \Phi_{q r}{ }^{k+1}=\Phi_{d r}{ }^{k}+T_{s}\left(\frac{d}{d t} \Phi_{q r}{ }^{k}\right)
\end{aligned}
$$

The change in rotor flux can be defined as [89]:

$$
\left(\begin{array}{l}
\frac{d}{d t} \Phi_{d r}{ }^{k} \\
\frac{d}{d t} \Phi_{q r}{ }^{k}
\end{array}\right)=A_{9}\left(\begin{array}{c}
I_{d s}{ }^{k} \\
I_{q s}{ }^{k} \\
\Phi_{d r}{ }^{k} \\
\Phi_{q r}{ }^{k}
\end{array}\right)+A_{10}\left(\begin{array}{c}
V_{d s}{ }^{k} \\
V_{q s}{ }^{k} \\
V_{d r}{ }^{k} \\
V_{q r}{ }^{k}
\end{array}\right)
$$

Where:

$$
\begin{aligned}
& A_{9}=\left(\begin{array}{cccc}
\frac{L_{m}}{T_{r}} & 0 & -\frac{1}{T_{\sigma}} & w_{r}{ }^{k} \\
0 & \frac{L_{m}}{T_{r}} & -w_{r}{ }^{k} & -\frac{1}{T_{r}}
\end{array}\right) \\
& A_{10}=\left(\begin{array}{llll}
0 & 0 & 1 & 0 \\
0 & 0 & 0 & 1
\end{array}\right)
\end{aligned}
$$

Where:

- $T_{r}=\frac{L_{r}}{R_{r}}$

- $T_{r}=\frac{\sigma L_{s}}{R_{\sigma}}$

- $R_{\sigma}=R_{s}+k_{r}{ }^{2} R_{r}$

- $k_{r}=\frac{L_{m}}{L_{r}}$

Combining (3-47) with (3-45) and (3-46), the following is derived [93]:

$$
\left(\begin{array}{c}
\Phi_{d r}{ }^{k+1} \\
\Phi_{q r}{ }^{k+1}
\end{array}\right)=A_{11}\left(\begin{array}{c}
i_{d s}{ }^{k} \\
i_{q s}{ }^{k} \\
\Phi_{d r}{ }^{k} \\
\Phi_{q r}{ }^{k}
\end{array}\right)+A_{12}\left(\begin{array}{c}
V_{d s}{ }^{k} \\
V_{q s}{ }^{k} \\
V_{d r}{ }^{k} \\
V_{q r}{ }^{k}
\end{array}\right)
$$


Where:

$$
\begin{aligned}
A_{11} & =\left(\begin{array}{cccc}
\frac{L_{m} T_{s}}{T_{r}} & 0 & 1-\frac{T_{s}}{T_{\sigma}} & T_{s} w_{r}{ }^{k} \\
0 & \frac{L_{m} T_{s}}{T_{r}} & -T_{s} w_{r}{ }^{k} & 1-\frac{T_{s}}{T_{\sigma}}
\end{array}\right) \\
A_{12} & =\left(\begin{array}{cccc}
0 & 0 & T_{S} & 0 \\
0 & 0 & 0 & T_{s}
\end{array}\right)
\end{aligned}
$$

Equations (3-44) and (3-48) form the basis for MPDTC. The algorithm presented in figure 39 can be followed to execute MPDTC, with now the next state variables being the rotor flux and electromagnetic torque. The control structure of MPDTC using FCS-MPC can be seen in figure 3-10 [96].

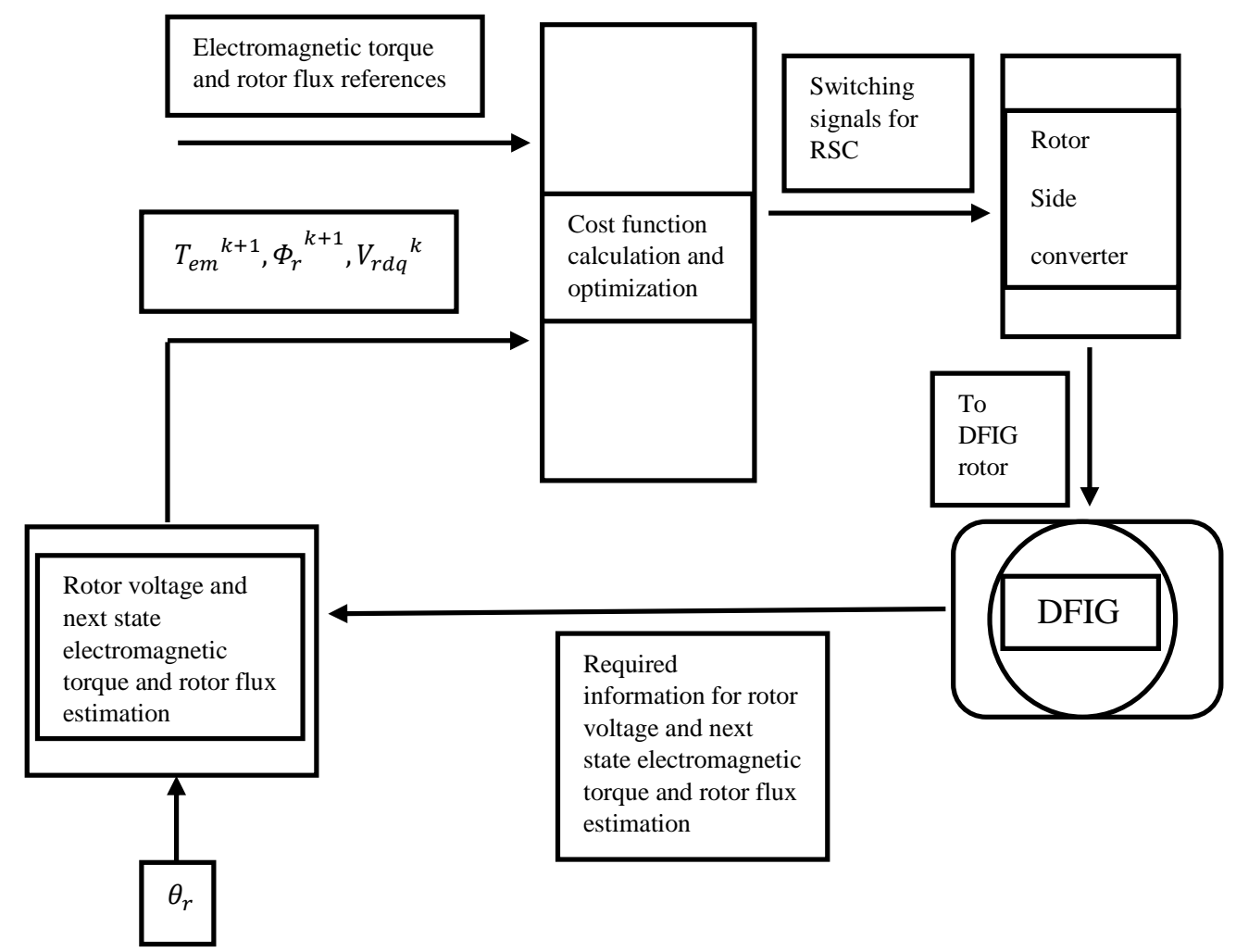

Figure 3-10: Control structure of MPDTC using FCS-MPC [96]

\subsection{Model predictive direct power control}

MPDPC is similar to DPC-ST in that the stator reactive and active powers are directly controlled. From the direct and quadrature stator power equations shown in chapter 2, as well as the electromagnetic torque equation shown in $(3-40)$, it is be seen that the stator powers are 
dependent on the stator direct and quadrature currents. Hence the stator powers at the next sampling instant is dependent on the stator direct and quadrature currents at the next sampling instant. Like the other predictive control techniques discussed, the slip angle is required. The stator direct and quadrature currents at the next sampling instant are shown in 3.6. The slip angle can be extracted as outlined in 3.1. The algorithm outlined in figure 3-9 can be used to execute MPDPC, with now the next state variables being the stator reactive and active powers. The control structure of MPDPC using FCS-MPC can be seen in figure 3-11 [97].

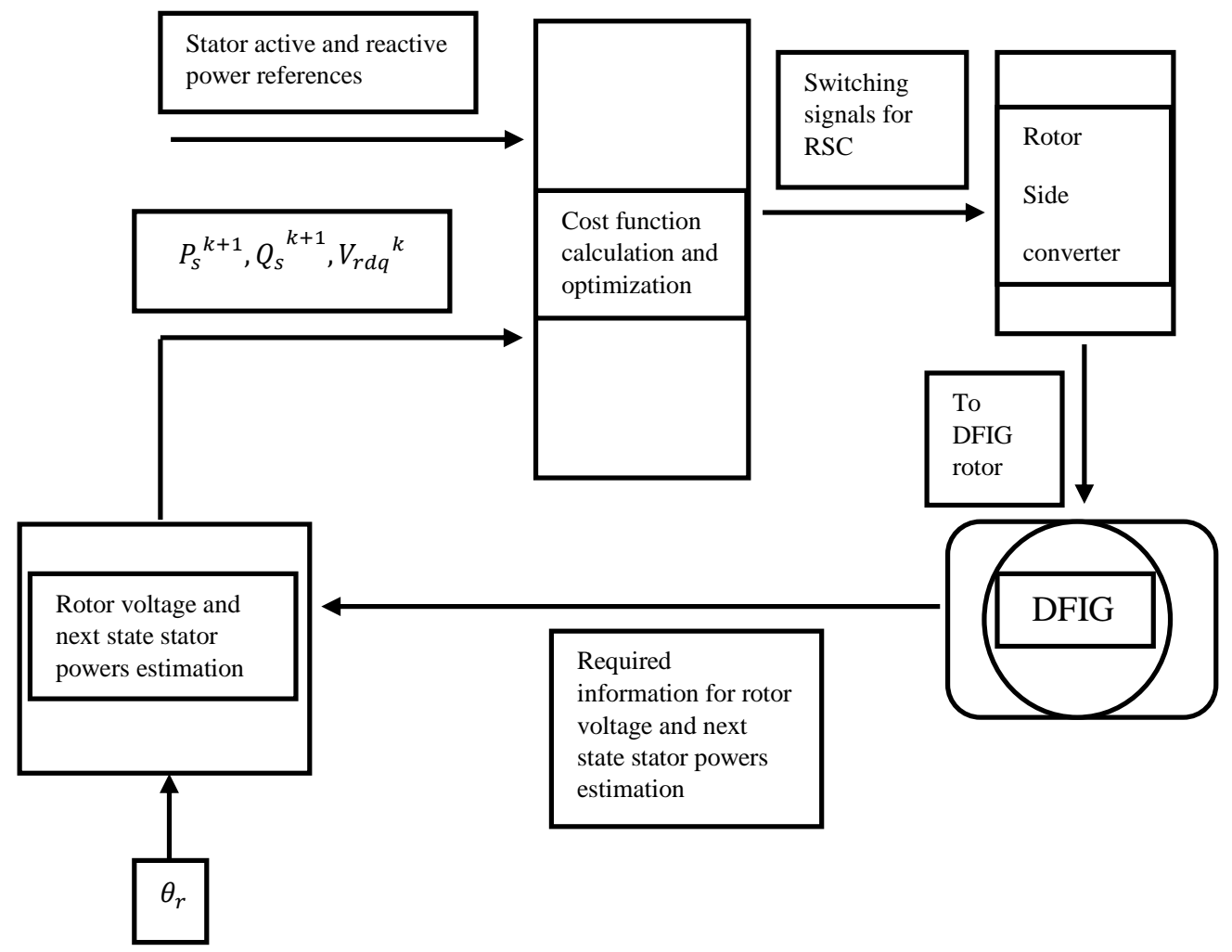

Figure 3-11: Control structure of MPDPC using FCS-MPC [97]

An outline of the research method followed in shown in figure 3-12. First, all four conventional control algorithms (FOC, DTC-ST, DTC-SVPWM and DPC-ST) will be implemented and analysed individually. These control algorithms will then be compared to each other in terms of state and dynamic performance, quality of output and control requirements. Then, the three MPC algorithms (MPCC, MPDTC and MPDPC) will be implemented and analysed individually. These control algorithms will then be compared to each other in terms of steady state and dynamic performance, quality of output and control requirements. Lastly, the relevant conventional and MPC control algorithms will be compared to each other in terms of steady state and dynamic response, quality of output and control requirements. 


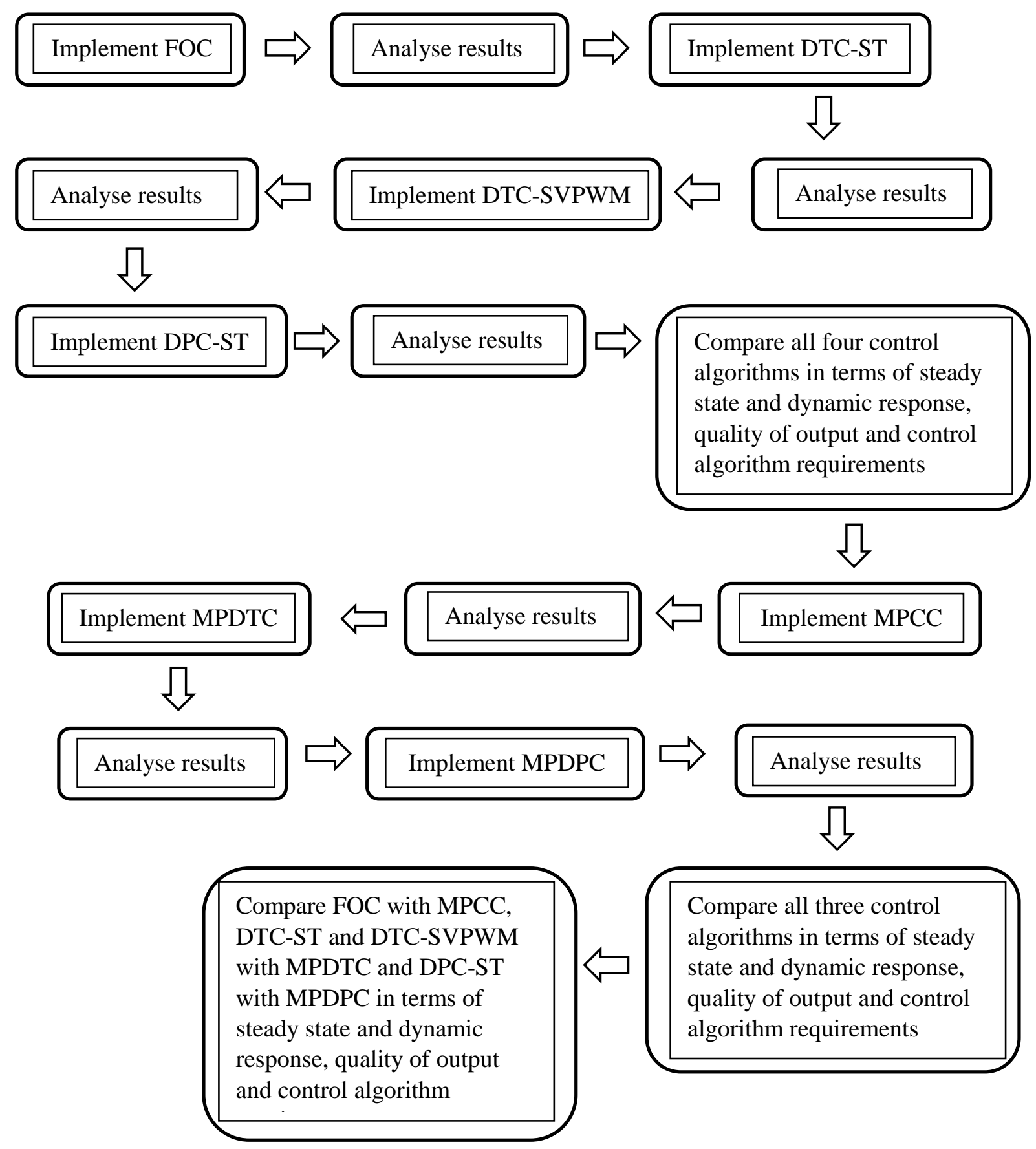

Figure 3-12: Flow chart of research method

\subsection{Conclusion}

This chapter provided the methodology of the various control methods which are used in the control of the DFIG. Each of the four conventional control methods and three MPC methods were explained in detail. The relevant equations, functional block diagrams and look up tables were all provided. The information provided in this chapter comprehensively describes the relevant control methods and will be used in the subsequent chapters so that these control methods can be critically evaluated. 


\section{Chapter 4: Performance analysis of conventional control methods applied to the doubly fed induction generator}

This chapter serves to evaluate the performance of the various conventional control methods applied to the control of the DFIG. The four conventional control methods are FOC, DTC-ST, DTC-SVPWM and DPC-ST. These control methods were explained in depth in chapter 3, with the relevant formulae and control structures provided. This chapter aims to evaluate the stator power steady state ripple and dynamic response of the four control methods. This chapter also aims to evaluate the stator and rotor currents in terms of distortion and equality of phases. The simulation conditions and control parameters for each control method is provided. The appropriate performance results are provided for each control method, with an analysis of results. The results obtained in this chapter form the basis for creating a comparison between the conventional control methods and control using MPC.

\subsection{Field-oriented control}

FOC provides stator power control directly (indirect FOC) or indirectly (indirect FOC). To allow for a comparison between FOC and MPCC, indirect FOC will be implemented. Furthermore, FOC without power control loop will be examined as it is commonly used and only makes use of two proportional-integral controllers, compared to the four used in FOC with power control loop [27].

The control method was tested by being applied to a 3 MW DFIG and simulated using MATLAB/Simulink. Since only control of the RSC was investigated, the machine was only operated at sub-synchronous speeds. Based on a machine frequency of $60 \mathrm{~Hz}$, the mechanical synchronous speed of the machine is $188.5 \mathrm{rad} / \mathrm{s}$. This means that any speed below this is a sub-synchronous speed. Since the aim was to evaluate the performance of the control method at different rotor speeds, two sub-synchronous speeds were chosen. One was close to the synchronous speed at $185 \mathrm{rad} / \mathrm{s}$ and one was lower than this at $169 \mathrm{rad} / \mathrm{s}$. In order to ensure that the control method had ample time to reach steady state at each rotor speed, each speed was simulated for 6 seconds. For the first 6 seconds, the performance of the control method at the rotor speed of $169 \mathrm{rad} / \mathrm{s}$ was evaluated. A step change from $169 \mathrm{rad} / \mathrm{s}$ to $185 \mathrm{rad} / \mathrm{s}$ was then applied at the 6 second mark and for the next 6 seconds, the performance of the control method at the speed of $185 \mathrm{rad} / \mathrm{s}$ was evaluated. 
A switching frequency of $100 \mathrm{kHz}$ was chosen. This corresponds to a sample time of $10 \mu \mathrm{s}$. SVOC was used to implement the control method, meaning that the rotor direct current was responsible for controlling the stator active power and the rotor quadrature current was responsible for controlling the stator reactive power. In order to provide the required control, the proportional-integral controllers were tuned until the best response is achieved. The optimal torque method for maximum active power extraction was used and an optimal coefficient of $k_{\text {opt }}=0.296$ was used for reference value calculation [167]. This means that the reference stator active power was determined based on the speed of the rotor. The reference stator reactive power was chosen at 0 Var. From this, the respective reference rotor currents were determined. The electromagnetic torque and stator active power were determined using (3-29), (3-30) and (3-40) with the stator reactive power determined using equation (2-45). The machine parameters used in the required calculations and measurements are found in Appendix A, with the relevant formulae and information found in chapter 3 . The performance of the control method is seen in figures 4-1 to 4-7.

Considering figure 4-1, at the lower speed the rotor direct current ripple is $90 \mathrm{~A}$, whereas at the higher speed this greatly decreases to $43.5 \mathrm{~A}$. The electromagnetic torque ripple at the lower and higher speeds are $366.5 \mathrm{~N} \mathrm{~m}$ and $176 \mathrm{~N} \mathrm{~m}$ respectively. This is seen in figure 4-2.

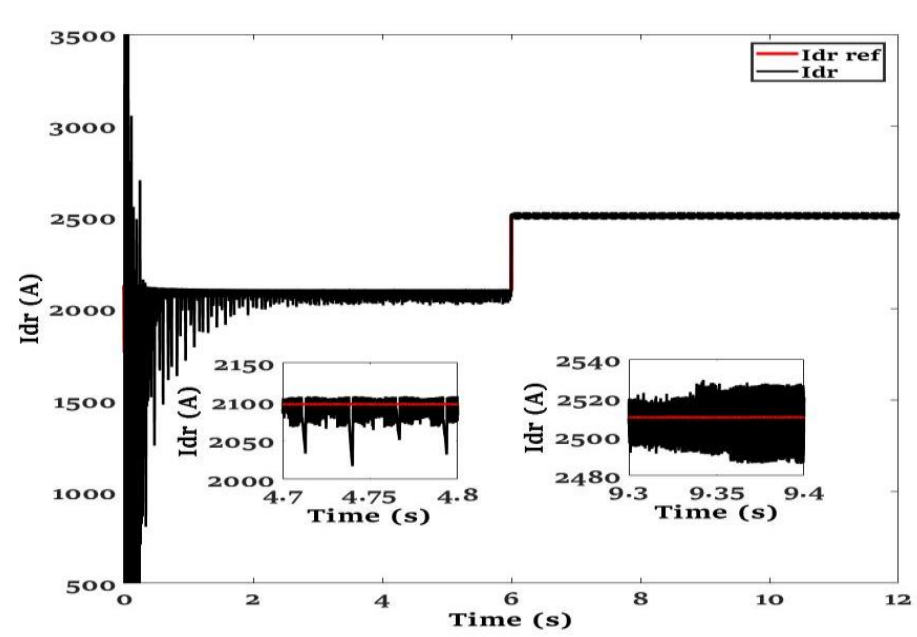

Figure 4-1: Rotor direct current response of FOC

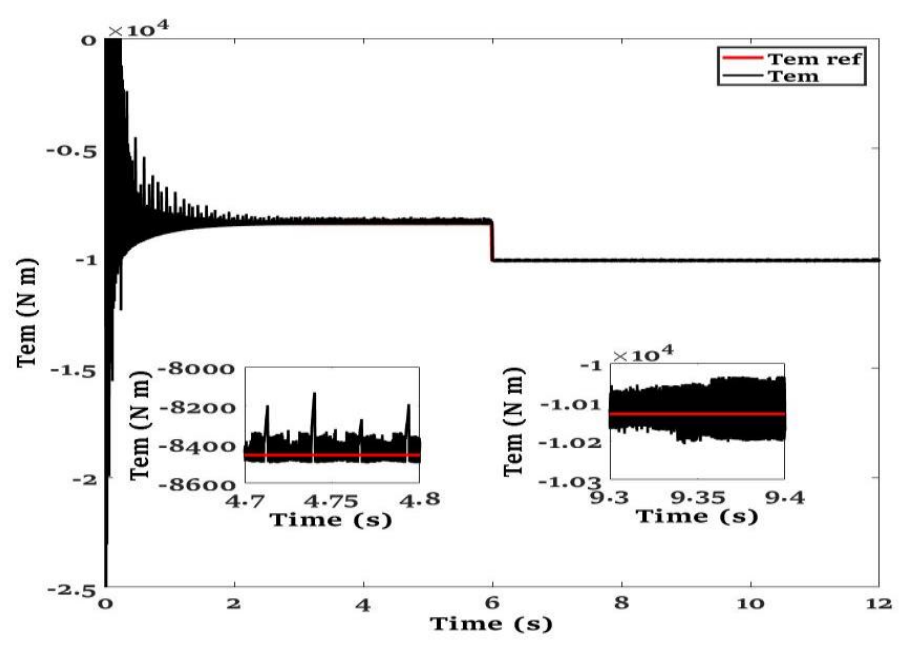

Figure 4-2: Electromagnetic torque response of FOC

Since the stator active power is directly proportional to the electromagnetic torque, an identical phenomenon is observed in figure 4-3, with the ripple being $69.08 \mathrm{~kW}$ and $33.18 \mathrm{~kW}$ at the lower and higher speeds respectively. The stator active power takes $1.44 \mathrm{~ms}$ to reach the next reference value. In figure 4-4, it is seen that the rotor quadrature current ripple at the lower speed is $48.5 \mathrm{~A}$, with this value decreasing to $43 \mathrm{~A}$ at the higher speed 


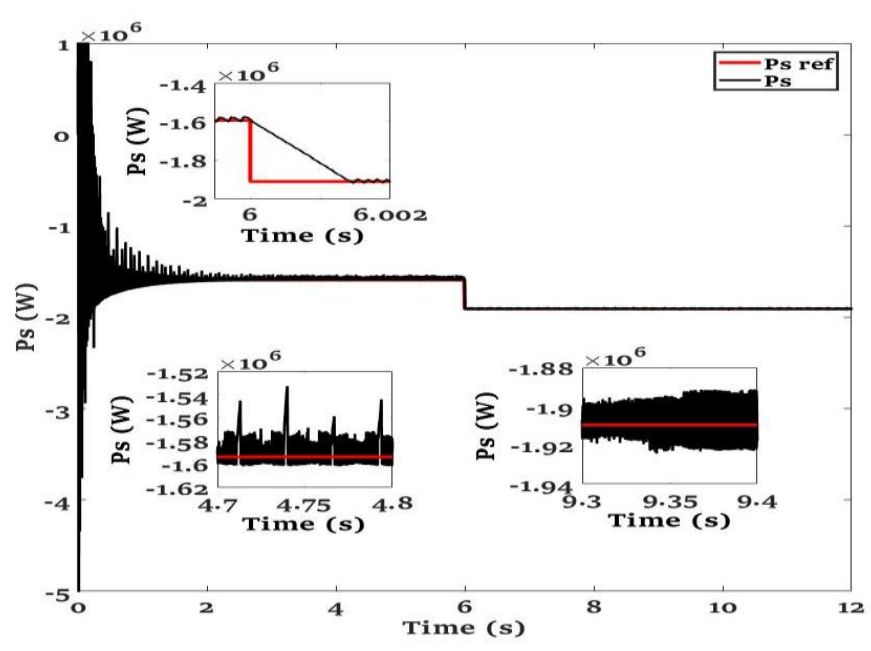

Figure 4-3: Stator active power response of FOC

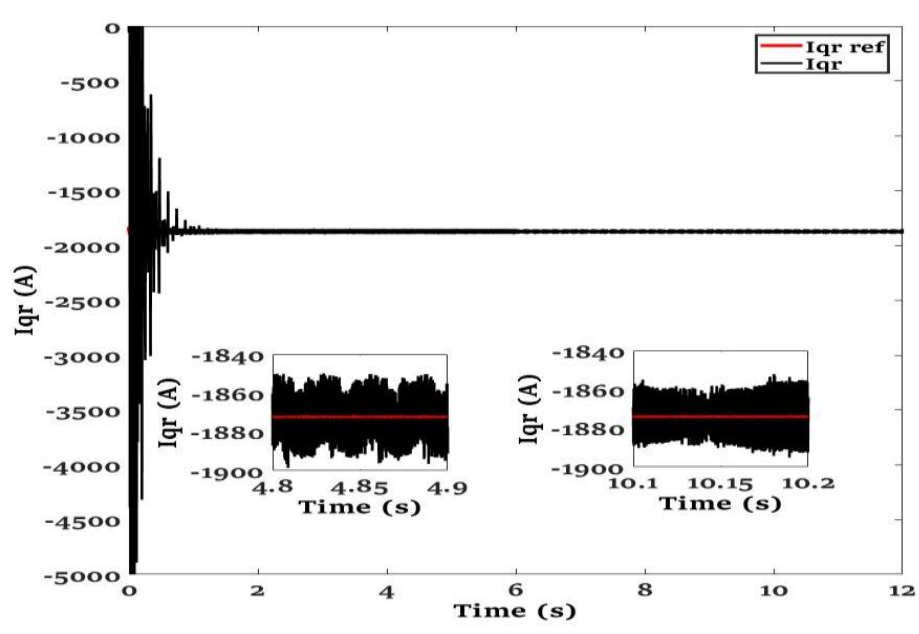

Figure 4-4: Rotor quadrature current response of FOC

Figure 4-5 shows the stator reactive power ripple, with the values of $37 \mathrm{kVAr}$ and $32.6 \mathrm{kVAr}$ occurring at the lower and higher speeds respectively. The three-phase rotor current, shown in figure 4-6, increases in magnitude and decreases in frequency at the higher speed. This is expected, as at the higher speed the slip is lower, and the electromagnetic torque (and stator active power) output is greater than at the lower speed. The rotor current waveform is almost smooth, with only a small amount of distortion occurring at both speeds. The waveform is almost perfectly balanced at both speeds.

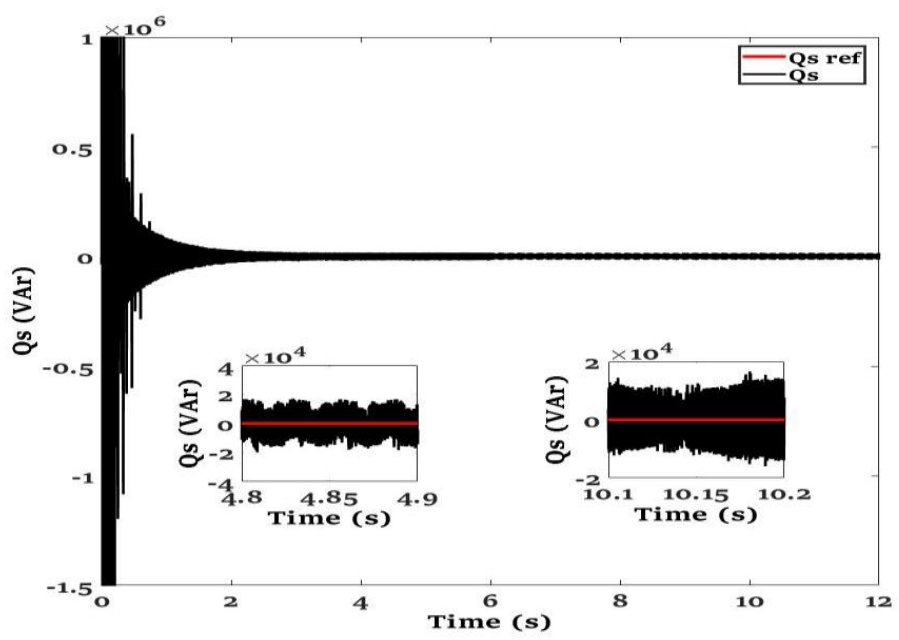

Figure 4-5: Stator reactive power response of FOC

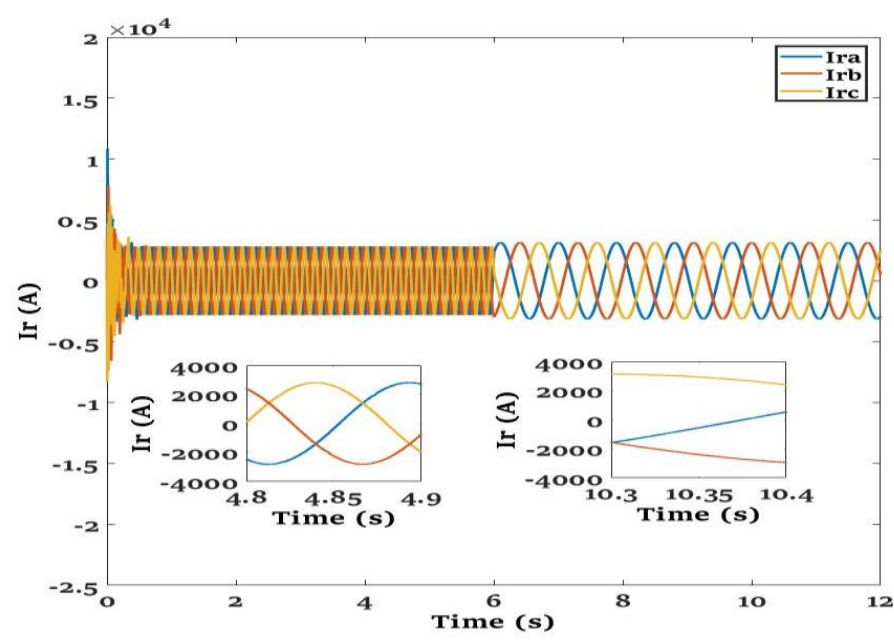

Figure 4-6: Three-phase rotor current response of FOC

The three-phase stator current, shown in figure 4-7, increases in magnitude at the higher speed.

This is also expected, since at the higher speed there is more active power being delivered via 
the stator. The current frequency stays constant and the waveforms are of good quality. At both speeds, only a small amount of distortion and a slight unbalance in waveforms occur.

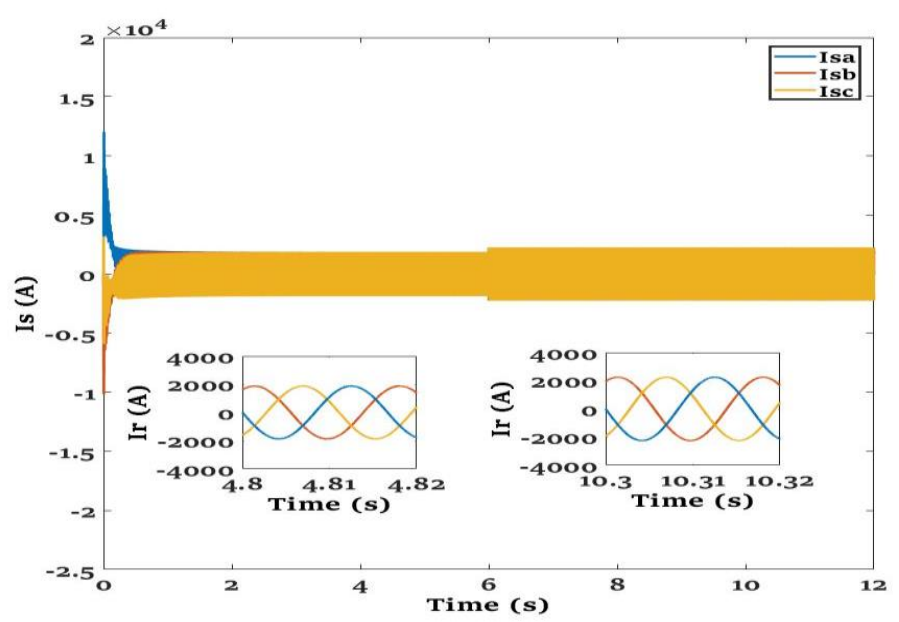

Figure 4-7: Three-phase stator current response of FOC

\subsection{Direct torque control using the switching table}

In 4.1, it was observed that the FOC method provides a strong steady state ripple, acceptable dynamic response, and good quality stator current waveforms. However, it requires a complex procedure which includes decoupling of the system measurements and the fine tuning of proportional-integral controllers. This means that should the generator be replaced with another generator with even slightly different machine parameters; the proportional-integral controllers would need to be tuned again. Also, because the slip angle is required for grid synchronization of the DFIG, accurate knowledge the rotor angle is required. The rotor angle is obtained directly from an encoder or via integration of the rotor electrical speed, which requires a tachometer. Practically, this equipment can provide slight errors in measurements, which can distort the frequency of voltage injected into the grid. Thus, the need for the rotor angle in FOC decreases the reliability of the control method. Although the rotor speed was used in 4.1 to obtain the reference stator power, slight variations are acceptable in this aspect. This however is unacceptable when it comes to the frequency of output. Furthermore, the FOC method requires extraction of the rotor reference currents and the addition of coupling terms at the output of the proportional-integral controllers. This requires accurate measurements of the machine stator resistance and inductance, rotor inductance and mutual inductance. Inaccurate measurements will result in a poor control performance. Practically, measurements of machine parameters such as inductance and resistance include a tolerance. This means that there exists a large possibility that the FOC method will not provide the most accurate 
performance. Hence the need for a control method which is void of all these requirements is required.

This subchapter aims to analyse the performance of the DTC-ST method. As explained earlier, this modulator-void control method directly controls the rotor flux and electromagnetic torque via the use of hysteresis controllers and a look up table. The hysteresis controller comprises of bandwidths, within which the respective variable is expected to be confined. Based on the output of the hysteresis controllers and the position of the rotor flux angle, the appropriate switching vector is applied to the rotor of the machine [28]. The bandwidth values require the machines rated stator active power to be known, but this is usually easily and accurately achieved. Also, should the generator be changed, only a small adjustment of bandwidth size needs to be changed. This is a huge advantage over the FOC method. Furthermore, since knowledge of the rotor angle is not required, the reliability of the control method is increased. In the FOC method, the rotor inductance and resistance, rotor inductance and resistance and mutual inductance was required. DTC-ST only requires two parameters; the stator resistance for calculation of the electromagnetic torque (like in 4.1) and the rotor resistance for calculation of the rotor flux. This reduction is parameter dependency will further increase the reliability of the control method. Furthermore, in large machines, the resistance values become so small that variations in their values have a negligible effect on the performance of the control method. This further increases the reliability of DTC-ST.

The control method was tested by being applied to a 3 MW DFIG and simulated using MATLAB/Simulink. Since only control of the RSC was investigated, the machine was only operated at sub-synchronous speeds. Since the aim was to evaluate the performance of the control method at different rotor speeds, two sub-synchronous speeds were chosen. One was close to the synchronous speed at $185 \mathrm{rad} / \mathrm{s}$ and one was lower than this at $169 \mathrm{rad} / \mathrm{s}$. In order to ensure that the control method had ample time to reach steady state at each rotor speed, each speed was simulated for 6 seconds. For the first 6 seconds, the performance of the control method at the rotor speed of $169 \mathrm{rad} / \mathrm{s}$ was evaluated. A step change from $169 \mathrm{rad} / \mathrm{s}$ to 185 $\mathrm{rad} / \mathrm{s}$ was then applied at the 6 second mark and for the next 6 seconds, the performance of the control method at the speed of $185 \mathrm{rad} / \mathrm{s}$ was evaluated.

The sample time was set at $10 \mu \mathrm{s}$. The optimal torque method for maximum active power extraction was used and an optimal co-efficient of $k_{\text {opt }}=0.296$ was used for reference value calculation [167]. This means that the electromagnetic torque reference was determined based on the speed of the rotor. The rotor flux reference was kept constant at a value equal to the approximate value of the stator flux. This is shown in Appendix A. The bandwidth of the electromagnetic torque was defined as $17 \%$ of the machines rated torque. The bandwidth of 
the rotor flux was defined as $5.5 \%$ of the reference rotor flux. The referemce stator reactive power was chosen as $0 \mathrm{VAr}$. The electromagnetic torque, stator reactive power and stator active power are measured as in 4.1, with the rotor flux being measured according to (327).The machine parameters used in the required calculations and measurements are found in Appendix A, with the relevant formulae and information found in chapter 3. The performance of DTC-ST can be seen in figures 4-8 to 4-13.

In figure 4-8, it is shown that the electromagnetic torque is almost perfectly kept within its bandwidth at both speeds with only a small deviation. At the lower speed, there exists small periodic spikes, but they cease to exist at the higher speed. It is also observed that the frequency of torque ripple decreases at the higher speed. Figure 4-9 shows the stator active power, which produces an identical pattern to figure 4-8. The stator active power takes $0.94 \mathrm{~ms}$ to reach the next reference value.

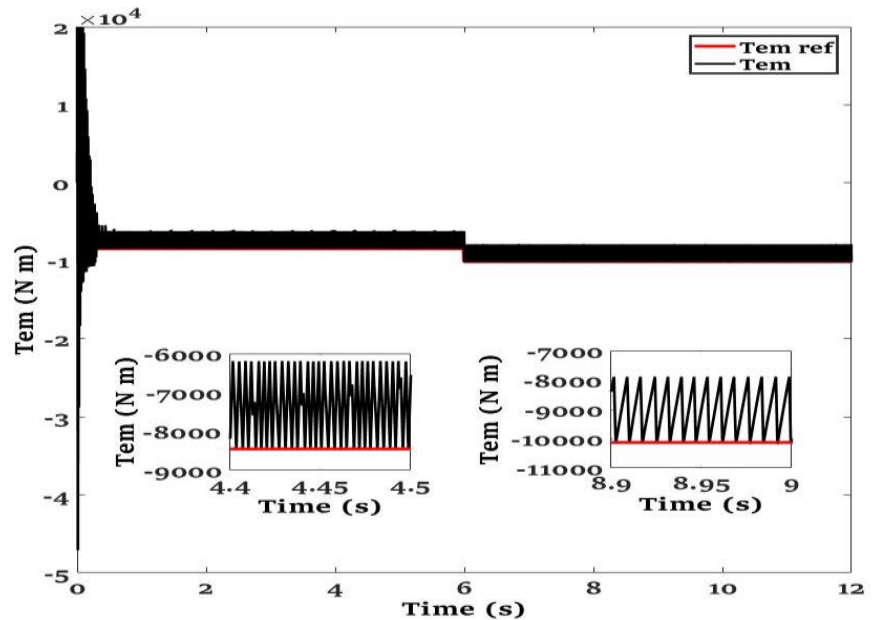

Figure 4-8: Electromagnetic torque response of DTC-ST

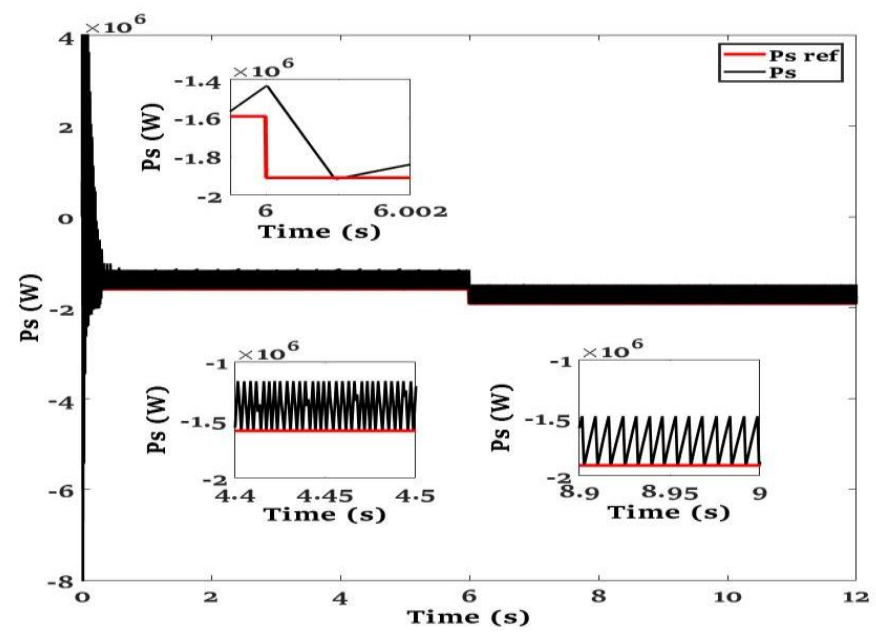

Figure 4-9: Stator active power response of DTC-ST

In figure 4-10, it is seen that the rotor flux is well kept within the specified bandwidth at both speeds. It is also observed that the frequency of flux ripple decreases at the higher speed. Figure 4-11 shows the stator reactive power, which strongly deviates from the reference value. This is expected, as no direct reactive power control measures were taken. 


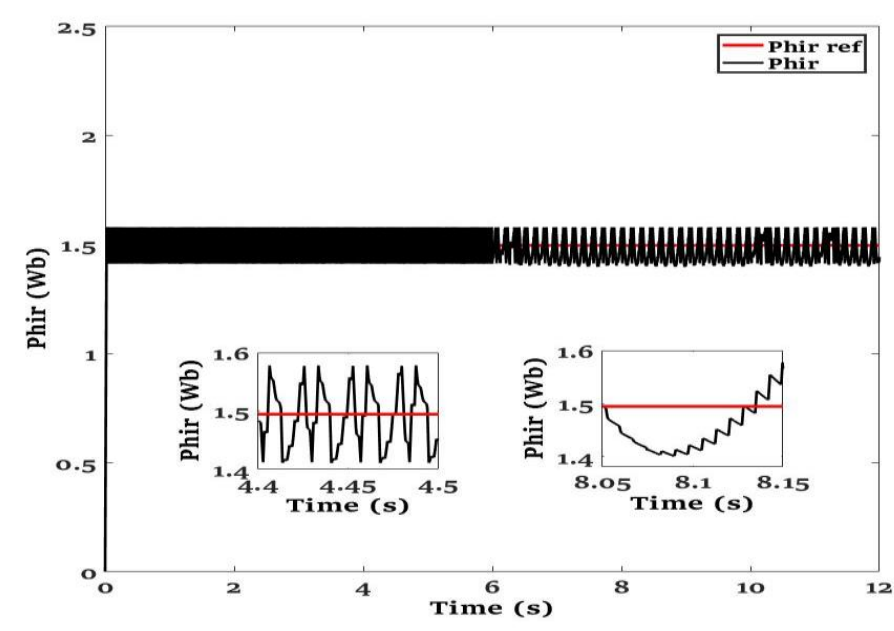

Figure 4-10: Rotor flux response of DTC-ST

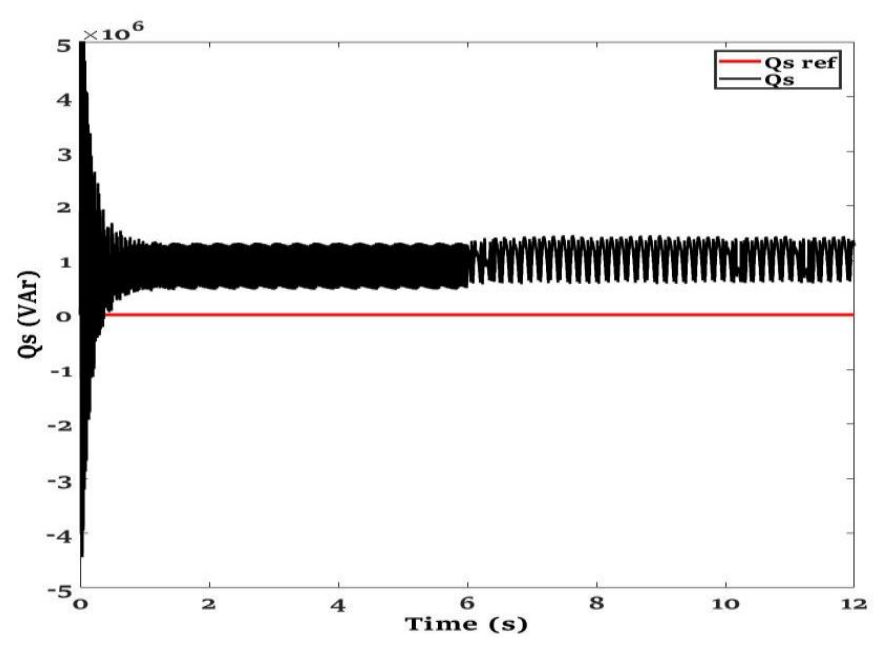

Figure 4-11: Stator reactive power response of DTC-ST

The three-phase rotor current, shown in figure 4-12, follows the expected shape, but is distorted at both speeds. However, the distortion improves at the higher speed. There also exists a slight unbalance at both speeds. In the three-phase stator current shown in figure 4-13, it is observed that at both speeds there is substantial distortion, but this improves at the higher speed. Furthermore, at both speeds, there exists a strong waveform unbalance.

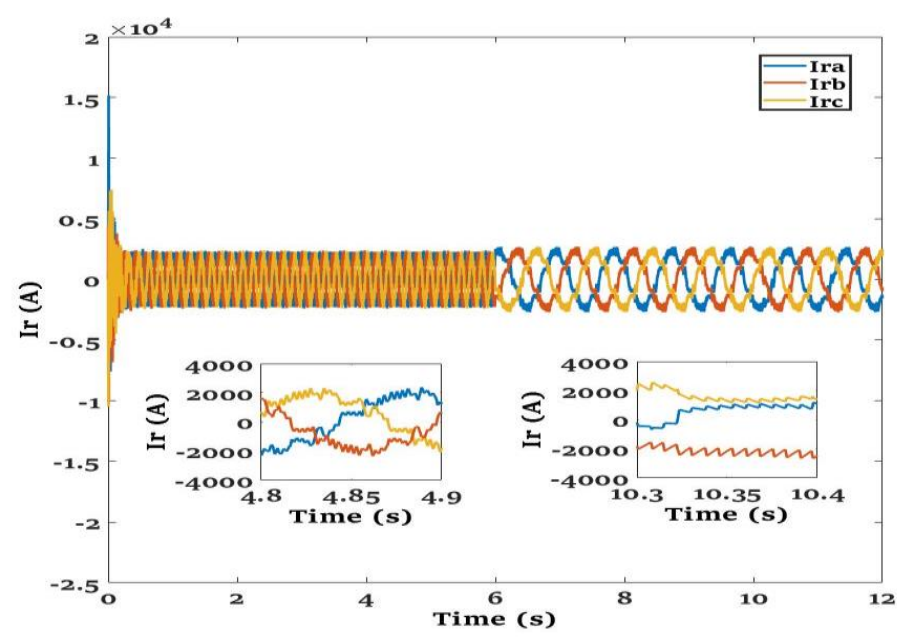

Figure 4-12: Three-phase rotor current response of DTC-ST

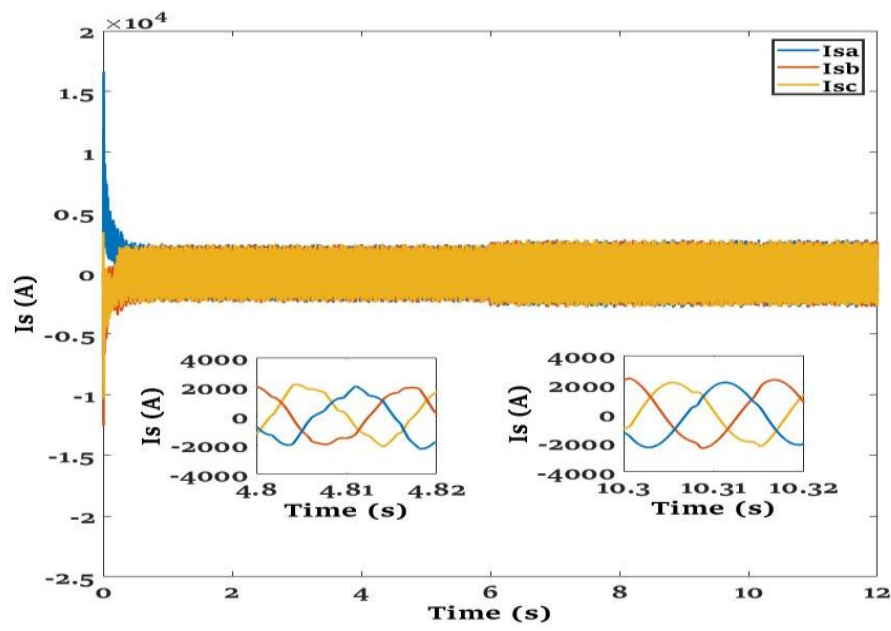

Figure 4-13: Three-phase stator current response of DTC-ST

\subsection{Direct torque control using space vector pulse width modulation}

In 4.2, it was shown that DTC-ST was successful in confining the electromagnetic torque and rotor flux within its respective bandwidths, whilst providing a strong dynamic response. 
However, because of the practicality of the system, the bandwidths were large hence the rotor flux and electromagnetic torque ripple was large. Furthermore, the stator current was highly distorted. These are highly undesirable traits and the need to eliminate these forms the basis of the DTC-SVPWM control method, which will be analysed in this subchapter. This control method, which is an alternative to the DTC-ST method, also directly controls the electromagnetic torque and rotor flux. However, instead of hysteresis controllers and a look up table, it makes use of proportional-integral controllers and a modulator. It is like the FOC method but directly regulates the electromagnetic torque and rotor flux. Like DTC-ST, only the stator and rotor resistance values are required. However, due to the use of proportionalintegral controllers, the complexity increases, and the control method becomes generator specific. Furthermore, due to the requirement of the slip angle, accurate rotor angle knowledge is required [90].

The control method was tested by being applied to a 3 MW DFIG and simulated using MATLAB/Simulink. Since only control of the RSC was investigated, the machine was only operated at sub-synchronous speeds. Since the aim was to evaluate the performance of the control method at different rotor speeds, two sub-synchronous speeds were chosen. One was close to the synchronous speed at $185 \mathrm{rad} / \mathrm{s}$ and one was lower than this at $169 \mathrm{rad} / \mathrm{s}$. In order to ensure that the control method had ample time to reach steady state at each rotor speed, each speed was simulated for 6 seconds. For the first 6 seconds, the performance of the control method at the rotor speed of $169 \mathrm{rad} / \mathrm{s}$ was evaluated. A step change from $169 \mathrm{rad} / \mathrm{s}$ to 185 $\mathrm{rad} / \mathrm{s}$ was then applied at the 6 second mark and for the next 6 seconds, the performance of the control method at the speed of $185 \mathrm{rad} / \mathrm{s}$ was evaluated.

The sample time was set at $10 \mu \mathrm{s}$, with the switching frequency at $100 \mathrm{kHz}$. The slip angle was extracted by aligning the stator voltage with the direct axis, meaning that the rotor direct voltage controls the electromagnetic torque whereas the rotor quadrature voltage controls the rotor flux. Had the stator flux been aligned with the direct axis, the rotor direct voltage would have controlled the rotor flux and the quadrature rotor voltage would have controlled the electromagnetic torque. The optimal torque method for maximum active power extraction was used and an optimal co-efficient of $k_{\text {opt }}=0.296$ was used for reference value calculation [167]. This means that the reference electromagnetic torque was determined based on the speed of the rotor. The rotor flux reference was kept constant throughout the experiment at a value equal to the approximate value of the stator flux. This is shown in Appendix A. The proportional-integral controllers were tuned until the best response was achieved. The reference stator reactive power was chosen as 0 Var. All measurements are as 4.2. The machine parameters used in the required calculations are found in Appendix A, with the relevant 
formulae and information found in chapter 3. The performance of DTC-SVPWM is seen in figures 4-14 to 4-19.

In figure 4-14, it is seen that the electromagnetic torque ripple at the lower and higher speeds are $184 \mathrm{~N} \mathrm{~m}$ and $172 \mathrm{~N}$ m respectively. As expected, the same pattern is observed in the stator active power shown in figure 4-15, with the ripple at $34.68 \mathrm{~kW}$ and $32.42 \mathrm{~kW}$ at the lower and higher speeds respectively. It is also observed that the stator active power takes $1.13 \mathrm{~ms}$ to reach the next reference value.

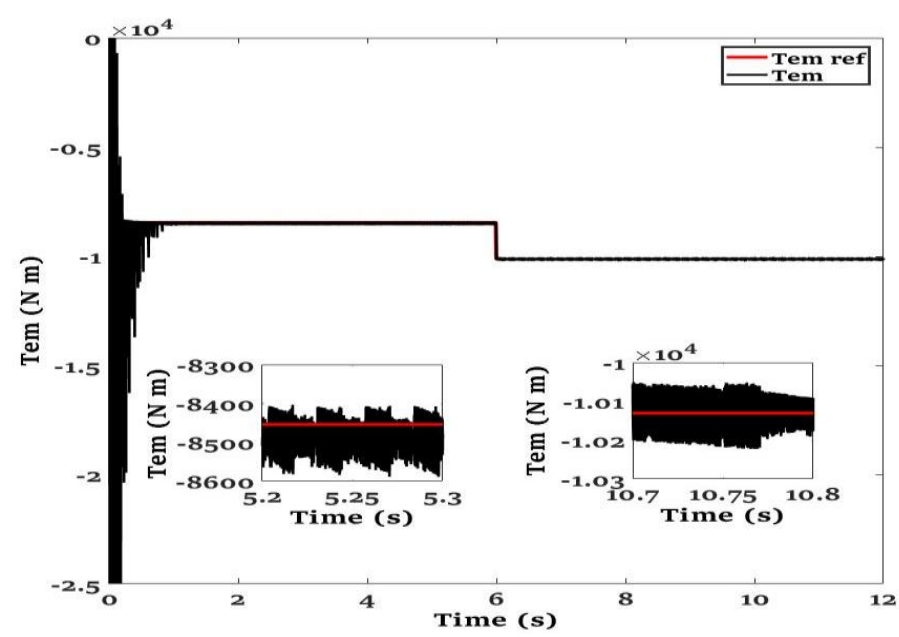

Figure 4-14: Electromagnetic torque response of DTC-SVPWM

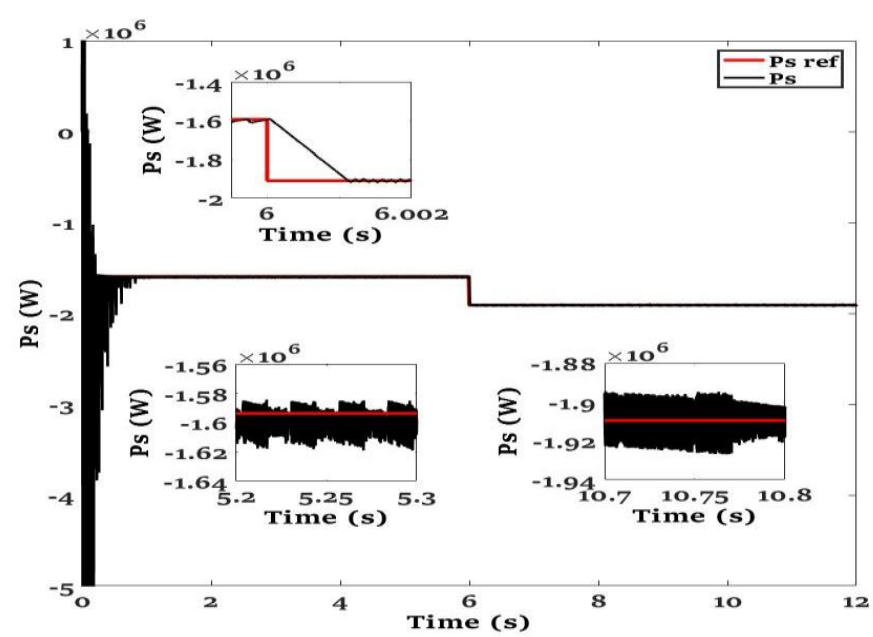

Figure 4-15: Stator active power response of DTC-SVPWM

Considering the rotor flux shown in figure $4-16$, the flux ripple is $8.5 \mathrm{mWb}$ at the lower speed and $8.1 \mathrm{mWb}$ at the higher speed. The stator reactive power, shown in figure $4-17$, strongly deviates from the reference value. This is once again because there is no direct stator reactive power control.

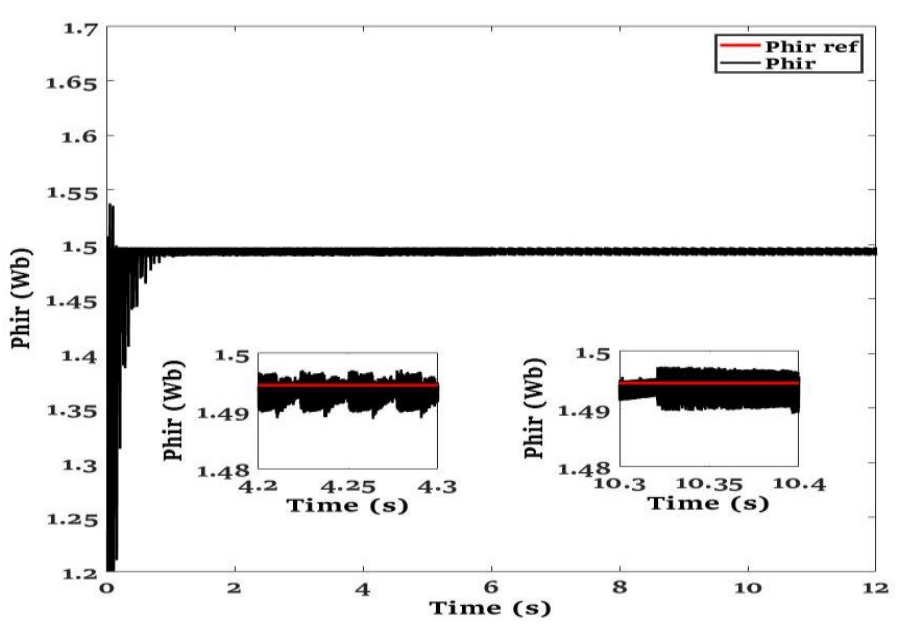

Figure 4-16: Rotor flux response of DTC-SVPWM

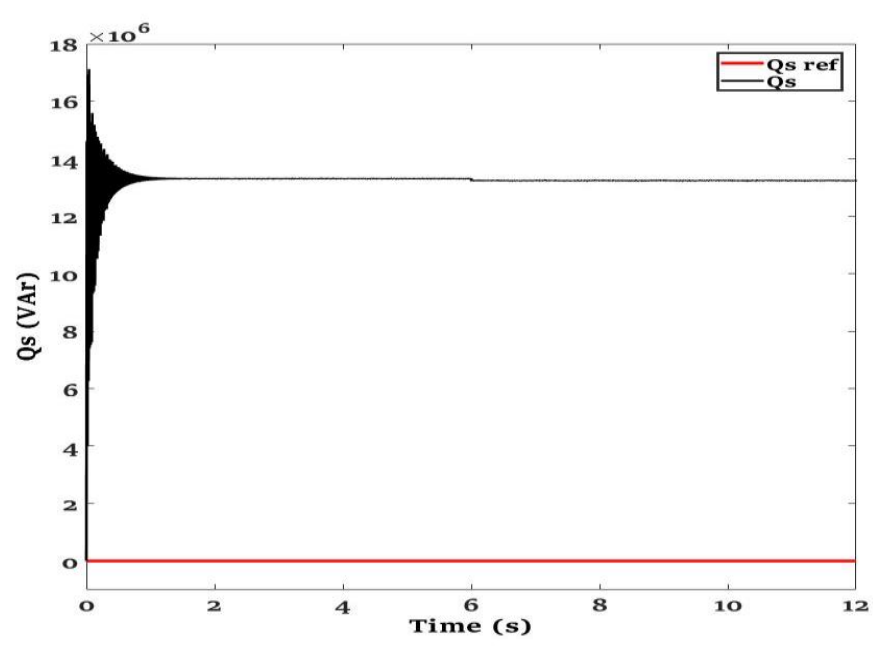

Figure 4-17: Stator reactive power response of DTC-SVPWM 
The three-phase rotor current, shown in figure 4-18, follows the expected trajectory. Furthermore, the waveforms are almost perfectly balanced and contain only a minute amount of distortion. This is at both speeds. The three-phase stator current, shown in figure 4-19, is of good quality. At both speeds, only a small amount of distortion and a slight unbalance in waveforms occur.

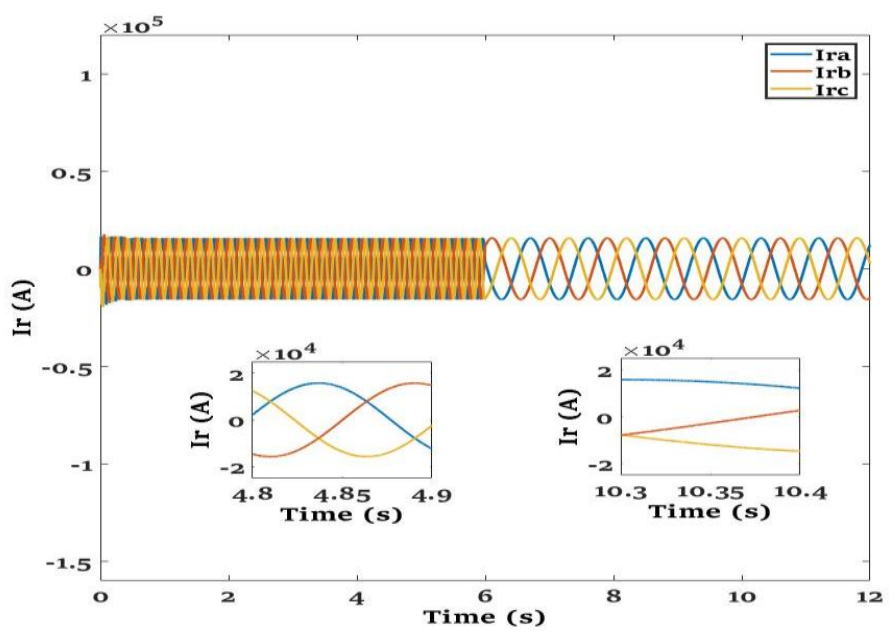

Figure 4-18: Three-phase rotor current response of DTC-SVPWM

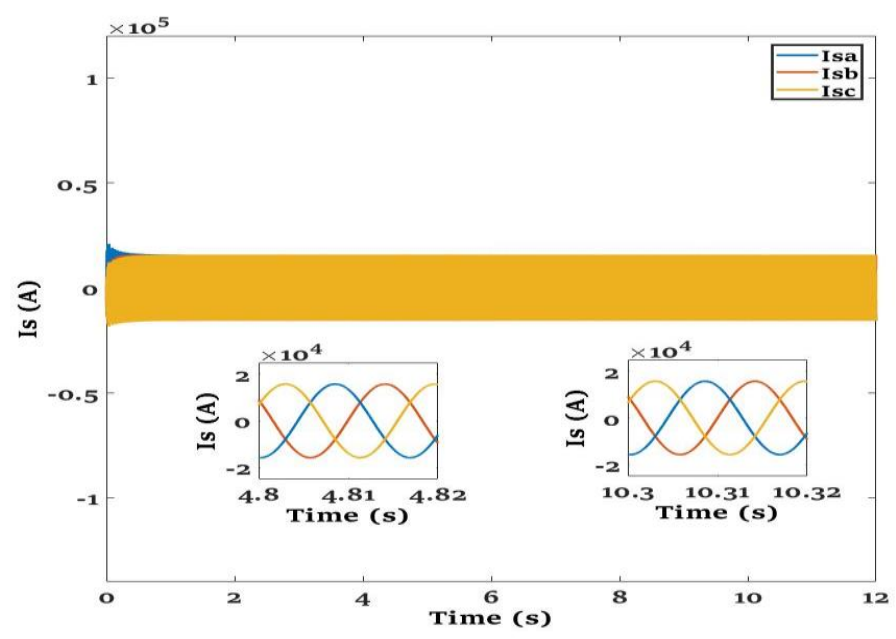

Figure 4-19: Three-phase stator current response of DTC-SVPWM

\subsection{Direct power control using the switching table}

The control methods evaluated in 4.2 and 4.3 showed that whilst the DTC techniques provided a good control response, there existed no reactive power control. Reactive power control is a critical component in an electrical system, as it is responsible for regulating the voltage in such system. During a fault when the grid voltage becomes low, reactive power needs to be injected into the system in order to maintain the grid voltage at an acceptable level. Similarly, when the grid voltage becomes too high, reactive power needs to be absorbed [7], [143]. The identification of the reactive power control deficiency of the DTC methods paved the way for a new control method, which will be discussed in this subchapter. This is the DPC-ST method. This method is almost identical to its torque counterpart evaluated in 4.2 , with the difference being that now the stator reactive and active powers are directly controlled. The aim of such control method is to maintain the advantages of DTC-ST, but also provide the critical stator reactive power control. DPC-ST has a distinct advantage over the three control methods already discussed in that only the stator resistance is required. This is for estimation of the electromagnetic torque and stator flux position. However, since the stator flux position is required in the rotor reference frame, accurate rotor angle information is required (for extraction of the slip angle) [29]. 
The control method was tested by being applied to a 3 MW DFIG and simulated using MATLAB/Simulink. Since only control of the RSC was investigated, the machine was only operated at sub-synchronous speeds. Since the aim was to evaluate the performance of the control method at different rotor speeds, two sub synchronous speeds were chosen. One was close to the synchronous speed at $185 \mathrm{rad} / \mathrm{s}$ and one was lower than this at $169 \mathrm{rad} / \mathrm{s}$. In order to ensure that the control method had ample time to reach steady state at each rotor speed, each speed was simulated for 6 seconds. For the first 6 seconds, the performance of the control method at the rotor speed of $169 \mathrm{rad} / \mathrm{s}$ was evaluated. A step change from $169 \mathrm{rad} / \mathrm{s}$ to 185 $\mathrm{rad} / \mathrm{s}$ was then applied at the 6 second mark and for the next 6 seconds, the performance of the control method at the speed of $185 \mathrm{rad} / \mathrm{s}$ was evaluated.

The sample time was set at $10 \mu \mathrm{s}$. The optimal torque method for maximum active power extraction was used and an optimal co-efficient of $k_{\text {opt }}=0.296$ was used for reference value calculation [167]. This means that the stator active power reference was determined based on the speed of the rotor. The reference stator reactive power was kept constant at 0 Var. The bandwidth of the stator active power was defined as $17 \%$ of the machines rated stator active power. The bandwidth of the stator reactive power was adjusted until an acceptable performance was achieved, which occurred at a bandwidth of $24.2 \%$ of the machines rated stator active power. All measurements were taken as in 4.1. The machine parameters used in the required calculations are found in Appendix A, with the relevant formulae and information found in chapter 3. The performance of the DPC-ST control method can be seen in figures 420 to $4-24$.

Considering the electromagnetic torque shown in figure 4-20, it is observed that the torque ripple is almost perfectly kept within its bounds with only a slight deviation. This is true at both rotor speed values. It is also observed that the frequency of torque ripple decreases at the higher speed. As expected, an identical response is seen in the stator active power which is shown in figure 4-21. The stator active power takes $1.15 \mathrm{~ms}$ to reach the next reference value. 


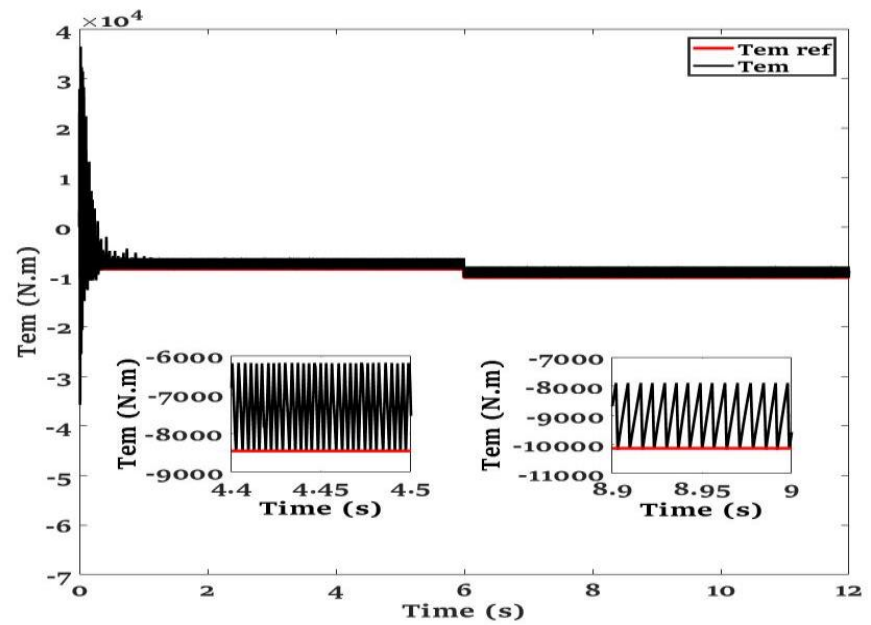

Figure 4-20: Electromagnetic torque response of DPC-ST

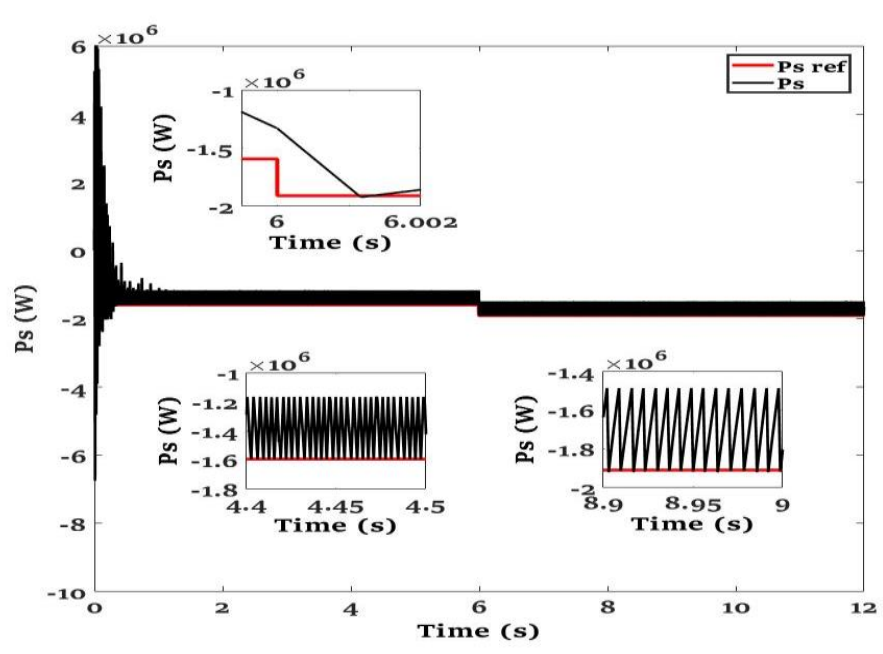

Figure 4-21: Stator active power response of DPC-ST

Figure 4-22 shows the stator reactive power, which is also kept within its bandwidth at both speeds. It is also observed that the frequency of stator reactive power ripple decreases at the higher speed. The three-phase rotor current, shown in figure 4-23, follows the expected trajectory but contains a large amount of distortion. This distortion stays constant irrespective of the change in rotor speed. Furthermore, there exists a small unbalance at both speeds.

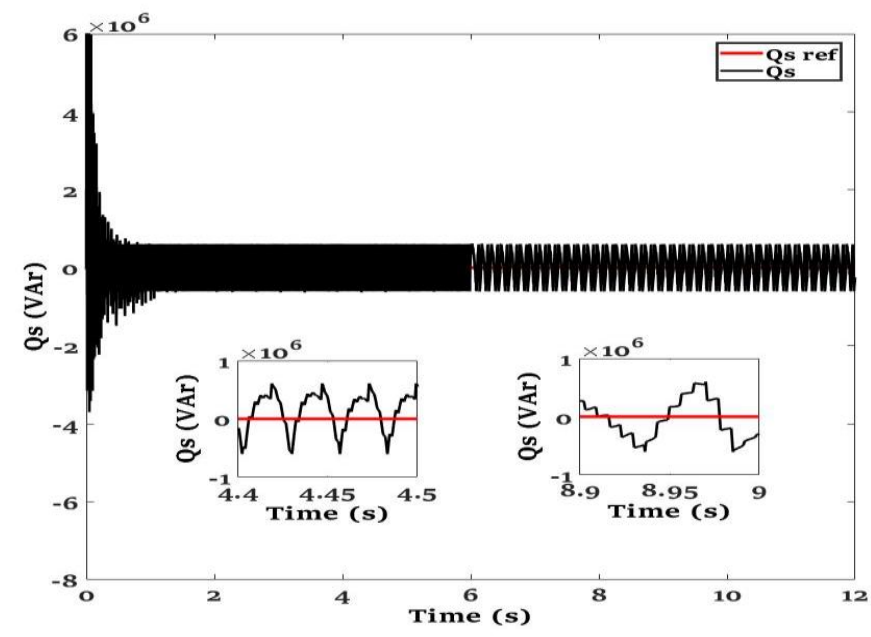

Figure 4-22: Stator reactive power response of DPC-ST

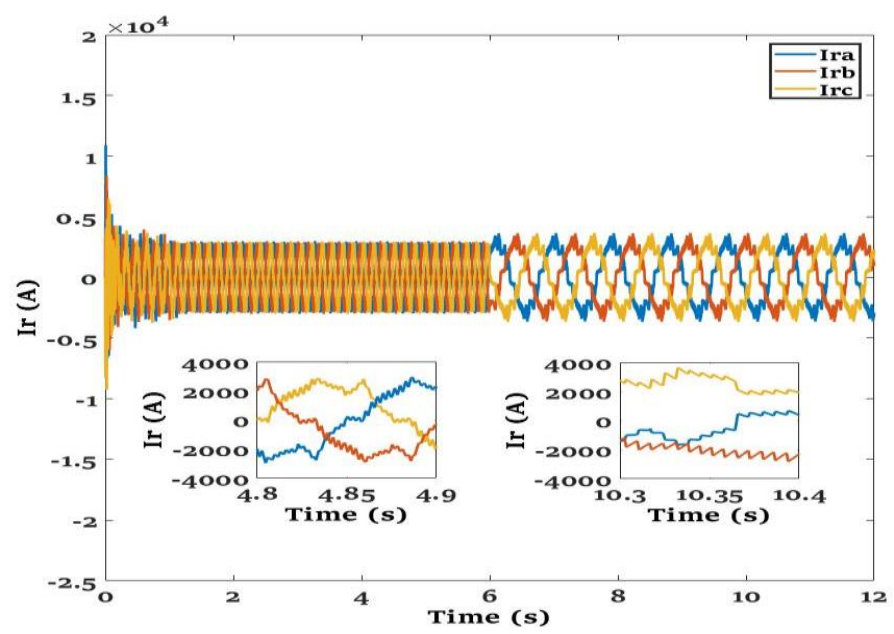

Figure 4-23: Three-phase rotor current response of DPC-ST

The stator current, shown in figure 4-24, contains a substantial amount of distortion at both speeds. However, this improves at the higher speed. Furthermore, the exists a strong waveform unbalance at both speeds. 


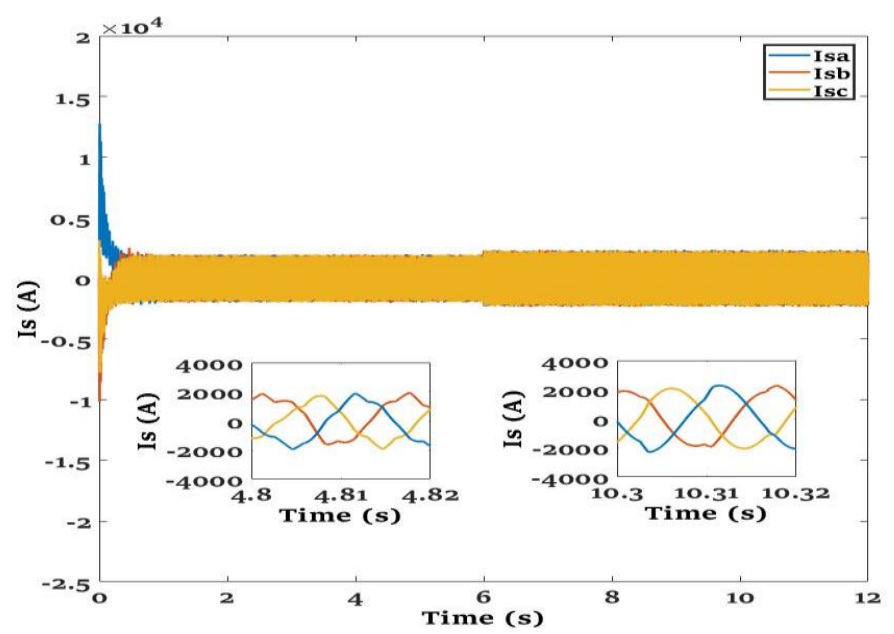

Figure 4-24: Three-phase stator current response of DPC-ST

\subsection{Conclusion}

This chapter provided the performance results of the conventional control methods applied to the DFIG. A discussion of the performance of each control method was provided. The results show that the DTC-SVPWM method produces the lowest ripples among all four control methods at both speed values. DTC-ST produces the best dynamic response but along with DPC-ST, produces the worst stator current outputs at both speeds. This is with regards to both distortion and equality of phases. DPC-ST provides reactive power control, which is not present in either of the DTC algorithms. FOC produces the slowest dynamic response but provides reactive power control and an acceptable steady state ripple at both speeds. FOC also produced good quality stator current waveforms at both speeds. This is with regards to both distortion and equality of phases. In terms of stator current distortion, DTC-SVPWM produced the best response at both speeds. Considering control method requirements, DPT-ST only required knowledge of the stator resistance, DTC-ST and DTC-SVPWM required knowledge of both the stator and rotor resistance and FOC required knowledge of the stator resistance, stator and rotor inductance and mutual inductance. Lastly, DTC-ST was the only control method that did not require knowledge of the rotor angle. 


\section{Chapter 5: Performance analysis of model predictive control applied to the control of the doubly fed induction generator}

In chapter 4, the performance of the conventional control methods applied to the DFIG were analysed. The relevant steady state ripple and dynamic response was evaluated for all four control methods. Furthermore, the rotor and stator current quality of each control method was analysed. This chapter serves to evaluate the performance of MPC applied to the control of the DFIG. There exist three predictive control methods which are MPCC, MPDTC and MPDPC. These control methods were explained in depth in chapter 3 , with the relevant formulae and control structures provided. This chapter aims to evaluate the relevant steady state ripple and dynamic response, as well as the rotor and stator current quality of the three control methods. Once again, the stator current quality is analysed in terms of distortion and equality of phases. The simulation conditions and control parameters for each control method is provided. The appropriate performance results are provided for each control method, with an analysis of results. To allow for accurate comparisons, all measurements are done identically to chapter 4.

\subsection{Model predictive current control}

As explained earlier, this control method is analogous to the FOC method in that the control of the stator power is accomplished by control of the rotor current. The difference is that the MPCC method does not use proportional-integral controllers and a modulator. Instead, it first predicts the next state direct and quadrature rotor currents based on the eight different switching states and applies the switching state which gives rise to the smallest error between the reference and next state rotor current values. Although there is no addition of coupling terms, accurate machine parameters are required for extraction of the rotor current references and prediction of next state variables. Like the FOC method, the slip angle is required for grid synchronization preservation [93],[94].

The control method was tested by being applied to a 3 MW DFIG and simulated using MATLAB/Simulink. Since only control of the RSC was investigated, the machine was only operated at sub-synchronous speeds. Based on a machine frequency of $60 \mathrm{~Hz}$, the mechanical synchronous speed of the machine is $188.5 \mathrm{rad} / \mathrm{s}$. This means that any speed below this is a sub-synchronous speed. Since the aim was to evaluate the performance of the control method at different rotor speeds, two sub-synchronous speeds were chosen. One was close to the 
synchronous speed at $185 \mathrm{rad} / \mathrm{s}$ and one was lower than this at $169 \mathrm{rad} / \mathrm{s}$. In order to ensure that the control method had ample time to reach steady state at each rotor speed, each speed was simulated for 6 seconds. For the first 6 seconds, the performance of the control method at the rotor speed of $169 \mathrm{rad} / \mathrm{s}$ was evaluated. A step change from $169 \mathrm{rad} / \mathrm{s}$ to $185 \mathrm{rad} / \mathrm{s}$ was then applied at the 6 second mark and for the next 6 seconds, the performance of the control method at the speed of $185 \mathrm{rad} / \mathrm{s}$ was evaluated.

The sample time was the same as in chapter 4 , at $10 \mu$ s. The slip angle was extracted by aligning the stator voltage with the direct axis, identically to the method used in the FOC experiment in 4.1. The optimal torque method for maximum active power extraction was used and an optimal co-efficient of $k_{\text {opt }}=0.296$ was used for reference value calculation [167]. This means that the reference stator active power was determined based on the speed of the rotor. The reference stator reactive power was chosen as 0 Var. From this, the respective reference rotor currents were determined. The machine parameters used in the calculation of reference values and prediction of next state variables are found in Appendix A, with the relevant formulae found in chapter 3. The performance of the control strategy is shown in figures 5-1 to 5-7.

Considering figure 5-1, at the lower speed the rotor direct current ripple is $32.5 \mathrm{~A}$ whereas at the higher speed it is $29 \mathrm{~A}$. The electromagnetic torque ripple at the lower and higher speeds are $132 \mathrm{~N}$ m and $117 \mathrm{~N} \mathrm{~m}$ respectively. This can be seen in figure 5-2.

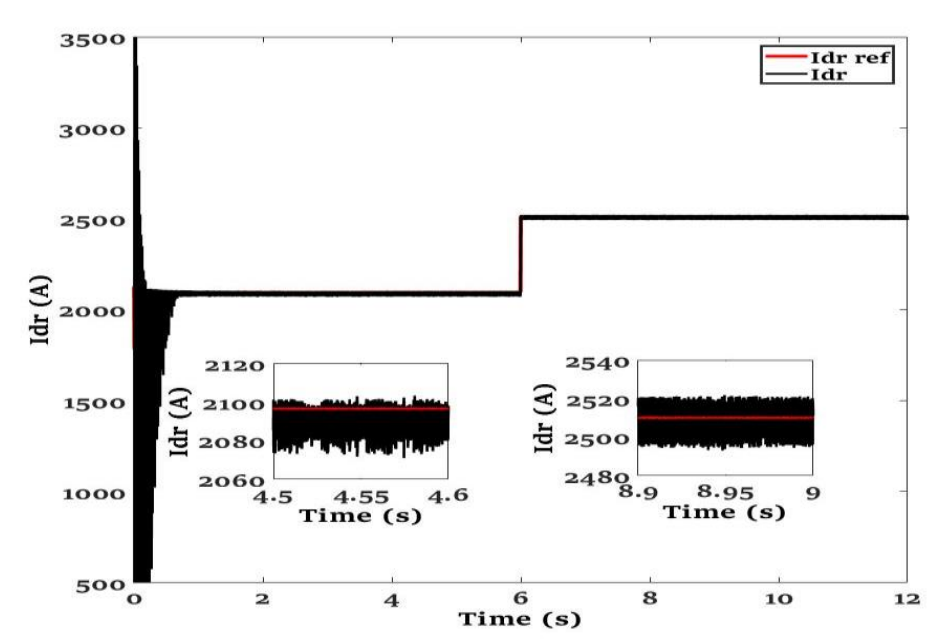

Figure 5-1: Rotor direct current response of MPCC

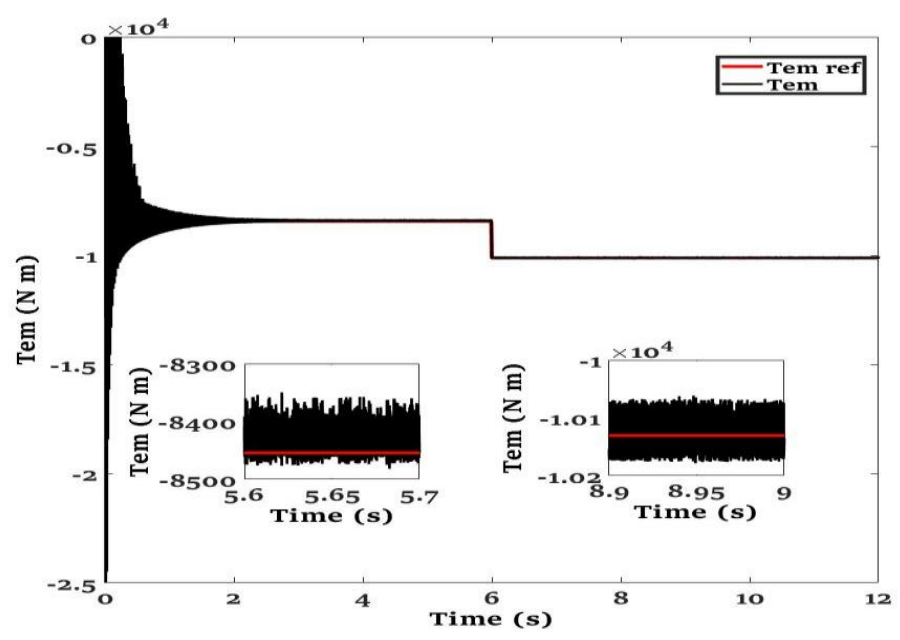

Figure 5-2: Electromagnetic torque response of MPCC

Since the stator active power is proportional to the electromagnetic torque, an identical phenomenon is observed in figure $5-3$, with the ripple being $24.88 \mathrm{~kW}$ and $22.05 \mathrm{~kW}$ respectively. The stator active power takes $0.67 \mathrm{~ms}$ to reach the next reference point. In figure 
$5-4$ it is seen that the rotor quadrature current ripple at the lower speed is $32.5 \mathrm{~A}$, with this value decreasing to $29 \mathrm{~A}$ at the higher speed.

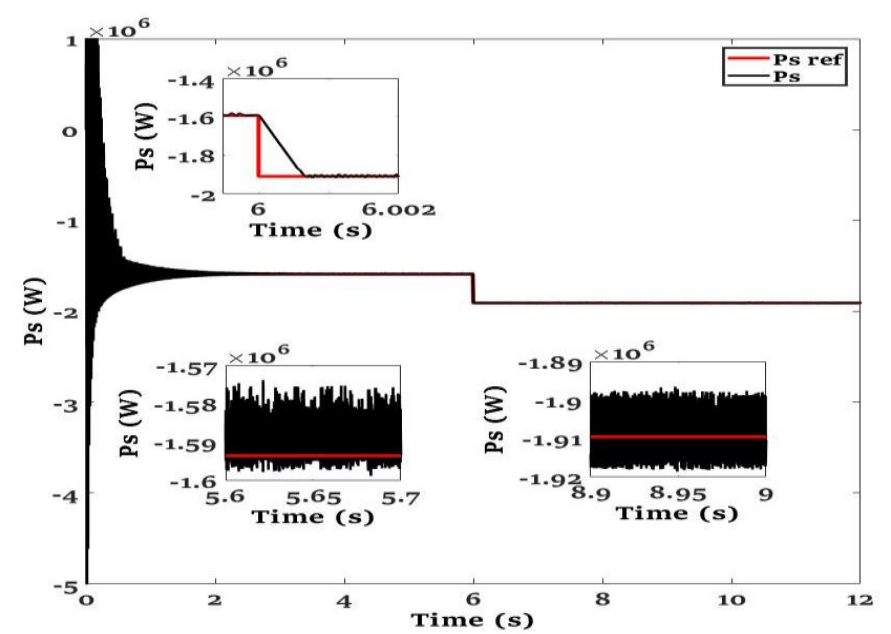

Figure 5-3: Stator active power response of MPCC

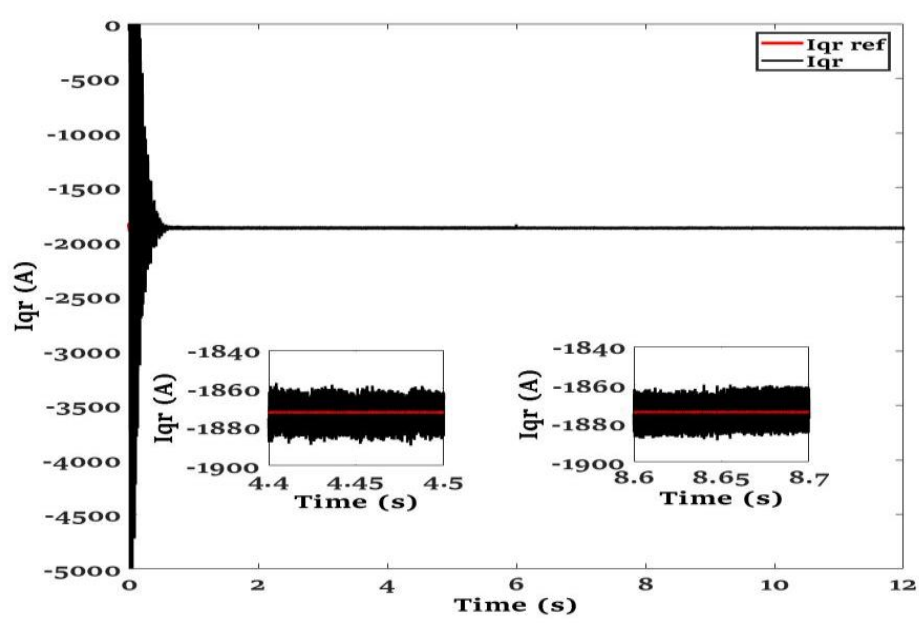

Figure 5-4: Rotor quadrature current response of MPCC

The stator reactive power ripple of $24.5 \mathrm{kVAr}$ and $22 \mathrm{kVAr}$ at the lower and higher speeds respectively is seen in figure 5-5. The three-phase rotor current, shown in figure 5-6, increases in magnitude and decreases in frequency at the higher speed. This is expected, as at the higher speed the slip is lower, and the electromagnetic torque (and stator active power) output is greater than at the lower speed. It can also be seen that at both speeds, the current waveforms are almost perfectly balanced and contain only a small amount of distortion

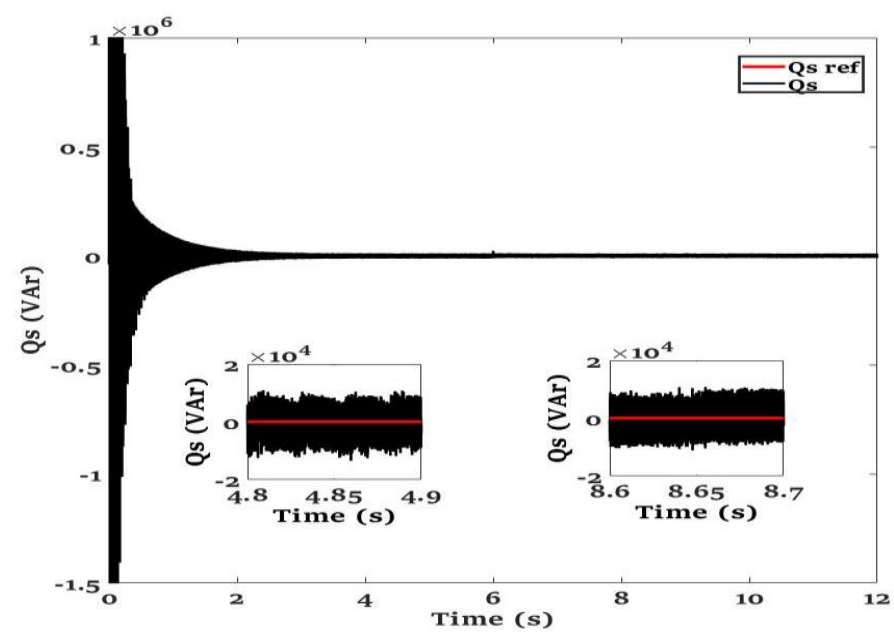

Figure 5-6: Stator reactive power response of MPCC

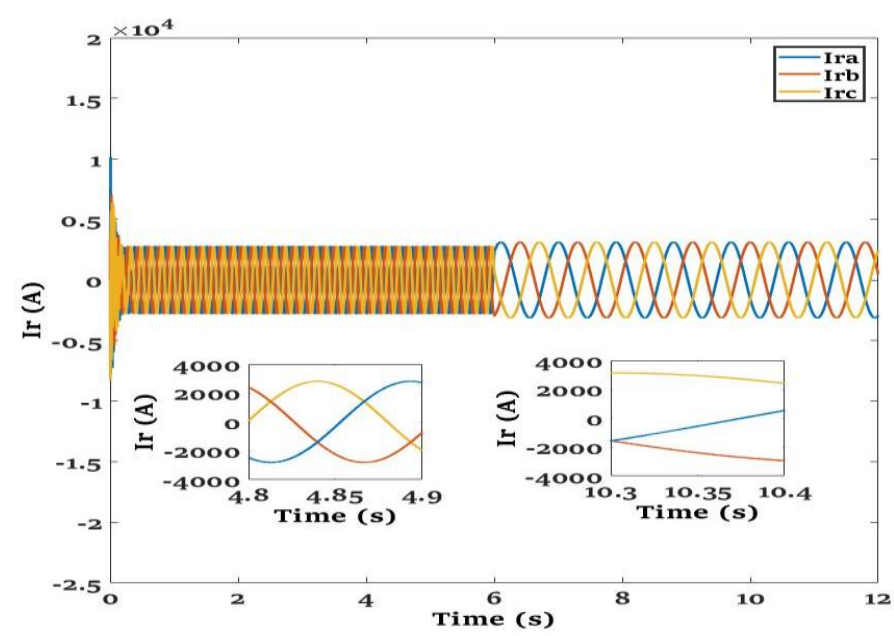

Figure 5-5: Three-phase rotor current response of MPCC

The three-phase stator current, shown in figure 5-7, increases in magnitude at the higher speed.

This is also expected, since at the higher speed there is more active power being delivered via 
the stator. The current frequency stays constant and the waveforms are of good quality. At both speeds, only a small amount of distortion and a slight unbalance in waveforms occur.

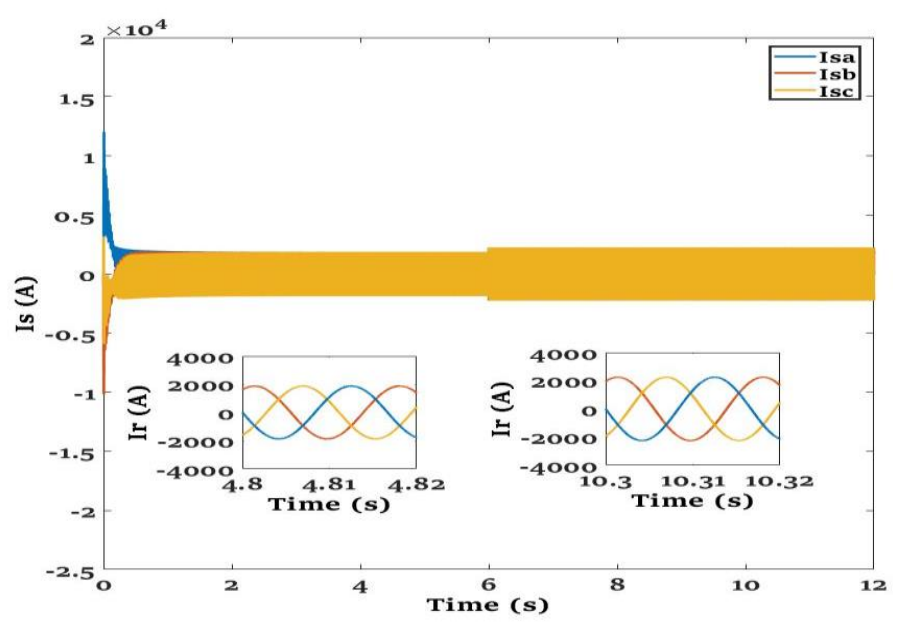

Figure 5-7: Three-phase stator current response of MPCC

\subsection{Model predictive direct torque control}

In 5.1, It was shown that the MPCC method provided a good steady state ripple and strong dynamic response. A new control method, called MPDTC, will be analysed in this subchapter. This method, just like DTC-ST and DTC-SVPWM, also directly controls the rotor flux and electromagnetic torque. However, there exists some differences. Unlike the switching table method, there is no predefined bandwidth to confine the variables in question. It also requires extraction of the slip angle, which is not true for DTC-ST. Furthermore, the two conventional DTC methods only require knowledge of the rotor and stator resistance However, in MPDTC, the estimation of the next state variables requires accurate measurement of all the machine resistance and inductance values. As explained earlier, these values are difficult to be measured accurately. This parameter and rotor angle knowledge dependency reduces the reliability of the control method. Unlike DTC-SVPWM, there is no proportional-integral controllers present. This reduces the complexity of the control method. As a consolation of its large machine parameter dependency, MPDTC is governed by a predefined algorithm. This means that adapting the control method to a new generator only requires acknowledgement of the new machine parameters. The method of execution of MPDTC is almost identical to the MPCC; the next state rotor flux and electromagnetic torque are determined based on the 8 possible switching states and the switching state which gives rise to the smallest errors of these two variables is implemented [93], [96]. 
The control method was tested by being applied to a 3 MW DFIG and simulated using MATLAB/Simulink. Since only control of the RSC was investigated, the machine was only operated at sub-synchronous speeds. Since the aim was to evaluate the performance of the control method at different rotor speeds, two sub synchronous speeds were chosen. One was close to the synchronous speed at $185 \mathrm{rad} / \mathrm{s}$ and one was lower than this at $169 \mathrm{rad} / \mathrm{s}$. In order to ensure that the control method had ample time to reach steady state at each rotor speed, each speed was simulated for 6 seconds. For the first 6 seconds, the performance of the control method at the rotor speed of $169 \mathrm{rad} / \mathrm{s}$ was evaluated. A step change from $169 \mathrm{rad} / \mathrm{s}$ to 185 $\mathrm{rad} / \mathrm{s}$ was then applied at the 6 second mark and for the next 6 seconds, the performance of the control method at the speed of $185 \mathrm{rad} / \mathrm{s}$ was evaluated.

The sample time was the same as in chapter 4 , at $10 \mu \mathrm{s}$. The slip angle was extracted by aligning the stator voltage with the direct axis, identical to the method used when evaluating DTC-SVPWM. The optimal torque method for maximum active power extraction was used and an optimal co-efficient of $k_{\text {opt }}=0.296$ was used for reference value calculation [167]. This means that the reference electromagnetic torque was determined based on the speed of the rotor. The reference stator reactive power was chosen as 0 Var. The machine parameters used in the calculation of reference values and prediction of next state variables are found in Appendix A, with the relevant formulae found in chapter 3. The performance of the control strategy is shown in figures 5-8 to 5-13.

In figure 5-8, it is seen that the electromagnetic torque ripple at the lower speed is $134 \mathrm{~N} \mathrm{~m}$ and $126.5 \mathrm{~N} \mathrm{~m}$ at the higher speed. As expected, the same pattern is observed in the stator active power shown in figure 5-9, with the ripple at $25.26 \mathrm{~kW}$ and $23.85 \mathrm{~kW}$ at the lower and higher speeds respectively. The stator active power takes $0.66 \mathrm{~ms}$ to reach the next reference point.

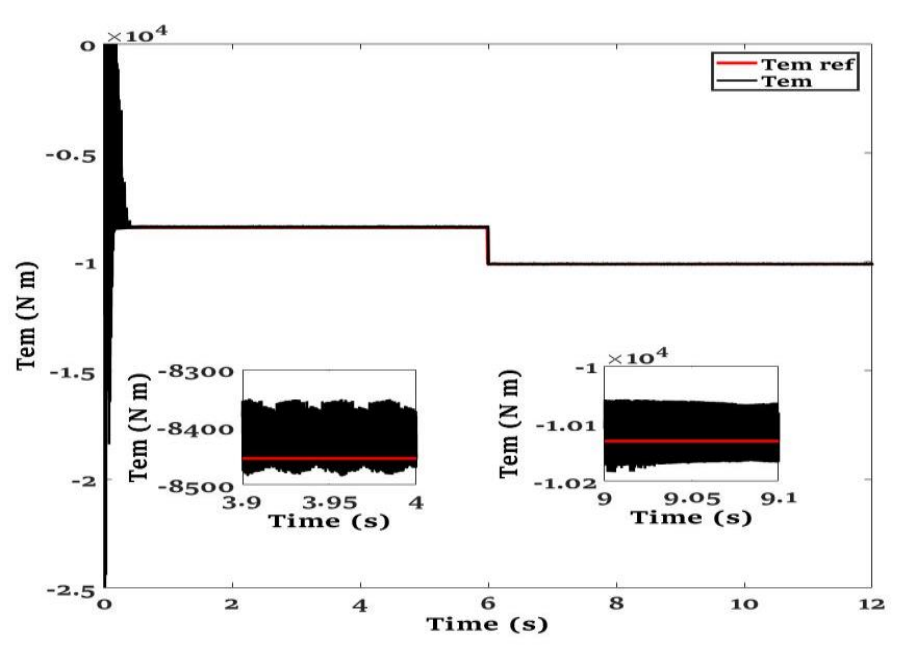

Figure 5-8: Electromagnetic torque response of MPDTC

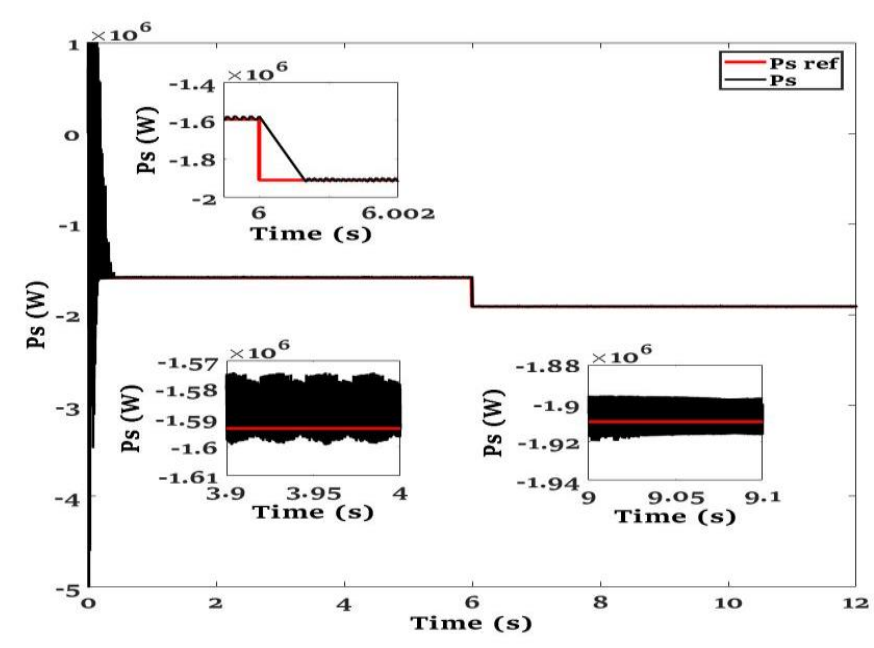

Figure 5-9: Stator active power response of MPDTC 
Considering the rotor flux shown in figure 5-10, the flux ripple is $36 \mathrm{mWb}$ at the lower speed with this value greatly decreasing to $9 \mathrm{mWb}$ at the higher speed. The stator reactive power, shown in figure 5-11, strongly deviates from the reference value. This is once again because there is no direct stator reactive power control.

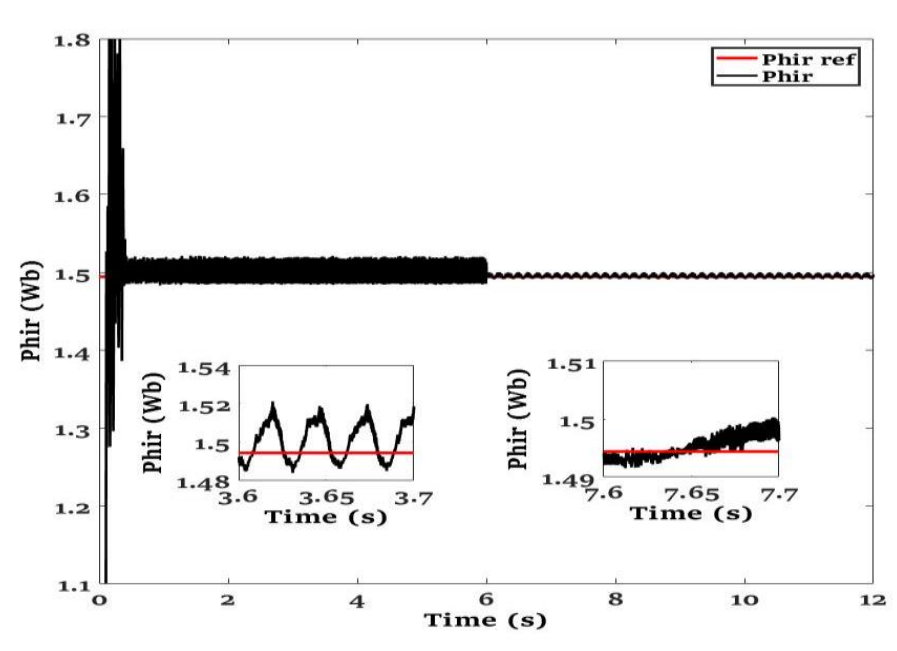

Figure 5-10: Rotor flux response of MPDTC

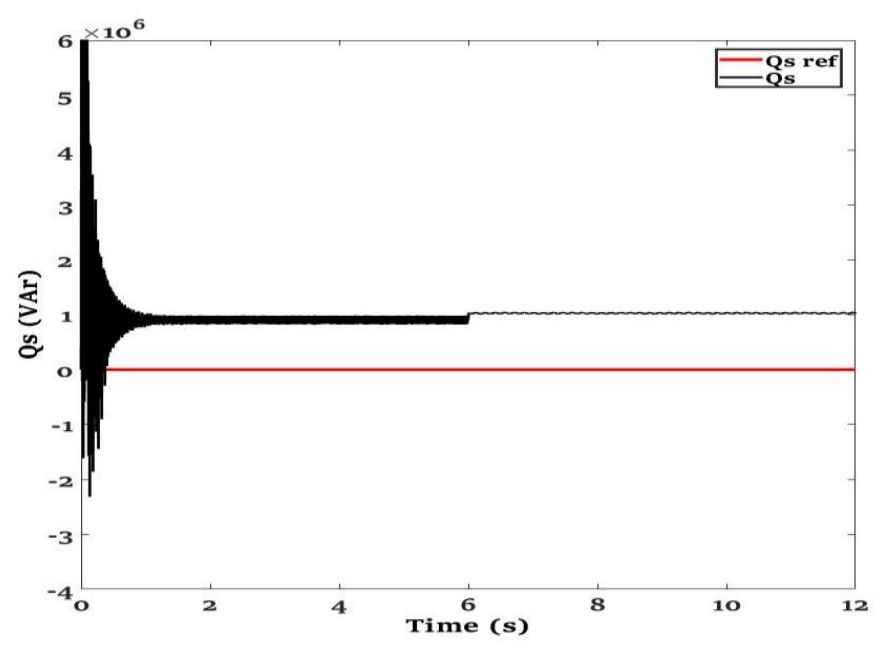

Figure 5-11: Stator reactive response of MPDTC

The three-phase rotor current, shown in figure 5-12, follows the expected trajectory. Furthermore, at both speeds, the waveforms are almost perfectly balanced and contain only a small amount of distortion. The three-phase stator current, shown in figure 5-18 is of good quality. At both speeds, only a small amount of distortion and a slight unbalance in waveforms occur.

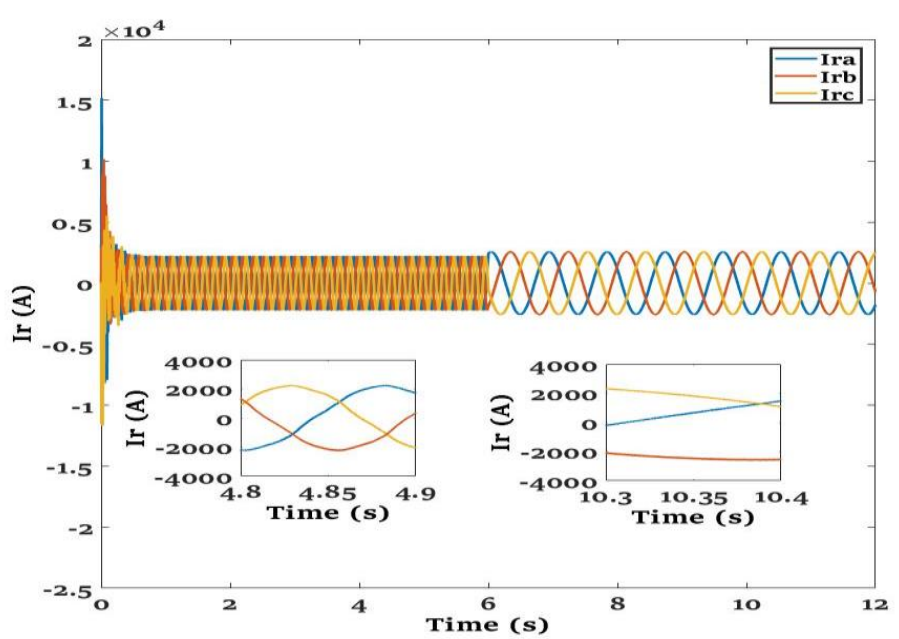

Figure 5-12: Three-phase rotor current response of MPDTC

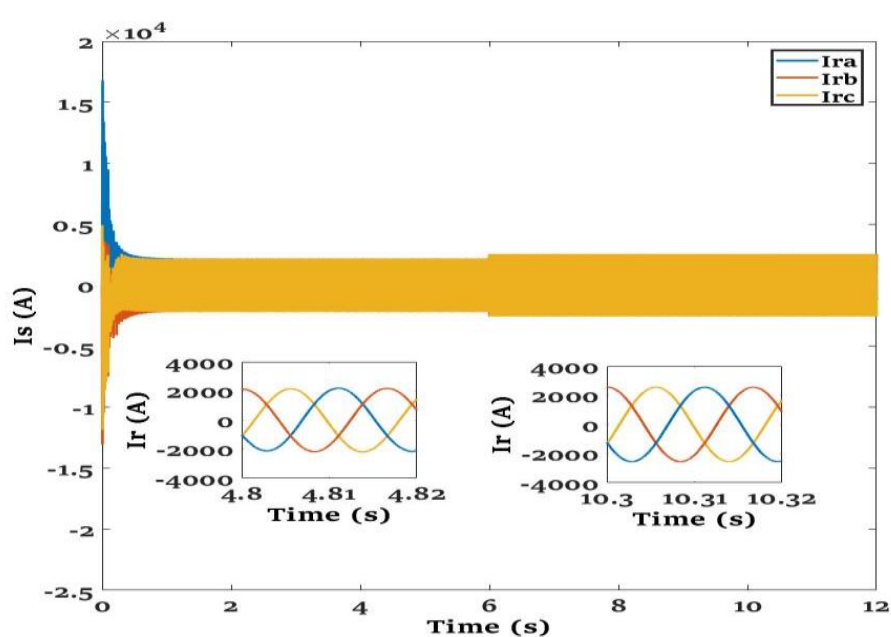

Figure 5-13: Three-phase stator current response of MPDTC 


\subsection{Model predictive direct power control}

In 5.2, it was shown that the MPDTC method provided a good steady state ripple at both speeds and strong dynamic response. However, like its switching table and space vector pulse width modulation counterparts, there existed no reactive power control. A new control method, called MPDPC, which will be analysed in this subchapter. This method, just like DPC-ST also directly controls the stator reactive and active powers. However, there exists some differences. Unlike the switching table method, there is no predefined bandwidth to confine the variables in question. Furthermore, DPC-ST required knowledge of only the stator resistance. MPDPC, however, requires knowledge of all the machine resistance and inductance values. As explained earlier, these values are difficult to be measured accurately. This large parameter dependency decreases the reliability of the control method. As a consolation to its large parameter dependency, MPDPC is governed by a predefined algorithm. This means that adapting the control method to a new generator only requires acknowledgement of the new machine parameters. The method of execution of MPDPC is almost identical to the MPCC and MPDTC methods; the next state stator reactive and active powers are determined based on the 8 possible switching states and the switching state which gives rise to the smallest errors of these two variables is implemented. There is a clear advantage over MPDTC in that MPDPC provides reactive power control [93], [97].

The control method was tested by being applied to a 3 MW DFIG and simulated using MATLAB/Simulink. Since only control of the RSC was investigated, the machine was only operated at sub-synchronous speeds. Since the aim was to evaluate the performance of the control method at different rotor speeds, two sub-synchronous speeds were chosen. One was close to the synchronous speed at $185 \mathrm{rad} / \mathrm{s}$ and one was lower than this at $169 \mathrm{rad} / \mathrm{s}$. In order to ensure that the control method had ample time to reach steady state at each rotor speed, each speed was simulated for 6 seconds. For the first 6 seconds, the performance of the control method at the rotor speed of $169 \mathrm{rad} / \mathrm{s}$ was evaluated. A step change from $169 \mathrm{rad} / \mathrm{s}$ to 185 $\mathrm{rad} / \mathrm{s}$ was then applied at the 6 second mark and for the next 6 seconds, the performance of the control method at the speed of $185 \mathrm{rad} / \mathrm{s}$ was evaluated.

The sample time was the same as in chapter 4 , at $10 \mu$ s. The slip angle was extracted by aligning the stator voltage with the direct axis, identical to the method used when evaluating the other predictive control methods. The optimal torque method for maximum active power extraction was used and an optimal co-efficient of $k_{\text {opt }}=0.296$ was used for reference value calculation [167]. This means that the reference stator active power was determined based on the speed of the rotor. The reference stator reactive power was chosen as 0 Var. The machine parameters 
used in the calculation of reference values and prediction of next state variables are found in Appendix A, with the relevant formulae found in chapter 3. The performance of the control method is shown in figures 5-14 to 5-18.

In figure 5-14, it can be seen that the electromagnetic torque ripple at the lower speed takes an impractical time to reach steady state. At the higher speed, the electromagnetic torque ripple is $184 \mathrm{~N} \mathrm{~m}$. As expected, the same is true for the stator active power, with the ripple at the higher speed being $34.68 \mathrm{~kW}$. This can be seen in figure $5-15$. The stator active power takes $0.67 \mathrm{~ms}$ to reach the next reference value.

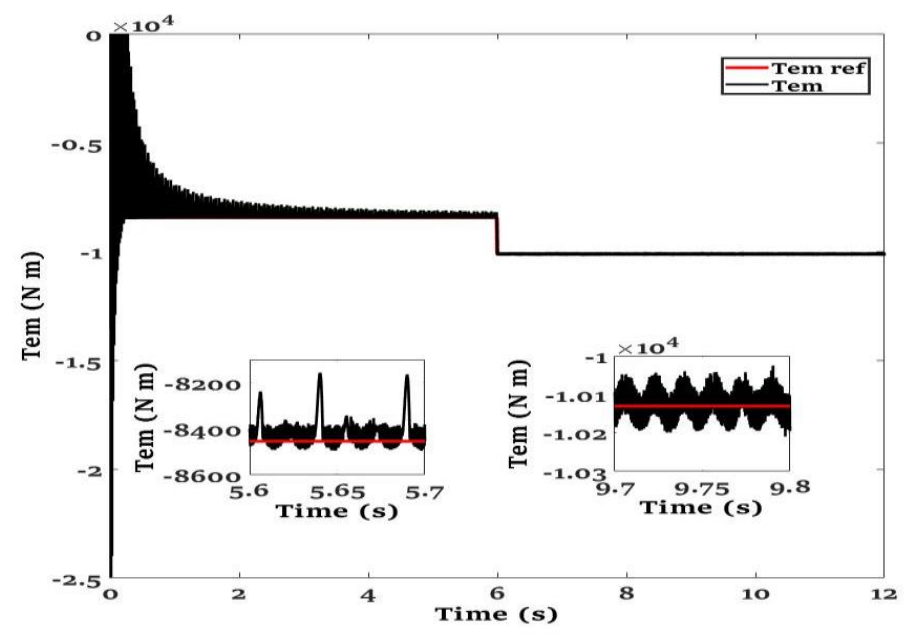

Figure 5-14: Electromagnetic torque response of MPDPC

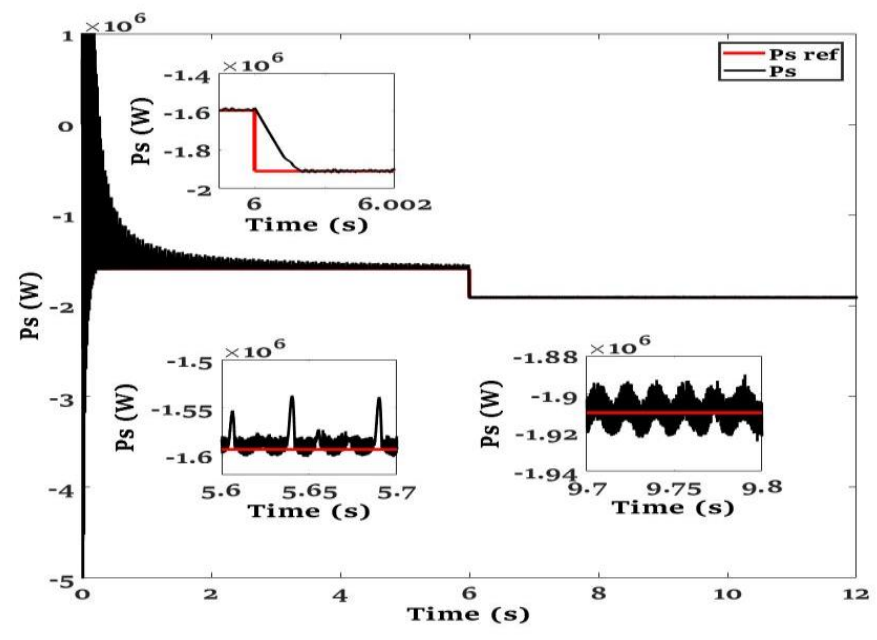

Figure 5-15: Stator active power response of MPDPC

The stator reactive power, shown in figure 5-16, has a ripple of $33 \mathrm{kVAr}$ and $33.5 \mathrm{kVAr}$ at the lower and higher speeds respectively. The three-phase rotor current, shown in figure 517 , contains a large amount of distortion at both speeds. Nevertheless, the waveform seems almost perfectly balanced at both speeds. 


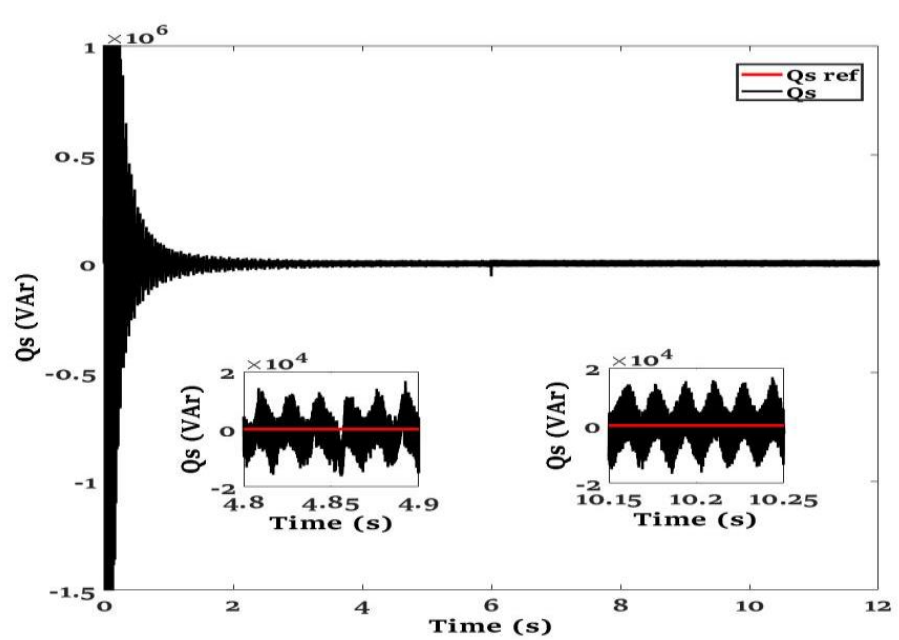

Figure 5-16: Stator reactive power response of MPDPC

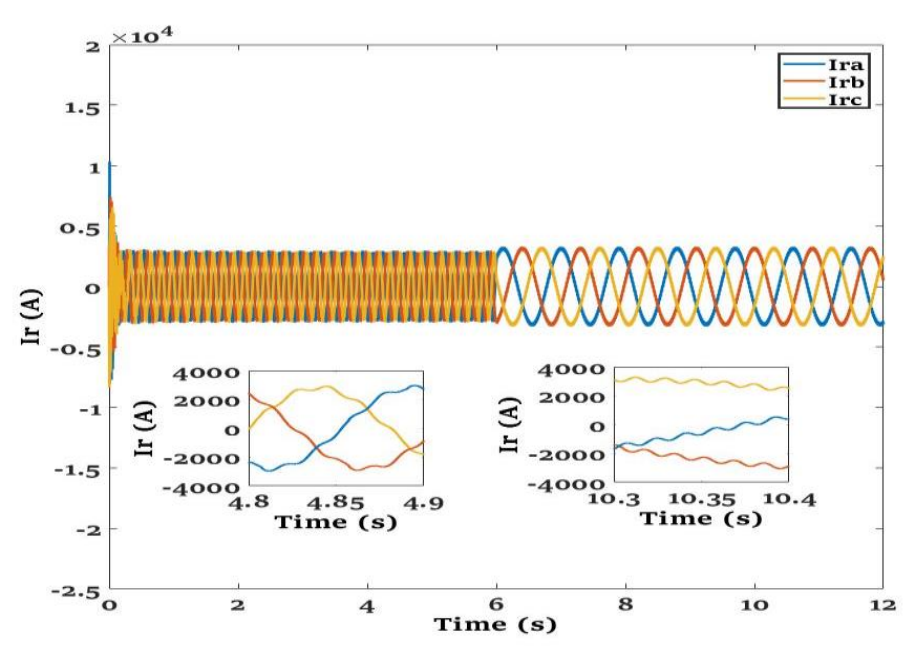

Figure 5-17: Three-phase rotor current response of MPDPC

The three-phase stator current, shown in figure 5-18 is of good quality. At both speeds, only a small amount of distortion and a slight unbalance in waveforms occur.

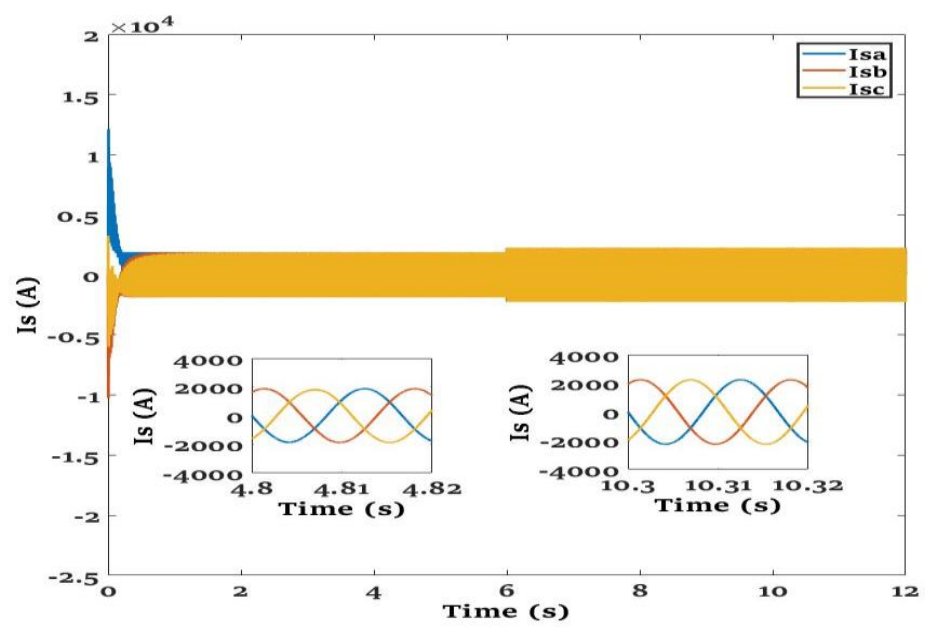

Figure 5-18: Three-phase stator current response of MPDPC

\subsection{Conclusion}

This chapter provided an evaluation of the performance of MPC applied to the control of the DFIG. A discussion of the performance of each control method was provided. The results show that model MPCC provided the best steady state ripple at both speeds, with MPDTC providing the best dynamic response. However, MPDTC provided no reactive power control, which puts it at a huge disadvantage when compared to the other two predictive control 
techniques. MPCC and MPDTC also produced a better steady state response than MPDPC at both speeds. The dynamic response of MPCC and MPDPC were equal. The stator current quality of all three control methods are approximately equal; all three control methods produce good quality stator currents which, at both speeds, contain only small amounts of distortion and a slight unbalance in waveforms. The results obtained from this chapter will allow for comparison between conventional control methods and control using MPC, which will be shown in the next chapter. 


\section{Chapter 6: Conclusion and future scope of work}

The research undertaken in this project was the investigation, implementation, and evaluation of the various types of control methods applied to the DFIG. First, the control methods already established were implemented. These methods are FOC, DTC-ST, DTC-SVPWM and DPCST. Once these control methods were implemented and evaluated in chapter 4, control of the DFIG using MPC was implemented. These methods were MPCC, MPDTC and MPDPC. The results from this implementation were evaluated in chapter 5. This chapter serves to make a comparison between the various control methods which were researched, implemented and evaluated. Furthermore, a description of possible future scope of work is provided.

\subsection{Conclusion}

Comparing FOC with DTC-ST, it is seen that the switching table method is easier to implement and has a faster response time. Furthermore, only the resistance values are required. In large machines such as this, the resistance can be ignored meaning that DTC-ST required no parameter knowledge. This greatly improves the reliability of the control method. There is also no need for knowledge of the rotor angle, thereby further increasing the reliability of the control method. FOC requires knowledge of the stator resistance, stator inductance, rotor inductance and mutual inductance. FOC also required knowledge of the rotor angle. However, FOC provided a better steady state ripple at both speeds. FOC also produced better stator current waveforms at both speeds. This is with regards to both distortion and equality of phases. FOC also provided the important reactive power control, which is not present in DTCST. Furthermore, FOC provides the advantage of a constant switching frequency whereas DTC-ST produces a variable switching frequency.

Comparing FOC with DTC-SVPWM, it is seen that the torque control method provided a better steady state ripple at both speeds, a better dynamic response and only requires knowledge of the rotor and stator resistance However, as with DTC-ST, DTC-SVPWM provides no reactive control, making FOC superior in this aspect. Considering the stator current, DTC-SVPWM produced a smaller distortion than FOC at both speeds. Upon comparison between DTC-ST and DTC-SVPWM, it is seen that the latter lacks simplicity and requires knowledge of the rotor angle. This reduces the reliability of the control system. DTCST also provides a faster response time. DTC-SVPWM does however provide a better steady state ripple at both speeds. DTC-SVPWM also produced better stator current waveforms at 
both speeds. This is with regards to both distortion and equality of phases. DTC-SVPWM also provides the advantages of a constant switching frequency, an aspect which is not present in DTC-ST.

When compared to each other, DPC-ST has a couple of advantages over DTC-ST. Firstly, only the stator resistance value is required. Secondly it provides the critical reactive power control. However, DTC-ST has a faster response time and does not require knowledge of the rotor angle. The stator currents for both control methods are almost the same at both speeds. This is with regards to both distortion and equality of phases. Comparing FOC and DPC-ST, it is seen that FOC provides a better steady state ripple at both speeds. FOC also produced better stator current waveforms at both speeds. This is with regards to both distortion and equality of phases. However, DPC-ST has a reduction in parameter dependency and has a stronger dynamic response. FOC also provides a constant switching frequency whereas DPCST does not.

Upon evaluation of the MPC methods, it is observed that all of the control methods rely upon all of the machine parameters; that is the stator and rotor resistances and inductances as well as the mutual inductance. Furthermore, all of the control methods require knowledge of the rotor angle. These two factors greatly decrease the reliability of these model predictive control methods. Upon comparison between MPCC and MPDTC, it is seen that the current control method provides a better steady state ripple at both speeds and reactive power control. MPDTC provides a strong competitive steady state ripple as well as a faster response time but lacks the critical component of reactive power control. Comparing MPDTC and MPDPC, is it seen that MPDTC provides a better steady state response at both speeds as well as a better dynamic response but is inferior to the latter due to the lack of reactive power control. When a comparison is made between MPCC and model MPDPC, it is seen that the former provides a better steady state ripple at both speeds, with the response time of these two control methods the same. The stator current quality of all three control methods are approximately equal; all three control methods produce good quality stator current which, at both speeds, produce only small amounts of distortion and a slight unbalance in waveforms.

Comparing FOC with MPCC, it is observed that the latter presents a better steady state response at both speeds, as well as a better dynamic response. Furthermore, at the higher speed, the stator current output of MPCC has a smaller distortion than. However, there is an increase in parameter dependency (four parameters in FOC and five in MPCC). Furthermore, MPCC produces a variable switching frequency as compared to the constant switching frequency in FOC. Comparing MPDTC with DTC-ST, it is seen that the former produces superior results in all aspects, a better steady state ripple at both speeds, a better dynamic response and better- 
quality stator current waveforms. This superior stator current is with regards to both distortion and equality of phases. However, it also requires the use of five parameters, as compared to two used by the switching table method. Furthermore, the switching table method does not require knowledge of the rotor angle. When MPDTC is compared to DTC-SVPWM, it is observed that the former has a better stator active power steady state response at both speeds as well as a better dynamic response. However, the space vector modulation control method produces a better steady state rotor flux ripple at both speeds Both control methods require knowledge of the rotor angle. Considering stator current quality, DTC-SVPWM produced a smaller distortion at both speeds. The space vector pulse width modulation technique only requires two machine parameters, as compared to five required by MPDTC. Finally, MPDPC is compared to DPC-ST. The result of this comparison shows that despite taking an impractical time to reach steady state at the lower speed, MPDPC provides a better steady state response at both speeds as well as a better dynamic response. MPDPC also produced better-quality stator current waveforms at both speeds. This is with regards to both distortion and equality of phases. However, DTC-ST only required knowledge of the stator resistance whereas MPDPC required knowledge of all of the machine parameters.

Upon completion of the research, implementation, and evaluation of the various control methods, it was noticed that each control method has advantages and disadvantages. In general, MPC provided strong steady state and dynamic results as well as acceptable stator current waveforms. Furthermore, there exists a predefined algorithm, meaning that a change of generator only required the update of machine parameters. However, it relies heavily on machine parameters, thereby decreasing the reliability of the control methods. There also exists a dependency of knowledge of the rotor angle, which is undesirable. Lastly, since OSVMPC was used, the MPC methods investigated produced a variable switching frequency. This is undesirable.

\subsection{Scope of future work}

Upon completion of this research project, various issues and possibilities concerning the use of the DFIG in WECS were identified. This paves way for a future scope of work and is as follows:

D The DTC methods provide many advantages but lack the critical aspect of reactive power control. This deficiency could affect the control responses and makes the control methods unsuitable for use when controlling a DFIG. Thus, devising a method 
to provide reactive power control would make these control methods strong competitors.

D The switching table control methods are simple and require very little machine information. They also provide strong dynamic responses. However, the stator current waveforms of these control methods are highly distorted and unsuitable to be injected into the grid. Elimination of these poor-quality stator currents would allow for these control techniques to be considered in the control of the DFIG. One method would be to design a filter either at the rotor or stator terminals.

The MPDPC method should be investigated and improved in terms of time taken to reach steady state at lower speeds.

It is known that wind farms are situated in areas where the electrical grid is usually weak. This would make unbalanced grid voltage prominent in wind farms, hence mitigation of thereof is imperative. Much work has done in field of rotor current control, but not much in DTC and DPC. This should be investigated.

Fault ride through capabilities of a generator is a crucial aspect of electrical power engineering. Although there has been substantial research in this field, very little has been done via the use of MPC. MPC has been shown to achieve good steady state and dynamic results, so the same may be true when considering fault ride through.

Other control methods such as artificial neural network, particle swarm optimization and sliding mode control should be applied to the control of the DFIG and their results should be critically evaluated in terms of response, feasibility and reliability.

The use of the 3-level neutral point clamped inverter should be applied to the control of the DFIG and its results evaluated. 


\section{References}

[1] A. N. Legesse, A. K. Saha and R. P. Carpanen, "Enhancing the Dynamic Performance of a Direct-Drive PMSG Wind Turbine Using Damping Controllers," in 24th Southern African Universities Power Engineering Conference, South Arica, 2016.

[2] A. N. Legesse, A. K. Saha and R. P. Carpanen, "Generating Wind Speed Time Series for Time Domain Simulation of Wind Turbines," in 5th Southern African Universities Power Engineering Conference, Stellenbosch, 2017.

[3] A. N. Legesse, A. K. Saha and R. P. Carpanen, "Characterisation of wind speed series and power in Durban," Journal of Energy in Southern Africa, vol. 28, no. 3, pp. 6678, 2017.

[4] "Types of renewable energy," EDF, [Online]. Available: https://www.edfenergy.com/for-home/energywise/renewable-energy-sources.

[5] B. Zientara, "How much electricity does a solar panel produce?," Solar Power Rocks, [Online]. Available: https://www.solarpowerrocks.com/solar-basics/how-muchelectricity-does-a-solar-panel-produce/.

[6] "Tidal Energy- Advantages \& Disadvantages |Tides |Renewable Resources," BYJUS, [Online]. Available: https://byjus.com/physics/tidal-energy/.

[7] "How much do wind turbines cost?," Windustry, [Online]. Available: http://www.windustry.org/how_much_do_wind_turbines_cost\#: :text=Commercia I\%20Wind\%20Turbines,\%243\%2D\%244\%20million\%20installed..

[8] "Power Electronics for Wind Turbines: Technological Inventions are coming up in Order to Reduce Production Cost | 2025 | REVE News of the wind sector in SPain and in the world," Evwind.es, [Online]. Available:

https://www.evwind.es/2019/05/28/power-electronics-for-wind-turbinestechnological-inventions-are-coming-up-in-order-to-reduce-production-cost2025/67377. 
[9] A. N. Legesse, A. K. Saha and R. P. Carpanen, "Damping Local Oscillations of a Directdrive PMSG Wind Turbine," International Journal of Engineering and Technology, vol. 9, no. 1, pp. 158-168, 2017.

[10] "Statistics - World Wind Energy Association," Wwindea.org, [Online]. Available: https://wwindea.org/information-2/information/.

[11] V. Yaramasu and B. Wu, in Model Predictive Control of Wind Energy Conversion Systems, New Jersey, John Wiley \& Sons, 2017, pp. 3-35.

[12] T. Dang, "Introduction, history and theory of wind power," in 41st North American Power Symposium, Starkville, 2010.

[13] S. Khillar, "Difference Between Horizontal and Vertical Axis Wind Turbine," Differencebetween.net, [Online]. Available:

http://www.differencebetween.net/technology/difference-between-horizontaland-vertical-axis-wind-turbine/.

[14] P. Nagare, A. Nair, R. Shettigar, P. Kale and P. Nambiar, "Vertical axis wind turbine," in 2015 International Conference on Technologies for Sustainable Development (ICTSD), Mumbai, 2015.

[15] N. Clark, "Wind Turbine Components and Descriptions: Essential Components to Have a Productive, Reliable, and Safe Wind Machine," in Small Wind, Elsevier, 2014, pp. 39-67.

[16] "What bearings are used in wind turbines? - Insight - Acorn Industrial Services Itd," Acorn-ind.co.uk, [Online]. Available: https://www.acorn-ind.co.uk/insight/Whatbearings-are-used-in-windturbines/\#: :text=Slewing\%20ring\%20bearings\%20are\%20generally,well\%20as\%20 accommodating\%20tilting\%20moments. .

[1 N. Sharpley, "Nacelles | How are they manufactured?," Windpower Engineering \&

7] Development, [Online]. Available: https://www.windpowerengineering.com/howis-a-nacelle-manufactured/.

[18] M. G. Simoes, "Power Bipolar Transistors," in Power Electronics Handbook, Elsevier, 2011, pp. 29-41. 
[19] J.-P. Matsinen, "ABB Conversations > Power grids and the importance of standards and grid codes," Abb-conversations.com, [Online]. Available: https://www.abbconversations.com/2016/10/power-grids-and-the-importance-of-standards-andgrid-

codes/\#: :text=Grid\%20codes\%20are\%20mainly\%20concerned,capabilities\%2C\%20 safety\%2C\%20and\%20security..

[20] "Global Wind Power Statistics - Wind Energy International Platform," Library.wwindea.org, [Online]. Available: https://library.wwindea.org/globalstatistics/.

[21] "World's top 10 countries in wind energy capacity - ET EnergyWorld," ETEnergyworld.com, [Online]. Available: https://energy.economictimes.indiatimes.com/news/renewable/worlds-top-10countries-in-wind-energy-capacity/68465090.

[22] "Wind energy penetration: country comparison 2019 | Statista," Statista, [Online]. Available: https://www.statista.com/statistics/217804/wind-energy-penetrationby-country/.

[23] "China's Electricity Consumption Increased by 4.5\% in 2019 | Energy Central," Energycentral.com, [Online]. Available: https://energycentral.com/news/chinaselectricity-consumption-increased-452019\#: :text=Overall\%2C\%20China's\%20power\%20generation\%20rose,of\%20the\% 20 country's\%20power\%20mix..

[24] M. E. Hossain, "Improvement of transient stability of DFIG based wind generator by using of resistive solid state fault current limiter," Ain Shams Engineering Journal, vol. 9, no. 4, pp. 2557-2570, 2018.

[25] J. Pollefliet, "Applications of Power Electronics," in Power Electronics: Switches and Converters, Elsevier, 2017, pp. 15.1-15.44.

[26] M. Liu, Y. Xu and Z. Chen, "Coordinated control strategy of DFIG under grid voltage unbalance conditions," in 2010 5th International Conference on Critical Infrastructure (CRIS), Beijing, 2010. 
[27] K. Kerrouchea, A. Mezouar and K. Belgacem, "Decoupled Control of Doubly Fed Induction Generator by," Energy Procedia, vol. 42, pp. 239-248, 2013.

[28] A. Wiama and A. Haddi, "Direct torque control-based power factor control of a DFIG," Special Issue on Emerging and Renewable Energy: Generation and Automation, pp. 296-305, 17 February 2019.

[29] M. Valikhani and C. Sourkounis, "A comparative study of rotor flux position- and stator flux position-based direct power control method in a DFIG wind turbine system," in 2014 Ninth International Conference on Ecological Vehicles and Renewable Energies (EVER), Monte-Carlo, 2014.

[30] Y. Reddy and B. Mehta, "Advanced process control systems," in Industrial Process Automation Systems, Butterworth-Heinemann, 2015, pp. 547-557.

[31] V. Q. B. NGO, "Algorithmes de conception de lois de commande," 22 June 2017. [Online]. Available: https://tel.archives-ouvertes.fr/tel01560359/file/73494_NGO_2017_archivage.pdf.

[32] N. G. Lantewa and N. Magaji, "Control of Doubly Fed Induction Generator of Variable Speed Wind Turbine System using Neural Network," in 2018 International Conference and Utility Exhibition on Green Energy for Sustainable Development (ICUE), Phuket, 2018.

[33] S. Mishra, S. K. Gagrai and M. Singh, "An ANN Based Simulation and Control of Grid Integrated DFIG for 2 MW Small Hydro Power Plant," in 2019 6th International Conference on Signal Processing and Integrated Networks (SPIN), Noida, 2019.

[34] M. M. Ismail and A. F. Bendary, "Protection of DFIG wind turbine using fuzzy logic control," Alexandria Engineering Journal, vol. 55, no. 2, pp. 941-949, 2016.

[35] K. Belmokhtar, M. L Doumbia and K. Agbossou, "Modelling and fuzzy logic control of DFIG based Wind Energy Conversion Systems," in 2012 IEEE International Symposium on Industrial Electronics, Hangzhou, 2012.

[36] J. Zou, C. Peng, H. Xu and Y. Yan, "A Fuzzy Clustering Algorithm-Based Dynamic Equivalent Modeling Method for Wind Farm With DFIG," IEEE Transactions on Energy Conversion, vol. 30, no. 4, pp. 1329-1337, 2015. 
[37] H. Yokoyama, u. Tatsuta and S. Nishikata, "Tip speed ratio control of wind turbine generating system connected in series," in 2011 International Conference on Electrical Machines and Systems, Beijing, 2011.

[38] H. H. El-Tamaly and A. Y. Nassef, "Tip speed ratio and Pitch angle control based on ANN for putting variable speed WTG on MPP," in 2016 Eighteenth International Middle East Power Systems Conference (MEPCON), Cairo, 2016.

[39] X. Anjun, L. Xu, H. Shuju, L. Nianhong and X. Honghua, "A new pitch control method for large scale wind turbine based on ADRC," in 2013 International Conference on Materials for Renewable Energy and Environment, Chengdu, 2013.

[40] G. Boukettaya, O. Naifar and A. Ouali, "A vector control of a cascaded doubly fed induction generator for a wind energy conversion system," in 2014 IEEE 11th International Multi-Conference on Systems, Signals \& Devices (SSD14), Barcelona, 2014.

[41] Y. Sahri, S. Tamalouzt and S. L. Belaid, "Direct Torque Control of DFIG Driven by Wind Turbine System Connected to the Grid," in 2018 International Conference on Wind Energy and Applications in Algeria (ICWEAA), Algiers, 2018.

[42] Y. Zhu and H. C. L. G. S. Zang, "Output Power Smoothing Control for a Wind Farm Based on the Allocation of Wind Turbines," in Large Grid Connected Wind Turbines, MDPI, 2018, pp. 64-82.

[43] M. M. Qasim, M. R. Overlin and J. L. Kirtley, "A Geometric Interpretation of Reference Frames and Transformations: dq0, Clarke, and Park," IEEE Transactions on Energy Conversion, vol. 34, no. 4, pp. 2070-2083, 2019.

[44] V. Yaramasu and B. Wu, "Overview of Digital Control Techniques," in Model Predictive Control of Wind Energy Conversion Systems, New Jersey, John Wiley \& Sons, 2017, pp. 91-116.

[45] S. N. Manias, "Inverters (DC-AC Converters)," in Power Electronics and Motor Drive Systems, Elsevier, 2017, pp. 271-500. 
[46] D. Monday, A. Chakrabarti and A. Sengupta, "Fundamental Models of Synchronous Machine," in Power System Small Signal Stability Analysis and Control, Elsevier, 2014, pp. 15-40.

[47] J. F. Silva and S. F. Pinto, "Linear and Nonlinear Control of Switching Power Converters," in Power Electronics Handbook 4th Edition, Butterworth-Heinemann, 2018, pp. 1141-1220.

[48] G. Abad and G. Iwanski, "Properties and Control of a Doubly Fed Induction Machine," in Power Electronics for Renewable Energy Systems, Transportation and Industrial Applications, John Wiley \& Sons, 2014, pp. 692-787.

[49] K. Bedouda, M. Ali-rachedic, T. Bahid and R. Lakelb, "Robust Control of Doubly Fed Induction Generator for Wind," Energy Procedia, vol. 24, pp. 886-899, 2015.

[50] D. A. Gorski, T. Balkowiec and W. Koczara, "Grid Connection of a Converter Controlled Squirrel-Cage Induction Generator," in 2018 7th International Conference on Renewable Energy Research and Applications (ICRERA), Paris, 2018.

[51] S. H. Qazi and M. M. Wazir, "Review on active filters and its performance with grid connected fixed and variable speed wind turbine generator," Renewable and Sustainable Energy Reviews, vol. 57, pp. 420-438, 2016.

[52] A. Akinrinde, A. Swanson and R. Tiako, "Dynamic Behavior of Wind Turbine Generator Configurations during Ferroresonant Conditions," 16 February 2019. [Online]. Available: https://doi.org/10.3390/en12040639.

[53] J. Liang and C. Feng, "Advanced AC and DC technologies to connect offshore wind farms into electricity transmission and distribution networks," in Eco-friendly Innovations in Electricity Transmission and Distribution Networks, Woodhead Publishing, 2015, pp. 263-290.

[54] N. Tleis, "Modelling of ac rotating machines," in Power Systems Modelling and Fault Analysis: Theory and Practice , Elsevier, 2008, pp. 371-468.

[55] A. N. Gogdare, G. A. Doroudi and M., "A new method to mitigate voltage fluctuation of a fixed speed wind farm using DFIG wind turbine," in 2012 Proceedings of 17th Conference on Electrical Power Distribution, Tehran, 2012. 
[56] R. D. Shukla, A. Singh and S. Singh, "GENERATORS FORVARIABLE SPEEDWIND ENERGYCONVERSION SYSTEMS:A COMPARATIVE STUDY," [Online]. Available: https://www.academia.edu/7688196/GENERATORS_FOR_VARIABLE_SPEED_WIND_ ENERGY_CONVERSION_SYSTEMS_A_COMPARATIVE_STUDY.

[57] M. Q. Duong and G. N. Sava, "Coordinated reactive power control of DFIG to improve LVRT characteristics of FSIG in wind turbine generation," in 2017 International Conference on Electromechanical and Power Systems (SIELMEN), Iasi, 2017.

[58] J. McCalley, "Doubly-fed electric machines - steady state analysis," Home.eng.iastate.edu, [Online]. Available: http://home.eng.iastate.edu/ jdm/wind/DFIG-SteadyState.ppt.

[59] M. Vicatos and J. Teqopoulos, "Steady State Analysis of a Doubly Fed Induction Generator under Synchronous Operation," IEEE Transactions on Energy Conversions, vol. 4, no. 3, 1989.

[60] M. R. Islam, Y. Guo and J. G. Zhu, "Steady state characteristic simulation of DFIG for wind power system," in International Conference on Electrical \& Computer Engineering (ICECE 2010), Dhaka, 2010.

[61] G. Byeon, I. K. Park and G. Jang, "Modeling and Control of a Doubly-Fed Induction Generator (DFIG)," Journal of Electrical Engineering \& Technology, vol. 5, no. 1, pp. 61-69, 2010.

[62] H. Chafouk and H. Ouyessaad, "Fault Detection and Isolation in DFIG Driven by a Wind Turbine," in (International Federation of Automatic Control, 2015.

[63] A. Bakouri, H. Mahmoudi and A. Abbou, "Modelling and optimal control of the doubly fed induction generator wind turbine system connected to utility grid," in 2016 International Renewable and Sustainable Energy Conference (IRSEC), Marrakech, 2016.

[64] L. L. Ntwasa, A. K. Saha and N. M. Ijumba, "Simulation Study of Induction Generatorbased Wind Turbine," in International Conference on Power System Technology, Hangzhou, 2010. 
[65] V. Q. B. Ngo, P. Rodriguez-Ayerb, S. Olaru and S.-I. Niculescu, "Model Predictive Direct Power Control of," in International Federation of Automatic Control, 2017.

[66] Y.-z. Liu, D.-w. Zhao, L. Zhang, L.-z. Zhu and N. Chen, "Simulation study on transient characteristics of DFIG wind turbine systems based on dynamic modeling," in 2014 China International Conference on Electricity Distribution (CICED), Shenzen, 2014.

[67] M. d. P. Gil, A. Sumper and O. Gomis-Bellmunt, "Modeling and control of a pitchcontrolled variable-speed wind turbine driven by a DFIG with frequency control support in PSS/E," in 2012 IEEE Power Electronics and Machines in Wind Applications, Denver, 2012.

[68] G. Ellis, "Nonlinear Behavior and Time Variation," in Control System Design Guide, Butterworth-Heinemann, 2012, pp. 235-360.

[69] S.-H. Kim, "Current Regulator of Alternating Current Motors," in Electric Motor Control, Elsevier Science, 2017.

[70] C. M. Martínez and C. Dongpu, "Integrated energy management for electrified vehicles," in iHorizon-Enabled Energy Management for Electrified Vehicles, Butterworth-Heinemann, 2019, pp. 15-75.

[71] J. Xu and L. Xie, "A PWA approach to Takagi-Sugeno fuzzy logic systems," in Control and estimation of piecewise affine systems, Woodhead Publishing, 2014, pp. 169192.

[72] A. Katbab, "Fuzzy logic and controller design-a review," in Proceedings IEEE Southeastcon '95. Visualize the Future, Raleigh, 1995.

[73] S. Walczak and N. Cerpa, "Artificial Neural Networks," in Encyclopedia of Physical Science and Technology, Aademic Press, 2001, pp. 631-645.

[74] M. Mohamed, "Model Predictive Control: An Effective Control Approach for High Performance Induction Machine Drives," [Online]. Available: http://paduaresearch.cab.unipd.it/10557/1/MOHAMED_MAHMOUD_Thesis.pdf. 
[75] S. Vazquez, J. I. Leon, F. L. G., J. Rodriguez, H. A. Young, A. Marquez and P. Zanchetta, "Model Predictive Control: A Review of Its Applications in Power Electronics," IEEE Industrial Electronics Magazine, vol. 8, no. 1, pp. 16-31, 2014.

[76] V. S., R. J., M. Rivera, L. G. Franquelo and M. Norambuena, "Model Predictive Control for Power Converters and Drives: Advances and Trends," IEEE Transactions on Industrial Electronics, vol. 64, no. 2, pp. 935-947, 2017.

[77] S. Xie, Y. Sun, M. Su, J. Lin and Q. Guang, "Optimal switching sequence model predictive control for three-phase Vienna rectifiers," IET Electric Power Applications , vol. 12, no. 7, pp. 1006-1013, 2018.

[78] S. Kouro, P. Cortes, R. Vargas, U. Ammann and J. Rodriguez, "Model Predictive Control-A Simple and Powerful Method to Control Power Converters," IEEE Transactions on Industrial Electronics, vol. 56, no. 6, pp. 1826 - 1838, 2009.

[79] R. N. Fard, "Finite Control Set Model Predictive Control in Power Converters," July 2013. [Online]. Available: https://ntnuopen.ntnu.no/ntnuxmlui/handle/11250/257691.

[80] "Math.purdue.edu," [Online]. Available: https://www.math.purdue.edu/files/academic/courses/2010spring/MA26200/1_10 .pdf.

[81] "Math.la.asu.edu," [Online]. Available: https://math.la.asu.edu/ dajones/class/275/ch2.pdf.

[82] "Forward and Backward Euler Methods," Web.mit.edu, [Online]. Available: http://web.mit.edu/10.001/Web/Course_Notes/Differential_Equations_Notes/nod e3.html.

[83] "Midpoint Method," Mymathlib.com, [Online]. Available: http://www.mymathlib.com/diffeq/midpoint_method.html.

[84] P. Cortes, S. Kouro, B. La Rocca, R. Vargas, J. Rodriguez, J. I. Leon, S. Vazquez and L. G. Franquelo, "Guidelines for weighting factors design in Model Predictive Control of power converters and drives," in 2009 IEEE International Conference on Industrial Technology, Gippsland, 2009. 
[85] M. Bouderbala, B. Bossoufi, H. A. Aroussi, A. Lagrioui, M. Taoussi, Y. Ihedrane and M. E. Ghamrasni, "Modeling and Power Controls of Wind Energy Conversion Systems Based on Doubly Fed Induction Generator," in 2018 6th International Renewable and Sustainable Energy Conference (IRSEC), Rabat, 2018.

[86] Y. Ihedrane, C. El Bekkali and B. Bossoufi, "Direct and indirect field oriented control of DFIG-generators for wind turbines variable-speed," in 2017 14th International Multi-Conference on Systems, Signals \& Devices (SSD), Marrakech, 2017.

[87] M. A. Kashkooli, S. M. Madani and R. Sadeghi, "Improved Direct Torque Control of DFIG with reduced torque and flux ripples at constant switching frequency," in 2016 7th Power Electronics and Drive Systems Technologies Conference (PEDSTC), Tehran, 2016.

[88] A. Zemmit, S. Messalti and A. Harrag, "A new improved DTC of doubly fed induction machine using GA-based PI controller," Ain Shams Engineering Journal, vol. 9, no. 4, pp. 1877-1885, 2018.

[89] S. M. Manias, "Introduction to Motor Drive Systems," in Power Electronics and Motor Drive Systems, Academic Press, 2017, pp. 843-967.

[90] R. Gupta and G. Dyanamina, "Matlab Simulation of DTC-SVM of Doubly Fed Induction Generator for Wind Energy System," in 2019 Innovations in Power and Advanced Computing Technologies (i-PACT), Vellore, 2019.

[91] U. Hari Krishna and P. P. Rajeevan, "A Direct Torque Control Scheme for Five-phase Induction Motor Drive with Reduced Current Distortion," in IEEE India International Conference on Power Electronics (IICPE), Jaipur, 2018.

[92] D. Zhi and L. Xu, "Direct Power Control of DFIG With Constant Switching Frequency and Improved Transient Performance," IEEE Transactions on Energy Conversion, vol. 22, no. 1, pp. 110-118, 2007.

[93] V. Yaramasu and B. Wu, "Control of DFIG WECS with Voltage Source Converters," in Model Predictive Control of Wind Energy Conversion Systems, New Jersey, John Wiley \& Sons, 2017, pp. 403-436. 
[94] Y. Wang, X. Zhang, Z. Xie and H. Yang, "Model predictive direct current control of DFIG at low switching frequency," in 2016 IEEE 8th International Power Electronics and Motion Control Conference (IPEMC-ECCE Asia), Hefei, 2016.

[95] A. A and Z. Diab, "Model Predictive Direct Power Control of Rotor Side Converter for DFIGs Driven by Variable Speed Wind Turbines," in 2018 25th International Workshop on Electric Drives: Optimization in Control of Electric Drives (IWED), Moscow, 2018.

[96] M. Mokhtari and S. A. Davari, "Predictive torque control of DFIG with torque ripple reduction," in 2016 IEEE International Conference on Power and Energy (PECon), Melaka, 2016.

[97] H. J. Fard, H. R. Najafi and G. Heidari, “Design of discrete predictive direct power control strategy on the doubly-fed induction generator based on Micro-Hydro Power Plant with the aim of active and reactive powers control," in 2016 21st Conference on Electrical Power Distribution Networks Conference (EPDC), Karaj, 2016.

[98] Ş. Demirbaş and S. Bayhan, "Grid synchronization of doubly fed induction generator in wind power systems," in 2011 International Conference on Power Engineering, Energy and Electrical Drives, Malaga, 2011.

[99] S. Gomez and J. Amenedo, "Grid synchronisation of doubly fed induction generators using direct torque control," in IEEE 2002 28th Annual Conference of the Industrial Electronics Society. IECON 02, Sevilla, 2002.

[100] J. Arbi, M. J.-B. Ghorbal, I. Slama-Belkhodja and L. Charaabi, "Direct Virtual Torque Control for Doubly Fed Induction Generator Grid Connection," IEEE Transactions on Industrial Electronics, vol. 56, no. 10, pp. 4163-4173, 2009.

[101] J.-B. G. Manel, A. Jihen and S.-B. Ilhem, "A novel approach of direct active and reactive power control allowing the connection of the DFIG to the grid," in 2009 13th European Conference on Power Electronics and Applications, Barcelona, 2009. 
[102] Y. Zhang, J. Zhu and J. Hu, "Model predictive direct torque control for grid synchronization of doubly fed induction generator," in 2011 IEEE International Electric Machines \& Drives Conference (IEMDC), Ontario, 2011.

[103] J. Hu, J. Zhu, Y. Zhang, G. Platt, Q. Ma and D. G. Dorrell, “Predictive Direct Virtual Torque and Power Control of Doubly Fed Induction Generators for Fast and Smooth Grid Synchronization and Flexible Power Regulation," IEEE Transactions on Power Electronics, vol. 28, no. 7, pp. 3182-3194, 2019.

[104] J. Hu, Y. Li and Z. Jianguo, "Multi-objective model predictive control of," IET Generation, Transmission \& Distribution, 2018.

[105] Y. Zhang, Z. Li, W. Xu, J. Hu and J. Zhu, "Grid synchronization of DFIG using model predictive direct power control," in 2011 International Conference on Electrical Machines and Systems, Beijing, 2011.

[106] J. L. Elizondo, A. Olloqui, M. Rivera, M. E. Macias, O. Probst, O. M. Micheloud and J. Rodriguez, "Model-Based Predictive Rotor Current Control for Grid Synchronization of a DFIG Driven by an Indirect Matrix Converter," IEEE Journal of Emerging and Selected Topics in Power Electronics, vol. 2, no. 4, pp. 715-726, 2014.

[107] Y. Li, L. Hang, G. Li, Y. Guo, Y. Zou, J. Chen, J. Li, J. Zhuang and S. Li, “An improved DTC controller for DFIG-based wind generation system," in 2016 IEEE 8th International Power Electronics and Motion Control Conference (IPEMC-ECCE Asia), Hefei, 2016.

[10 M. M. Baggu, "Advanced contr anced control techniques for doubly f ol techniques

8] for doubly fed induction gener ed induction generatorbased wind turbine conv based wind turbine converters to improve low $v$ e low voltage ride- oltage ridethrough during system imbalances," 2009. [Online]. Available: https://scholarsmine.mst.edu/cgi/viewcontent.cgi?article=2893\&context=doctoral_ dissertations.

[109] G. Abad, M. Á. Rodriguez and J. Poza, "Two-Level VSC Based Predictive Direct Torque Control of the Doubly Fed Induction Machine With Reduced Torque and Flux Ripples at Low Constant Switching Frequency," IEEE Transactions on Power Electronics, vol. 230, no. 3, pp. 1050-1061, 2008. 
[110] J. K. K. Kang and S. K. Sul, "New direct torque control of induction motor for minimum torque ripple and constant switching frequency," IEEE Trans. Ind. Appl., vol. 35, no. 5, pp. 1076-1086, 1999.

[111] C. Martins, X. Roboam, T. Meynard and A. Carvalho, "Switching frequency imposition and ripple reduction in DTC drives by using a multilevel converter," IEEE Transactions on Power Electronics, vol. 17, no. 2, pp. 286-297, 2002.

[112] "Model Predictive Direct Power Control of a PWM Rectifier With Duty Cycle Optimization," IEEE Transactions on Power Electronics, vol. 28, no. 11, pp. 5343$5351,2013$.

[113] A. Bouafia, J.-P. Gaubert and F. Krim, "Predictive Direct Power Control of ThreePhase Pulsewidth Modulation (PWM) Rectifier Using Space-Vector Modulation (SVM)," IEEE Transactions on Power Electronics, vol. 25, no. 1, pp. 228-236, 2010.

[114] P. CortÉs, J. Rodríguez, P. Antoniewicz and M. Kazmierkowski, “Direct Power Control of an AFE Using Predictive Control," IEEE Transactions on Power Electronics, vol. 23, no. 5, pp. 2516-2523, 2008.

[115] D. E. Quevedo, R. P. Aguilera, M. A. Perez, P. Cortes and R. Lizana, “Model Predictive Control of an AFE Rectifier With Dynamic References," IEEE Transactions on Power Electronics, vol. 27, no. 7, pp. 3128-3136, 2012.

[116] D.-K. Choi and K.-B. Lee, "Dynamic Performance Improvement of AC/DC Converter Using Model Predictive Direct Power Control With Finite Control Set," IEEE Transactions on Industrial Electronics, vol. 62, no. 2, pp. 757-767, 2015.

[117] H. Fang, Z. Zhang, X. Feng and R. Kennel, "Ripple-reduced model predictive direct power control for active front-end power converters with extended switching vectors and time-optimised control," IET Power Electronics, vol. 9, no. 9, pp. 19141923, 2016.

[118] J. Hu, J. Zhu and D. G. Dorrell, "Predictive Direct Power Control of Doubly Fed Induction Generators Under Unbalanced Grid Voltage Conditions for Power Quality Improvement," IEEE Transactions on Sustainable Energy, vol. 6, no. 3, pp. 943-950, 2015. 
[119] S. Wangsathitwong, S. Sirisumrannukul, S. Chatratana and W. Deleroi, "Symmetrical Components-Based Control Technique of Doubly Fed Induction Generators under Unbalanced Voltages for Reduction of Torque and Reactive Power Pulsations," in 2007 7th International Conference on Power Electronics and Drive Systems, Bankok, 2007.

[120] M. Chomat, J. Bendl and L. Schreier, "Extended vector control of doubly fed machine under unbalanced power network conditions," in 2002 International Conference on Power Electronics, Machines and Drives (Conf. Publ. No. 487), Santa Fe, 2002.

[121] A. G. Abo-Khalil, D.-C. Lee and J.-I. Jang, “Control of Back-to-Back PWM Converters for DFIG Wind Turbine Systems under Unbalanced Grid Voltage," in 2007 IEEE International Symposium on Industrial Electronics, Vigo, 2007.

[122] J.-b. Hu, Y.-k. He and H. Nian, "Enhanced control of DFIG-used back-to-back PWM VSC under unbalanced grid voltage conditions," Journal of Zhejiang UniversitySCIENCE A, vol. 8, pp. 1330-1339, 2007.

[123] L. Xu and Y. Wang, "Dynamic Modeling and Control of DFIG-Based Wind Turbines Under Unbalanced Network Conditions," IEEE Transactions on Power Systems, vol. 22, no. 1, pp. 314-323, 2007.

[124] H.-S. Song and K. Nam, "Dual current control scheme for PWM converter under unbalanced input voltage conditions," IEEE Transactions on Industrial Electronics, vol. 46, no. 5, pp. 953-959, 1999.

[125] H.-S. Song, I.-W. Joo and K. Nam, "Source voltage sensorless estimation scheme for PWM rectifiers under unbalanced conditions," IEEE Transactions on Industrial Electronics, vol. 50, no. 6, pp. 1238-1245, 2003.

[126] B. Yin, R. Oruganti, S. K. Panda and A. K. S. Bhat, "An Output-Power-Control Strategy for a Three-Phase PWM Rectifier Under Unbalanced Supply Conditions," IEEE Transactions on Industrial Electronics, vol. 55, no. 5, pp. 2140-2151, 2008. 
[127] M. Liserre, T. R. and F. Blaabjerg, "Multiple harmonics control for three-phase grid converter systems with the use of PI-RES current controller in a rotating frame," IEEE Transactions on Power Electronics, vol. 21, no. 3, pp. 836-841, 2006.

[128] I. Etxeberria-Otadui, A. L. De Heredia, H. Gaztanaga, S. Bacha and M. Reyero, "A Single Synchronous Frame Hybrid (SSFH) Multifrequency Controller for Power Active Filters," IEEE Transactions on Industrial Electronics, vol. 53, no. 5, pp. 1640$1648,2006$.

[129] R. Teodorescu, F. Blaajberg, M. Liserre and P. Loh, “Proportional-resonant controllers and filters for grid-connected voltage-source converters," IEE Proceedings - Electric Power Applications, vol. 153, no. 5, pp. 750-762, 2006.

[130] J. Hu, Y. He, L. Xu and B. W. Williams, "Improved Control of DFIG Systems During Network Unbalance Using PI-R Current Regulators," IEEE Transactions on Industrial Electronics, vol. 56, no. 2, pp. 439-451, 2009.

[131] L. Xu, "Coordinated Control of DFIG's Rotor and Grid Side Converters During Network Unbalance," IEEE Transactions on Power Electronics, vol. 23, no. 3, pp. 1041-1049, 2008.

[132] J. Hu, H. Wang, Y. He and L. Xu, "Improved rotor current control of wind turbine driven doubly fed induction generators during network unbalance," in 2009 International Conference on Sustainable Power Generation and Supply, Nanjing, 2009.

[133] J. Hu, H. Xu and Y. He, "Coordinated Control of DFIG's RSC and GSC Under Generalized Unbalanced and Distorted Grid Voltage Conditions," IEEE Transactions on Industrial Electronics, vol. 60, no. 7, pp. 2808-2819, 2013.

[134] H. Xu, J. Hu, H. Nian and Y. He, "Dynamic modeling and improved control of DFIG under unbalanced and distorted grid voltage conditions," in 2012 IEEE International Symposium on Industrial Electronics, Hangzhou, 2012.

[135] M. A. A. Rani, C. Nagamani, G. S. Ilango and A. Karthikeyan, "An Effective Reference Generation Scheme for DFIG With Unbalanced Grid Voltage," IEEE Transactions on Sustainable Energy, vol. 5, no. 3, pp. 1010-1018, 2014. 
[136] B. B. Pimple, V. Y. Vekhande and B. G. Fernandes, "New direct torque control of DFIG under balanced and unbalanced grid voltage," in TENCON 2010 - 2010 IEEE Region 10 Conference, Fukuoka, 2010.

[137] G. Abad, M. Á. Rodríguez, G. Iwanski and J. Poza, "Direct Power Control of DoublyFed-Induction-Generator-Based Wind Turbines Under Unbalanced Grid Voltage," IEEE Transactions on Power Electronics, vol. 25, no. 2, pp. 442-452, 2010.

[138] P. Zhou, Y. He and D. Sun, "Improved Direct Power Control of a DFIG-Based Wind Turbine During Network Unbalance," IEEE Transactions on Power Electronics, vol. 24, no. 11, pp. 2465-2474, 2009.

[139] A. Izanlo, S. A. Gholamian and M. V. Kazemi, "A new DPC method for single VSC based DFIG under unbalanced grid voltage condition," in 2016 7th Power Electronics and Drive Systems Technologies Conference (PEDSTC), Tehran, 2016.

[140] J. Hu, J. Zhu and D. G. Dorrell, “Model-predictive direct power control of doubly-fed induction generators under unbalanced grid voltage conditions in wind energy applications," in IET Renewable Power Generation, 2014.

[141] Y. Zhang and D. Xu, "Multiple-vectors-based model predictive direct power control of doubly fed induction generator under unbalanced grid voltage condition," in 2017 20th International Conference on Electrical Machines and Systems (ICEMS), Sydney, 2017.

[142] D. Sun and X. Wang, "Low-Complexity Model Predictive Direct Power Control for DFIG Under Both Balanced and Unbalanced Grid Conditions," IEEE Transactions on Industrial Electronics, vol. 63, no. 8, p. 63, 5186-5196.

[143] G. F. Gontijo, T. C. Tricarico, B. W. França, L. F. da Silva and E. L. van Emmerik, “Robust Model Predictive Rotor Current Control of a DFIG Connected to a Distorted and Unbalanced Grid Driven by a Direct Matrix Converter," IEEE Transactions on Sustainable Energy, vol. 10, no. 3, pp. 1380-1392, 2019.

[144] M. E. Zarei and B. Asaei, "Predictive direct torque control of DFIG under unbalanced and distorted stator voltage conditions," in 2013 12th International Conference on Environment and Electrical Engineering, Wroclaw, 2013. 
[145] G. Lammert, T. Heß, M. Schmidt, P. Schegner and M. Braun, "Dynamic grid support in low voltage grids - fault ride-through and reactive power/voltage support during grid disturbances," in 2014 Power Systems Computation Conference, Wrloclaw, 2014.

[146] J. LÓpez, E. Gubĺa, P. Sanchis, X. Roboam and L. Marroyo, "Wind Turbines Based on Doubly Fed Induction Generator Under Asymmetrical Voltage Dips," IEEE Transactions on Energy Conversion , vol. 23, no. 1, pp. 321-330, 2009.

[147] J. Yao, H. Li, Y. Liao and Z. Chen, "An Improved Control Strategy of Limiting the DCLink Voltage Fluctuation for a Doubly Fed Induction Wind Generator," IEEE Transactions on Power Electronics, vol. 23, no. 3, pp. 1205-1213, 2008.

[148] M. I. Martinez, G. Tapia, A. Susperregui and H. Camblong, "Sliding-Mode Control for DFIG Rotor- and Grid-Side Converters Under Unbalanced and Harmonically Distorted Grid Voltage," IEEE Transactions on Energy Conversion, vol. 27, no. 2, pp. 328-339, 2012.

[149] M. Reddak, A. Berdai, A. Gourma and A. Nouaiti, "Nonlinear control strategy for wind turbine based on DFIG to enhance the LVRT capability," in 2016 International Renewable and Sustainable Energy Conference (IRSEC), Marrakech, 2016.

[150] S. Sahoo, A. Mishra, K. Chatterjee and C. K. Sharma, "Enhanced fault ride Through ability of DFIG-based wind energy system using superconducting fault current limiter," in 2017 4th International Conference on Power, Control \& Embedded Systems (ICPCES), Allahabad, 2017.

[151] "Specification of rotor side voltage source inverter of a doubly-fed induction generator for achieving ride-through capability," in IET Renewable Power Generation, 2007.

[152] J. Morren and S. de Haan, "Ridethrough of wind turbines with doubly-fed induction generator during a voltage dip," IEEE Transactions on Energy Conversion, vol. 20, no. 2, pp. 435-441, 2005. 
[153] A. Kasem, E. El-Saadany, H. El-Tamaly and M. Wahab, “An improved fault ridethrough strategy for doubly fed induction generator-based wind turbines," in IET Renewable Power Generation, 2008.

[154] L. Ran, D. Xiang, P. Tavner and S. Yang, "Control of a doubly fed induction generator in a wind turbine during grid fault ride-through," in 2006 IEEE Power Engineering Society General Meeting, Montreal, 2006.

[155] F. K. A. Lima, A. Luna, P. Rodriguez, E. H. Watanabe and F. Blaabjerg, "Rotor Voltage Dynamics in the Doubly Fed Induction Generator During Grid Faults," IEEE Transactions on Power Electronics, vol. 25, no. 1, pp. 118-130, 2010.

[156] C. Feltes, H. Wrede, F. W. Koch and I. Erlich, "Enhanced Fault Ride-Through Method for Wind Farms Connected to the Grid Through VSC-Based HVDC Transmission," IEEE Transactions on Power Systems, vol. 24, no. 3, pp. 1537-1546, 2009.

[157] Z. Peng and H. Yikang, "Control Strategy of an Active Crowbar for DFIG Based Wind Turbine under Grid Voltage Dips," in International Conference on Electrical Machines and Systems 2007, Seoul, 2007.

[158] R. Mohsen and P. Mostafa, "Transient Performance Improvement of Wind Turbines With Doubly Fed Induction Generators Using Nonlinear Control Strategy," IEEE Transactions on Energy Conversion , vol. 25, no. 2, pp. 514-525, 2010.

[159] M. Reddak, A. Berdai, A. Gourma and A. Belfqih, "Integral backstepping control based maximum power point tracking strategy for wind turbine systems driven DFIG," in 2016 International Conference on Electrical and Information Technologies (ICEIT), Tangiers, 2016.

[160] M. Rahimi and M. Parniani, "Efficient control scheme of wind turbines with doubly fed induction generators for low voltage ride-through capability enhancement," in $n$ IET Renewable Power Generation, 2009.

[161] M. Rahimia and M. Parniani, "Low voltage ride-through capability improvement of DFIG-based wind turbines under unbalanced voltage dips," International Journal of Electrical Power \& Energy Systems, vol. 60, pp. 82-95, 2014. 
[162] J. Luo, H. Zhao, S. Gao and M. Han, "A Low Voltage Ride Through Strategy of DFIG based on Explicit Model Predictive Control," International Journal of Electrical Power \& Energy Systems, vol. 119, 2020.

[163] W. Srirattanawichaikul, S. Premrudeepreechacharn and .. Kumsuwan, “A comparative study of vector control strategies for rotor-side converter of DFIG wind energy systems," in 2016 13th International Conference on Electrical Engineering/Electronics, Computer, Telecommunications and Information Technology (ECTI-CON), Chiang Mai, 2016.

[164] N. Sarma, P. M. Tuohy, J. M. Apsley, Y. Wang and S. Djurović, "DFIG stator fluxoriented control scheme execution for test facilities utilising commercial converters," IET Renewable Power Generation, vol. 12, no. 12, pp. 1366-1374, 2018.

[165] N. Sarma, J. M. Apsley and S. Djurovic, "Implementation of a conventional DFIG stator flux oriented control scheme using industrial converters," in 2016 IEEE International Conference on Renewable Energy Research and Applications (ICRERA), Birmingham, 2016.

[166] B. Subudhi and P. S. Ogeti, "Optimal preview stator voltage-oriented control of DFIG WECS," IET Generation, Transmission \& Distribution , vol. 12, no. 4, pp. 1004-1013, 2018.

[167] O. Al-Zabin, "Rotor Current Control Design for DFIG-based Wind Turbine Using PI, FLC and Fuzzy PI Controllers," 2019. [Online]. Available: https://scholarworks.rit.edu/cgi/viewcontent.cgi?article=11469\&context=theses.

[168] R. K. Patel and G. Dyanamina, "Direct torque control of doubly fed induction generator for wind energy conversion system," in 2017 8th International Conference on Computing, Communication and Networking Technologies (ICCCNT), Delhi, 2017.

[169] G. Abad, J. Lopez, M. A. Rodrıguez, L. Marroyo and G. Iwanski, "Direct Control of the Doubly Fed Induction Machine," in Doubly Fed Induction Machine: Modelling and Control for Wind Energy Generation, New Jersey, John Wiley \& Sons, 2011, pp. 363474.

[170] Z. Koutsogiannis, G. Adamidis and A. Fyntanakis, "Direct torque control using space vector modulation and dynamic performance of the drive, via a fuzzy logic 
controller for speed regulation," in 2007 European Conference on Power Electronics and Applications, Aalborg, 2007.

[171] I. S. Mohamed, S. A. Zaid, M. F. Abu-Elyazeed and H. M. Elsayed, "Classical methods and model predictive control of three-phase inverter with output LC filter for UPS applications," in 2013 International Conference on Control, Decision and Information Technologies, Hammamet, 2013. 


\section{Appendix A: DFIG Parameters used in simulations}

$$
\begin{aligned}
& P_{s}=2483.1 \mathrm{~kW} \\
& V_{s}=690 \mathrm{~V} \\
& V_{r}=158.7 \mathrm{~V} \\
& I_{s}=2076.2 \mathrm{~A} \\
& I_{r}=2673.1 \mathrm{~V} \\
& f_{s}=60 \mathrm{~Hz} \\
& P_{p}=2 \\
& S_{m a x}=0.2 \\
& R_{s}=1.443 \mathrm{~m} \Omega \\
& R_{r}=1.125 \mathrm{~m} \Omega \\
& L_{l s}=0.094 \mathrm{mH} \\
& L_{l r}=0.085 \mathrm{mH} \\
& L_{m}=0.802 \mathrm{mH}
\end{aligned}
$$

Approximate value of stator flux $=1.4944 \mathrm{~Wb}$ 


\section{Appendix B: MPDTC algorithm}

function s_opt

$=$ RSC $(V d c$, theta,wm,vs_dq,is_dq,ir_dq,s_123,Tab_abc,k_phi,Tref,phir_dq,Phirref,mat1, mat2, mat3, mat4)

\%mat $1=[(\mathrm{Lm} * \mathrm{Ts}) / \operatorname{Tr} 0$ 1-(Ts/T_sigma) Ts;0 (Lm*Ts)/Tr -Ts 1(Ts/T_sigma) $]$

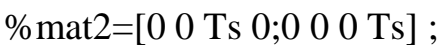

$\%$ mat3=[Lr*Ts 0 -Lm*Ts $0 ; 0$ Lr*Ts $0-\mathrm{Lm} * \mathrm{Ts}]$;

\%mat4=[1-Rs*Lr*Ts $\mathrm{Lm}^{\wedge} 2 * \mathrm{Ts} \mathrm{Rr} * \mathrm{Lm}^{*} \mathrm{Ts} \mathrm{Lm} * \mathrm{Lr} * \mathrm{Ts} ;-\mathrm{Lm}^{\wedge} 2 * \mathrm{Ts}$ 1-Rs*Lr*Ts -Lm*Lr*Ts $\mathrm{Rr} * \mathrm{Lm} * \mathrm{Ts}]$;

$\%$ sigma $=1-\mathrm{Lm}^{\wedge} 2 /\left(\mathrm{Ls}^{*} \mathrm{Lr}\right)$

$\% \operatorname{Tr}=\mathrm{Lr} / \mathrm{Rr}$

$\% \mathrm{Kr}=\mathrm{Lm} / \mathrm{Lr}$

$\% \mathrm{R} \_$sigma $=\mathrm{Rs}+(\mathrm{Kr})^{\wedge} 2 * \mathrm{Rr}$

$\% \mathrm{~T} \_$sigma $=(\operatorname{sigma} * \mathrm{Ls}) / \mathrm{R} \_s i g m a ;$

$\%$ k_phi=ws*sigma*Ls*Lr*Ts

$\%$ Tab_abc $=(2 / 3) *[1-1 / 2-1 / 2 ; 0 \operatorname{sqrt}(3) / 2-\operatorname{sqrt}(3) / 2] ;$

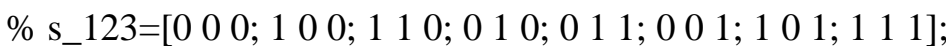

ws $=376.9911$;

Rs $=1.443 \mathrm{e}-3$;

$\mathrm{wr}=\mathrm{ws}-\mathrm{wm}$; 


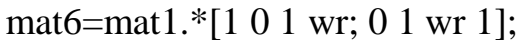

mat5=mat4.*[1 wm $1 \mathrm{wm} ; \mathrm{wm} 1 \mathrm{wm} 1]$;

j_op $=1$;

g_op = 1000000000;

for $\mathrm{j}=1: 1: 8$

st_123=transpose $\left(\mathrm{s} \_123(\mathrm{j},:)\right)$;

vr_dq $=V d c *\left[\cos (\right.$ theta $) \sin ($ theta $) ;-\sin ($ theta $) \cos ($ theta) $] * T a b \_a b c * s t \_123$;

is_dq_1 $=$ mat $5 *[$ is_dq;ir_dq $]+$ mat $3 *\left[v s \_d q ; v r \_d q\right]+\left[\mathrm{k} \_p h i * i s \_d q(2,:) ;-\mathrm{k} \_p h i * i s \_d q(1,:)\right]$;

phir_dq_1=mat6*[is_dq;phir_dq]+mat2*[vs_dq;vr_dq];

aphi $=\operatorname{sqrt}((\text { phir_dq_1(1,:) }))^{\wedge} 2+($ phir_dq_1(2,:) $\left.\left.)\right)^{\wedge} 2\right)$;

phs_d_1=(vs_dq(2,:)-Rs*is_dq_k1(2,:))/ws;

phs_q_1=-1*((vs_dq(1,:)-Rs*is_dq_k1(1,:))/ws);

Tem_1=3*(phs_d_1 $*_{\text {is_dq_1 }}(2,:)-$ phs_q_ $1 *$ is_dq_1 $\left.1(1,:)\right)$;

$\mathrm{g}=(\text { Tref-Tem_1 })^{\wedge} 2+\left((\text { Phirref-aphi })^{\wedge} 2\right) ;$

if $(\mathrm{g}<\mathrm{g}$ _op $)$

j_op = j;

g_op $=$ g;

end

end

s_opt=transpose(s_123(j_op,:)); 